Mon. Not. R. Astron. Soc. 000,17?? (2018) Printed October 15, $2018 \quad$ (MN LATEX style file v2.2)

\title{
A study of the HI and optical properties of Low Surface Brightness galaxies: spirals, dwarfs and irregulars
}

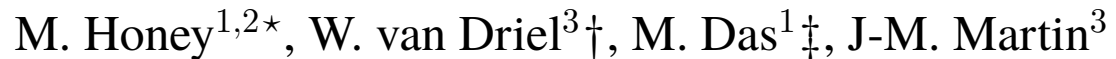 \\ ${ }^{1}$ Indian Institute of Astrophysics, Koramanagala, Bangalore 560034, India. \\ ${ }^{2}$ Pondicherry University, $R$. Venkataraman Nagar, Kalapet, 605014 Pondicherry, India. \\ ${ }^{3}$ GEPI, Observatoire de Paris, PSL Université, CNRS, 5 place Jules Janssen, 92190 Meudon, France
}

Accepted 2017 December 18. Received 2017 December 13; in original form 2017 November 10.

\begin{abstract}
We present a study of the HI and optical properties of nearby $(z \leqslant 0.1)$ Low Surface Brightness galaxies (LSBGs). We started with a literature sample of $\sim 900$ LSBGs and divided them into three morphological classes: spirals, irregulars and dwarfs. Of these, we could use 490 LSBGs to study their HI and stellar masses, colours and colour magnitude diagrams, and local environment, compare them with normal, High Surface Brightness (HSB) galaxies and determine the differences between the three morphological classes. We found that LSB and HSB galaxies span a similar range in $\mathrm{HI}$ and stellar masses, and have a similar $M_{\mathrm{HI}} / M_{\star}{ }^{-}$ $-M_{\star}$ relationship. Among the LSBGs, as expected, the spirals have the highest average HI and stellar masses, both of about $10^{9.8} M_{\odot}$. The LSGBs' $(g-r)$ integrated colour is nearly constant as function of HI mass for all classes. In the colour magnitude diagram, the spirals are spread over the red and blue regions whereas the irregulars and dwarfs are confined to the blue region. The spirals also exhibit a steeper slope in the $M_{\mathrm{HI}} / M_{\star}-M_{\star}$ plane. Within their local environment we confirmed that LSBGs are more isolated than HSB galaxies, and LSB spirals more isolated than irregulars and dwarfs. Kolmogorov-Smirnov statistical tests on the HI mass, stellar mass and number of neighbours indicates that the spirals are a statistically different population from the dwarfs and irregulars. This suggests that the spirals may have different formation and $\mathrm{HI}$ evolution than the dwarfs and irregulars.
\end{abstract}

Key words: galaxies: evolution - galaxies: general - galaxies: spiral - galaxies: structure radio lines: galaxies.

\section{INTRODUCTION}

Low Surface Brightness galaxies (LSBGs) are late-type disc galaxies that span the same mass range as the High Surface Brightness (HSB) disc galaxies that define the Hubble sequence, but whose average surface brightness is 5-10 times lower. The proper definition of an LSBG is through a measure of central disc surface brightness. Historically, an LSBG is defined as having a $B$-band central surface brightness fainter than 23.0 mag $\operatorname{arcsec}^{-2}$ (Impey \& Bothun 1997. Sprayberry et al. 1997), which is $4 \sigma$ less than found originally in the central surface brightness distribution of HSB galaxies by Freeman (1970). This implies that LSBGs are either intrinsically rare, or heavily selected against. Their stellar discs are generally embedded in extended HI gas discs (e.g., McGaugh, Schombert \& Bothun 1995. Mishra et al. 2017).

\footnotetext{
* E-mail : mhoney@iiap.res.in

† E-mail : wim.vandriel@obspm.fr

‡E-mail : mousumi@iiap.res.in
}

The LSB nature of these galaxies arises from their low disc stellar surface density $\left(\Sigma_{*}\right)$, which is due to the larger average separation between stars than in normal, HSB discs, as well as from their low star formation rates (SFRs) (O'Neil et al. 2004, Wyder et al. 2007, Boissier et al. 2008, Zhong et al. 2010, Schombert, McGaugh \& Maciel 2013, Young, Kuzio de Naray \& Wang 2015). Their dust content is also low (Hinz et al. 2007, Rahman et al. 2007) and their discs appear to be metal poor (McGaugh 1994 Kuzio de Naray, McGaugh \& de Blok 2004). They are however rich in neutral hydrogen (HI) gas (de Blok, McGaugh \& van der Hulst 1996, Burkholder, Impey \& Sprayberry 2001, O'Neil et al. 2004 Du et al. 2015) and their HI mass to luminosity ratios are much higher than those of HSB galaxies (O'Neil et al. 2004). Their HI rotation curves indicate that their optical discs are embedded in very massive dark matter halos (de Blok \& McGaugh 1997). Molecular gas, which is critical for star formation, is rare in LSBGs (O’Neil, Hofner \& Schinnerer 2000, Das et al. 2006, Das, Boone \& Viallefond 2010). This suggests that the combination of low $\Sigma_{*}$ 
discs and dominant dark matter halos prevents disc instabilities from forming in these galaxies (Ghosh \& Jog|2014, Honey et al. 2016).

There are several ways to define LSBGs in practice. For our study we have used the LSBG catalogues of Schombert \& Bothun (1988), Schombert et al. (1992) and Impey et al. (1996) (see also 2).

In the past few years there have been several surveys to detect LSBGs in optical images which were all selected on their low central surface brightness using the Sloan Digital Sky Survey (SDSS): Zhong et al. (2008) identified 12,282 and Shao et al. (2015) 1235 LSBGs, and Williams et al. (2016) found 343 low-luminosity LSBGs for the Galaxy And Mass Assembly (GAMA) project. In the Virgo cluster, Giallongo et al. (2015) and Davies, Davies \& Keenan (2016) found 303 new LSBGs and 11 ultra faint LSBGs respectively. Besides these, Du et al. (2015) reported 1129 new LSBGs with large HI masses.

Morphologically, LSBGs can be broadly divided into the classes of spirals, irregulars and dwarfs. The largest LSB spirals, which are often referred to as giant LSBGs (e.g., Das 2013), are located in isolated environments, often near void walls (Rosenbaum et al. 2009). However the irregulars and dwarfs are found in both underdense and crowded environments (see Sect. 3.8. The origin of LSBGs is not fully understood, but their overall isolated environments must play some role in their formation and evolution (Hoffman, Silk \& Wyse 1992).

Although there have been many studies of LSBGs, there has not yet been a study that specifically compares the optical and cold gas properties of the abovementioned morphological subclasses of LSBGs (spirals, dwarfs and irregulars). Such a comparison is important as it can throw light on both the origin and the evolution of LSBGs. In this paper we address these issues.

We examine the HI masses, gas mass fractions (which we define as the ratio of the total $\mathrm{HI}$ and stellar masses, $M_{\mathrm{HI}} / M_{\star}$ ), absolute magnitudes, stellar masses, optical colours and the colour magnitude diagrams of LSBGs in general and of their subclasses. We also compare these properties of LSBGs with those of normal HSB galaxies.

Throughout this paper, unless indicated otherwise, we use distances $D$ based on a simple Hubble flow model, $D=V / H_{0}$, where $V$ is the heliocentric radial velocity and the Hubble constant $H_{0}=$ $70 \mathrm{~km} \mathrm{~s}^{-1} \mathrm{Mpc}^{-1}$. The outline of our paper is as follows: in Section 2 we describe our sample selection, in Section 3 we describe our analysis of the data and the results, and we present our conclusions in Section 4

\section{SAMPLE SELECTION}

Our initial sample consists of the total of 897 objects listed in the LSB galaxy catalogues of Schombert \& Bothun (1988), Schombert et al. (1992) and Impey et al. (1996).

All galaxies listed in these catalogues have known redshifts. We set an upper limit of 0.1 to the redshifts, to study only LSBGs within the local universe, and removed the 19 objects with $z>0.1$.

Although these catalogues have different selection criteria (see below), the objects contained in them clearly look like LSBGs on photographic plates and have been used in other studies. We prefer to use these older studies over more recent, but significantly less deep surveys (such as Zhong et al. 2008 and Shao et al. 2015) which are based on central disc surface brightness determinations using SDSS images (York et al. 2000, Alam et al. 2015), because their galaxies often do not have corresponding HI observations and usually no explicit identifications.

Impey et al. (1996) defined their sample using a central surface brightness of greater than 22 magnitude $\operatorname{arcsec}^{-2}$ in the $B$ band, from UK Schmidt Telescope IIIa-J plates measured in the automated plate measuring (APM) survey (see Sprayberry, Impey \& Irwin 1996 for further details). Schombert \& Bothun (1988) and Schombert et al. (1992) defined their samples by visual inspection of blue plates of the Second Palomar Observatory Sky Survey (POSSII) (Reid et al. 1991), which has a surface brightness detection limit of 26.0 magnitude $\operatorname{arcsec}^{-2}$. Their catalogues mainly contains LSB objects that were not detected in the previous, less deep First Palomar Observatory Sky Survey (POSS-I) (Minkowski \& Abell 1963) which has a detection limit of $\sim 25.2$ magnitude $\operatorname{arcsec}^{-2}$ (Cornell et al. 1987). It includes previously catalogued UGC and NGC galaxies which they found to have LSB tails, discs, spiral arms or tails on the deeper POSS-II plates.

LSBGs span a wide range of morphological classes, from spirals, dwarfs to irregulars. We collected information on the centre positions, redshifts and optical morphological classification of the sample galaxies (see Table 1) using the NASA Extragalactic Database (NED ${ }^{1}$ We included the following NED morphological classifications in our three classes: $\mathrm{Sa}, \mathrm{Sb}, \mathrm{Sc}, \mathrm{Sd}$ and $\mathrm{Sm}$ for the spirals, Im and Irr for the irregulars, and dE, dI and dm for the dwarfs. Though we have also listed 13 interacting or merging galaxies and 33 lenticulars, we have not used them for further analysis.

The morphological classifications from NED are generally based on optical images from early photographic surveys. To verify these, we visually examined the entire sample using the SDSS composite gri-band colour images from the final Data Release 12 (DR12) 2 see Alam et al.(2015). For the dwarfs, it is sometimes difficult to distinguish between disc systems and spheroidals through visual inspection of relatively shallow SDSS optical images. It is therefore possible that our dwarfs category also contains gas-poor spheroidal dE-type systems. For 341 galaxies we modified the NED classification and listed our new determinations in Table 1

\footnotetext{
1 http://ned.ipac.caltech.edu/

2 http://www.sdss.org/dr12/
} 
Table 1. Global properties of the LSBGs in the initial sample of 897 galaxies - Note: sample page only, the full version is included after the References

\begin{tabular}{|c|c|c|c|c|c|c|c|c|c|c|c|}
\hline galaxy name & $\begin{array}{c}\text { RA \& DEC } \\
(\mathrm{J} 2000.0)\end{array}$ & $\begin{array}{r}D \\
(\mathrm{Mpc}) \\
\end{array}$ & $\begin{array}{l}\text { morphology } \\
{[\mathrm{NED}]}\end{array}$ & class & $\begin{array}{c}\text { HI flux } \\
\text { (Jy km/s) }\end{array}$ & $\begin{array}{c}\log \left(M_{\mathrm{HI}}\right) \\
\left(M_{\odot}\right)\end{array}$ & $\begin{array}{c}M_{\mathrm{r}} \\
(\mathrm{mag})\end{array}$ & $\begin{array}{l}(g-r) \\
(\mathrm{mag}) \\
\end{array}$ & $\begin{array}{r}\log \left(M_{\star}\right) \\
\left(M_{\odot}\right)\end{array}$ & Iso & Flag $c$ \\
\hline \multicolumn{12}{|c|}{ 1. With HI detections: } \\
\hline LSBC F539-V01 & $00: 11: 29.00+21: 25: 52.0$ & 113.3 & $\mathrm{Sm}$ & spiral & 2.37 & 9.86 & -18.52 & 0.34 & 8.75 & 1 & good \\
\hline LSBC F608-V01 & $00: 12: 48.25+14: 31: 31.1$ & 26.1 & $\mathrm{Sd}$ & dwarf & 3.47 & 8.75 & -14.71 & 0.24 & 7.09 & 10 & good \\
\hline $0012+0218$ & $00: 14: 59.97+02: 34: 48.3$ & 256.3 & $\mathrm{dI}$ & dwarf & 0.69 & 10.03 & -19.15 & 0.36 & 9.02 & $\ldots$ & good \\
\hline $0014+0210$ & $00: 16: 41.72+02: 27: 34.4$ & 59.1 & Sm: & star & 0.75 & 8.79 & -15.62 & 1.34 & 8.91 & 1 & not used \\
\hline LSBC F608-01 & $00: 17: 15.90+17: 31: 23.0$ & 14.3 & Im: & irregular & 2.18 & 8.02 & -13.99 & 0.92 & 7.71 & 15 & not used \\
\hline LSBC F473-V01 & $00: 17: 18.30+26: 51: 41.0$ & 127.3 & $\mathrm{Im}$ & irregular & 1.36 & 9.72 & -18.57 & 0.33 & 8.76 & 1 & good \\
\hline LSBC F608-V02 & $00: 23: 06.06+15: 08: 25.6$ & 78.8 & $\mathrm{Sd}$ & irregular & 0.85 & 9.09 & -17.05 & 0.50 & 8.37 & 10 & good \\
\hline LSBC F539-02 & $00: 23: 15.76+20: 15: 59.1$ & 81.7 & Im: & spiral & 1.56 & 9.39 & -19.56 & 0.42 & 9.27 & 11 & good \\
\hline LSBC F473-01 & $00: 25: 56.90+23: 55: 24.0$ & 80.5 & $\mathrm{Im}$ & irregular & 0.95 & 9.16 & -17.83 & 0.40 & 8.56 & 3 & good \\
\hline LSBC F473-V02 & $00: 26: 21.00+24: 38: 35.0$ & 51.1 & Irr & irregular & 1.40 & 8.93 & -16.40 & 1.31 & 9.18 & 2 & good \\
\hline $0023+0044$ & $00: 26: 24.98+01: 01: 12.0$ & 75.7 & $\mathrm{Sd}$ & spiral & 1.51 & 9.31 & -19.04 & 0.49 & 9.16 & 3 & good \\
\hline $0025+0221$ & $00: 27: 46.98+02: 38: 23.5$ & 58.1 & dI & dwarf & 0.49 & 8.59 & -16.81 & 0.14 & 7.81 & 13 & good \\
\hline $0029+0037$ & $00: 31: 43.27+00: 54: 02.6$ & 76.6 & & spiral & 1.09 & 9.18 & -18.47 & 0.36 & 8.75 & 3 & good \\
\hline $0029+0226$ & $00: 31: 45.35+02: 42: 53.3$ & 34.0 & $\mathrm{dI}$ & dwarf & 1.11 & 8.48 & -14.38 & -0.50 & 5.87 & 2 & bad \\
\hline LSBC F473-V03 & $00: 34: 46.10+22: 46: 46.0$ & 83.4 & $\mathrm{Sm}$ & spiral & 1.19 & 9.29 & -17.66 & 0.55 & 8.68 & 1 & good \\
\hline $0049+0105$ & $00: 52: 01.86+01: 21: 42.9$ & 184.0 & $\mathrm{Sm}$ & spiral & 1.15 & 9.96 & -18.61 & 0.41 & 8.87 & $\ldots$ & good \\
\hline 0051-0227 & $00: 54: 21.40-02: 11: 45.1$ & 77.7 & Sd pec sp & spiral & 2.65 & 9.58 & -17.69 & 0.30 & 8.36 & 1 & good \\
\hline LSBC F682-V01 & $00: 56: 41.10+10: 20: 23.0$ & 148.6 & $\mathrm{Sc}$ & spiral & 1.35 & 9.85 & -19.58 & 0.26 & 9.07 & 1 & good \\
\hline LSBC F682-01 & $00: 57: 31.89+10: 21: 48.2$ & 39.4 & $\mathrm{Sm}$ & spiral & 2.53 & 8.97 & -16.03 & 0.24 & 7.62 & 1 & good \\
\hline $0056+0044$ & $00: 58: 55.46+01: 00: 17.7$ & 76.5 & Irr & irregular & 3.38 & 9.67 & -17.90 & 0.13 & 8.22 & 7 & good \\
\hline $0056+0020$ & $00: 58: 55.89+00: 36: 27.9$ & 77.6 & dI & dwarf & 2.38 & 9.53 & -17.04 & 0.14 & 7.90 & 7 & good \\
\hline LSBC F682-V02 & $01: 01: 51.57+10: 16: 21.8$ & 163.2 & $\mathrm{Sm}$ & spiral & 0.75 & 9.67 & -19.71 & 0.43 & 9.35 & $\ldots$ & good \\
\hline $0103+0030$ & $01: 06: 07.17+00: 46: 33.7$ & 74.3 & $\mathrm{Sd}$ & spiral & 1.40 & 9.26 & -17.99 & 0.38 & 8.59 & 5 & good \\
\hline $0108+0242$ & $01: 11: 21.26+02: 58: 22.8$ & 143.3 & $\mathrm{Sc}$ & spiral & 1.30 & 9.80 & -19.98 & 0.32 & 9.30 & 1 & good \\
\hline $0110+0046$ & $01: 12: 50.69+01: 02: 48.8$ & 15.8 & dI & dwarf & 6.23 & 8.56 & -13.65 & -0.10 & 6.10 & 9 & not used \\
\hline
\end{tabular}


We excluded a total of 74 galaxies from further analysis, for the following reasons; they are marked accordingly in Table 1 where all are also flagged as 'not used': (i) 44 are not visible in the SDSS images (they are marked as 'no SDSS galaxy'). As these are very LSB systems, judging from the LSBGs source catalogues' data and our inspection of POSS-II plates, it is not surprising that they are not visible on the less deep SDSS images. Since we cannot determine their morphological types, we cannot use them for further analysis, (ii) three were found be star-like, (iii) two appeared too HSB (marked as 'too bright'), (iv) eight were significantly displaced from their catalogued positions (marked with 'location is off'), and (v) we are not sure about the morphological class for another 17 galaxies (marked as '...').

Our sample of LSB galaxies with morphological classification thus contains 758 galaxies, of which $426(56 \%)$ are spirals, $107(14 \%)$ are irregulars and $225(30 \%)$ are dwarfs. Hereafter this sample is referred to as Sample I.

\section{ANALYSIS AND RESULTS}

The following global properties of the initial sample of 897 galaxies are listed in Table 1 see the text for further details:

- galaxy name: catalogue name taken from the LSBGs samples from which the galaxy was selected (see Sect. 2);

- RA \& DEC: Right Ascension and Declination of the SDSS spectroscopic source in epoch $\mathrm{J} 2000.0$ coordinates;

- $D$ : distance (in $\mathrm{Mpc}$ ) $=V / H_{0}$, where $V$ is the heliocentric radial velocity in $\mathrm{km} \mathrm{s}^{-1}$, for a Hubble constant $H_{0}=70$ $\mathrm{km} \mathrm{s}^{-1} \mathrm{Mpc}^{-1}$;

- morphology $[\mathrm{NED}]$ : optical morphological classification, taken from NED;

- morphological class: global optical morphological class (spiral, irregular, dwarf), based on our visual inspection of SDSS DR12 images;

- HI flux: $F_{\mathrm{HI}}$, integrated $\mathrm{HI}$ line flux (in $\mathrm{Jy} \mathrm{km} \mathrm{s}^{-1}$ );

- $\log \left(M_{\mathrm{HI}}\right)$ : total HI mass (in $\left.M_{\odot}\right)$;

- $M_{\mathrm{r}}$ : absolute $r$-band magnitude corrected for Galactic extinction following Schlegel, Finkbeiner \& Davis (1998), as also used by SDSSDR12);

- $(g-r)$ : integrated $(g-r)$ colour corrected for Galactic extinction following Schlegel, Finkbeiner \& Davis (1998), as also used by SDSS DR12;

- $M_{\star}$ : total stellar mass, estimated following Bell \& de Jong (2001) (in $M_{\odot}$ );

- Iso: number of near neighbours within $1 \mathrm{Mpc}$ radius and \pm 500 $\mathrm{km} \mathrm{s}^{-1}$ from the systemic velocity of the target galaxy;

- Flag: (i) on SDSS photometry: 'good' indicates no BADSKY, BRIGHT, NOPROFILE, SATURATED, SUSPICIOUS DETECTIONS (like cosmic ray or CCD artifact-MAYBECR, MAYBE-EGHOST), or INTERPOLATION ERRORS (PSFFLUX-INTERP) flags; 'bad' indicates the target has (at least) one of these flags, or (ii) 'not used' indicates either not included in Sample I (see Section 2) or fainter than the absolute magnitude limit $M_{\mathrm{r}}$ $=-14 \mathrm{mag}$ (see Section 3.2.2.

\subsection{H I mass}

The integrated, mean homogenized $21 \mathrm{~cm}$ HI line fluxes $\left(F_{\mathrm{HI}}\right.$, in Jy $\mathrm{km} \mathrm{s}^{-1}$ ) were taken from the online HyperLeda databas $\AA^{4}$ (based on their $m_{21}$ values, see also Paturel et al. 2003b; Paturel et al. 2003a). We found that 449 galaxies from Sample I have published HI detections. Of these, 246 are classified as spirals, 122 as dwarfs and 81 as irregulars. The remaining 309 galaxies do not have HI data listed in HyperLeda. As we cannot determine from the HyperLeda data if they are either not observed or not detected, we have marked them all as "without HI data" in our plots and tables.

We determined the total $\mathrm{HI}$ masses, $M_{\mathrm{HI}}$, using the relationship $M_{\mathrm{HI}}=2.36 \times 10^{5} \mathrm{D}^{2} F_{\mathrm{HI}}\left(M_{\odot}\right)$, where $D$ is the distance in Mpc and $F_{\mathrm{HI}}$ the integrated $\mathrm{HI}$ line flux (in Jy $\mathrm{km} \mathrm{s}^{-1}$ ).

\subsubsection{H I mass distributions}

LSBGs are $\mathrm{HI}$ rich in nature, and they have on average an $\sim 8$ times higher $M_{\mathrm{HI}} / L$ ratio than HSB galaxies, sometimes exceeding 10 $M_{\odot} / L_{\odot, \mathrm{B}}\left(\mathrm{O}^{\prime} \mathrm{Neil}\right.$ et al. 2004). The HI masses of our sample span a wide range, from $10^{7}$ to $10^{11} M_{\odot}$ (see Fig. 1), with the spirals at the high end, the dwarfs at the low end and the irregulars in between. The mean HI masses and their standard deviations of the spirals, irregulars and dwarfs are $\log \left(M_{\mathrm{HI}} / M_{\odot}\right)=9.78 \pm 0.40,9.20 \pm 0.42$ and $8.95 \pm 0.69$, respectively. Thus LSBGs clearly have massive HI reservoirs, which may be linked to their low star formation rates (Boissier et al. 2008, Wyder et al. 2009).

\subsection{Absolute magnitudes and colours}

The basic photometric data of our sample galaxies are taken from the SDSS DR12 archival data. We retrieved apparent model magnitudes in the $g, r$ and $i$-bands together with the Galactic extinction coefficients from Schlegel, Finkbeiner \& Davis (1998) for these bands.

\subsubsection{Galaxies with underestimated SDSS magnitudes}

Low Surface Brightness galaxies, by their very nature, are faint. Hence, it is quite easy and natural for most imaging studies to miss extended, very LSB flux in these objects at levels where it effectively competes with the noise in the night sky. This can have serious consequences for determining their total magnitude, as in some cases (like for large disc scale lengths) the bulk of the luminosity comes from outer regions fainter than 25 mag $\operatorname{arcsec}^{-2}$.

The SDSS is no exception in this respect. Based on our experience with the NIBLES HI survey of total stellar-mass selected SDSS galaxies (van Driel et al. 2016), we looked for objects for which the total SDSS magnitudes appear to be "misunderestimated", which can lead to (severely) reduced luminosities and hence unphysically high $M_{\mathrm{HI}} / L$ ratios.

For galaxies that are extremely faint we know there is a high probability that their parameters are erroneous. For this reason we only included galaxies in our sample that are more luminous than $M_{\mathrm{r}}=-14$ (after re-examination of their photometry as described hereafter).

For 290 galaxies in sample I we found that their listed absolute magnitudes were fainter than -14 , which appears too low for the kind of objects we are studying, and that their $M_{\mathrm{HI}} / L_{\mathrm{r}}$ ratios 


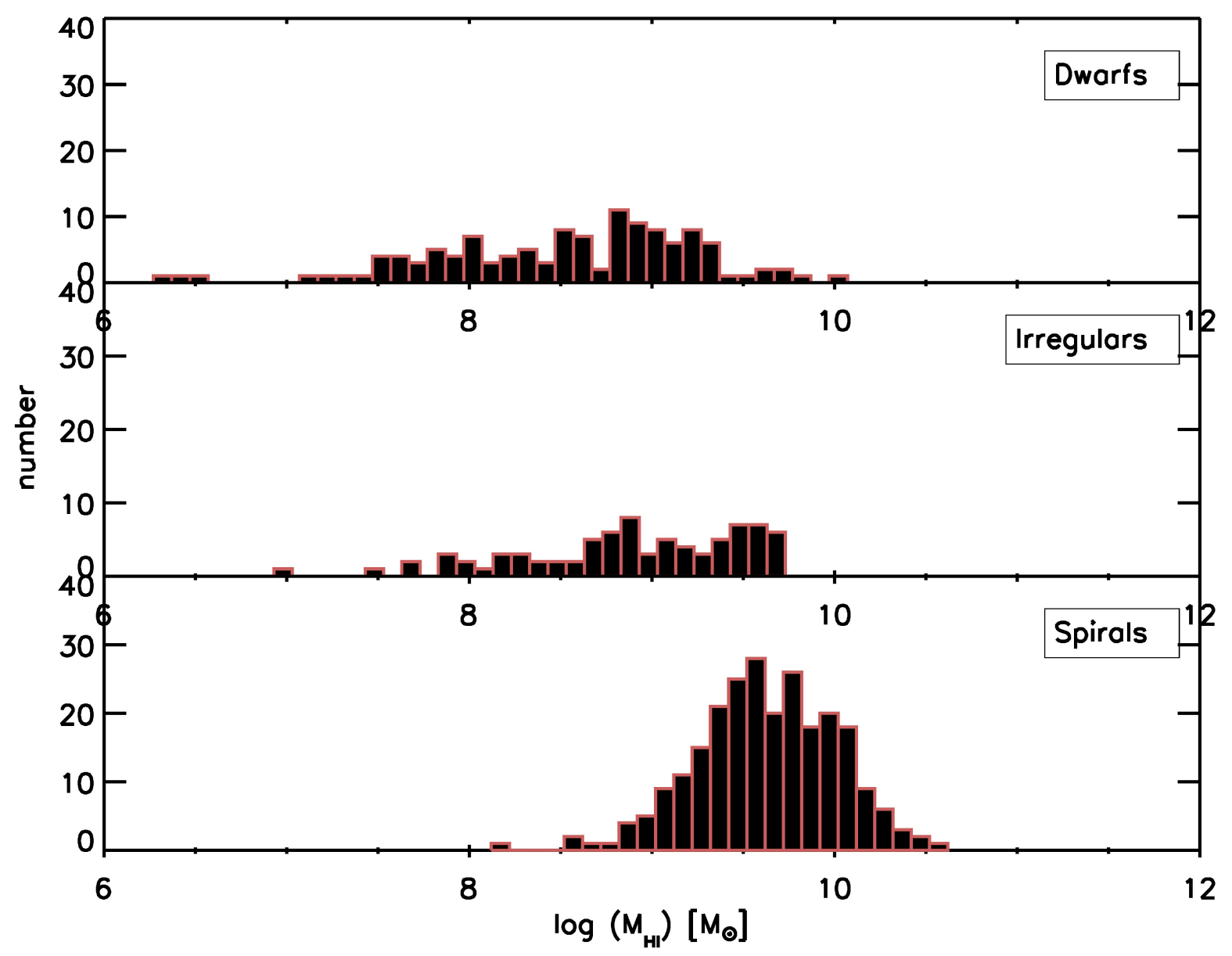

Figure 1. Histograms of the total HI mass distributions $\left(\log \left(M_{\mathrm{HI}}\right)\right.$, in $\left.M_{\odot}\right)$ of the three morphological classes into which we divided our LSB galaxy sample: dwarfs, irregulars and spirals. We used 246 spirals, 81 irregulars and 122 dwarfs for this plot. The bin size in $\log \left(M_{\mathrm{HI}}\right)=0.10$.

were unphysically high, up to over a thousand. As in the case of NIBLES, we found that among these, 130 are dwarf-like objects of small optical apparent size that have numerous SDSS photometric sources within their outlines (see Fig. 2). Some of these sources have Petrosian radii much smaller than the apparent size of the galaxy, indicating that the magnitudes of these sub-structure sources cannot represent the total brightness of the entire galaxy. Also like in NIBLES, we found 160 luminous galaxies where the SDSS spectroscopic and photometric source was in fact a distinct sub-structure outside the central region, which also leads to "misunderestimated" total magnitudes. We therefore re-examined all these 290 galaxies in order to check whether their magnitudes are underestimated or if they are really intrinsically faint.

\subsubsection{Re-examination of galaxies with underestimated magnitudes}

First of all, the $\sim 290$ galaxies that have an absolute $r$-band magnitude $M_{\mathrm{r}}>-14$ were extracted from the original sample. They were all re-examined using their composite SDSS DR12 rgb colour images. For each galaxy we found there is more than one photometric source associated with it, sometimes of quite different magnitudes. We applied the same method used for NIBLES to assess and correct the "misunderestimated" magnitude problem. For each galaxy, we searched for all photometric sources whose centre positions lie within $30^{\prime \prime}$ distance from the galaxy's centre coordinates, and selected the brightest. We again calculated the total absolute magnitude, now using only the brightest source per galaxy. We also used this method to correct the total magnitude of the 271 more luminous galaxies whose underestimated "total" magnitudes were those of sub-structures within their discs.

For only $15 \%$ (19/130) of the dwarf-like galaxies we found that their absolute magnitudes using the brightest source were still fainter than -14 . This may be due to an error in the magnitude measurement, or an intrinsic property of the galaxy. Images of these 19 low-luminosity galaxies are shown in Fig. 2 and their properties are listed in Table 2 Since these galaxies are fainter than our lower magnitude limit, we did not use these galaxies for further optical studies.

The criteria for the "good" SDSS photometry flag (see Sect 3 removed a further 117 galaxies from our previously defined Sample I , leaving a total of 622 galaxies to be used for further analysis, referred to as Sample II hereafter.

\subsection{3 r-band luminosity as a function of H I mass}

The absolute $r$-band magnitude, $M_{\mathrm{r}}$, as a function of total $\mathrm{HI}$ mass is shown in Fig. 3 for LSB spirals, dwarfs and irregulars. All morpho- 


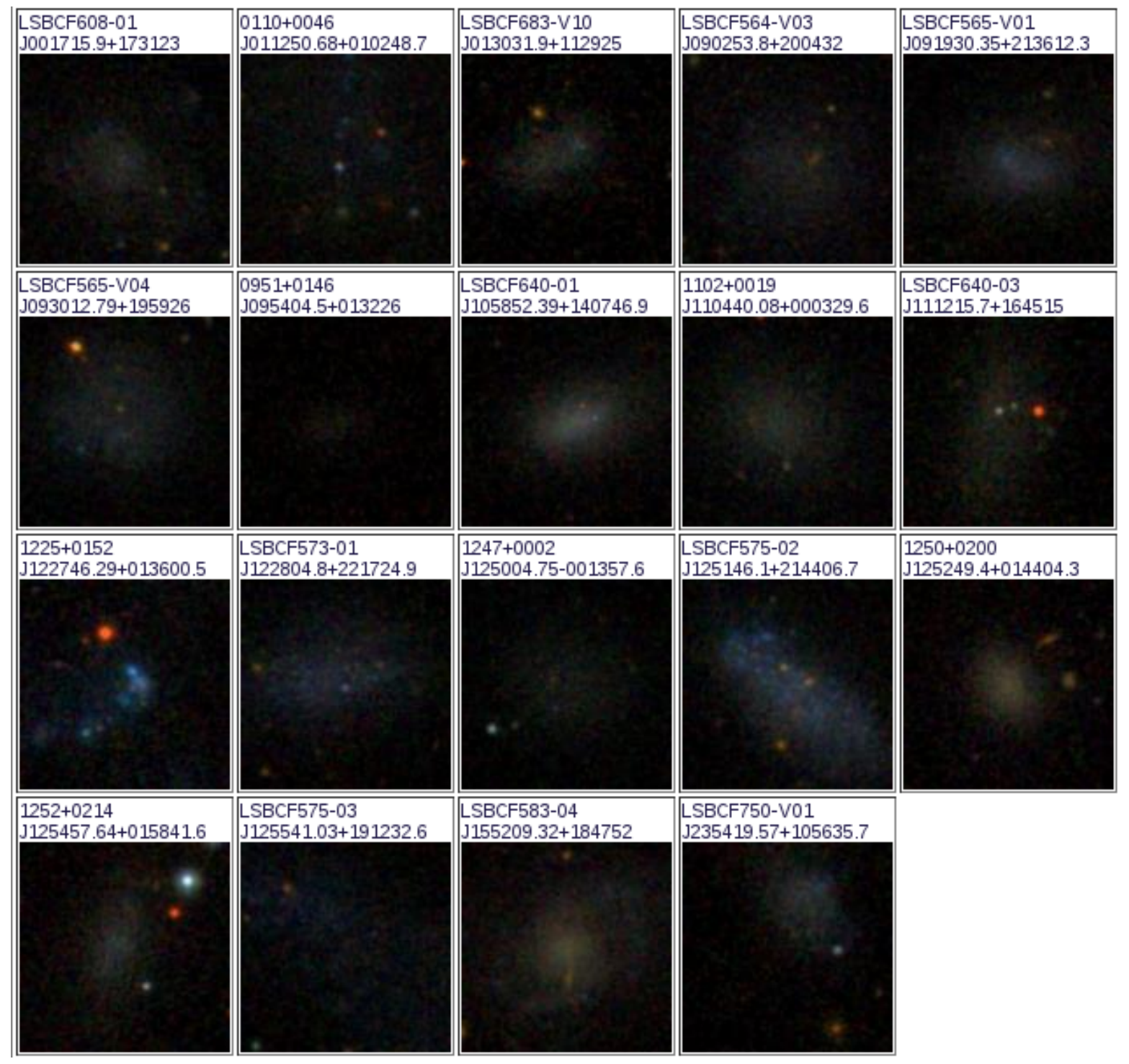

Figure 2. SDSS composite gri colour images of the 19 LSB galaxies with "misunderestimated" luminosities (see Sect. 3.2.1, whose corrected $r$-band absolute magnitude based on the brightest SDSS photometric source within its outlines still remains fainter than -14 . The size of each image is $45^{\prime \prime} \times 45^{\prime \prime}$. In all images north is up and east is left. The galaxy catalogue names as used in the tables and their SDSS coordinates are shown in the top-left corner of each image.

logical types show a similar correlation, with more luminous galaxies having more gas; a similar relationship is observed in the $B$-band (Sprayberry et al. 1995, O’Neil, Bothun \& Schombert|2000).

A linear LSQ fit to all data (blue line in Fig. 3) has a slope of $-2.69 \pm 0.09$ with an intercept of $6.89 \pm 0.88$.

\subsubsection{Colour as a function of H I mass}

We examined how the integrated $(g-r)$ galaxy colours vary as a function of total HI mass (see Fig. 4) but did not note any obvious global correlation for dwarfs and irregulars. Our result is similar to earlier studies using $(B-V)$ colours (e.g., O’Neil, Bothun \& Schombert 2000). The reason for this could be the low star formation rate in these galaxies: even though they contain large quantities of HI, the combined stellar and gas surface density is still lower than the threshold value for star formation (Das, Boone \& Viallefond 2010). In earlier studies (e.g., Mishra et al.|2015, Schombert \& McGaugh 2015), it is also found that some LSB discs undergo episodic star formation, lasting for only $\sim 10^{8}$ years, which makes the galaxies bluer due to the sudden injection of young, massive stars.

However, the data suggest that the HI-rich LSB spirals (with $\left.\log \left(M_{\mathrm{HI}}\right)>9.8\right)$ have $(g-r)$ colours that are on average approximately 0.5 magnitude redder compared to the lower-luminosity spirals, dwarfs and irregulars.

It has been noted previously (Sprayberry et al. 1995) that the $(B-V)$ colours of giant LSBGs are redder than those of averagesized LSB galaxies, but similar to HSB galaxies. Earlier studies have also shown the existence of red galaxies that are HI-rich, both LSBGs (van der Hulst et al. 1987, O'Neil et al. 1997, O'Neil, Bothun \& Schombert 2000) and HSB spirals (e.g., Schommer \& Bothun 1983, van Driel et al. 2016).

The stellar content of giant LSB spirals is more dominated by old stars compared to the LSB dwarfs and irregulars (Sprayberry et al. 1995). It may also be due to the presence of bright bulges that are seen in giant LSB spirals like UGC 6614 and Malin 2. 
Table 2. All galaxies with corrected $M_{\mathrm{r}}$ fainter than $-14 \mathrm{mag}$

\begin{tabular}{lcc}
\hline galaxy name & $\begin{array}{c}M_{\mathrm{r}} \\
(\mathrm{mag})\end{array}$ & $\begin{array}{c}\text { Petrosian radius } \\
\left({ }^{\prime \prime}\right)\end{array}$ \\
\hline LSBC F608-01 & -13.99 & 17.3 \\
0110+0046 & -13.64 & 17.3 \\
LSBC F683-V10 & -13.82 & 8.7 \\
LSBC F564-V03 & -12.63 & 43.8 \\
LSBC F565-V01 & -12.69 & 1.2 \\
LSBC F565-V04 & -13.09 & 1.2 \\
0951+0146 & -12.71 & 1.2 \\
LSBC F640-01 & -13.48 & 6.7 \\
1102+0019 & -13.65 & 17.3 \\
LSBC F640-03 & -13.70 & 1.2 \\
1225+0152 & -12.71 & 1.9 \\
LSBC F573-01 & -13.27 & 17.3 \\
1247+0002 & -13.07 & 17.3 \\
LSBC F575-02 & -13.96 & 10.3 \\
1250+0200 & -13.50 & 5.6 \\
1252+0214 & -13.86 & 17.8 \\
LSBC F575-03 & -12.46 & 27.0 \\
LSBC F583-04 & -13.89 & 0.9 \\
LSBC F750-V01 & -13.92 & 6.7 \\
\hline
\end{tabular}

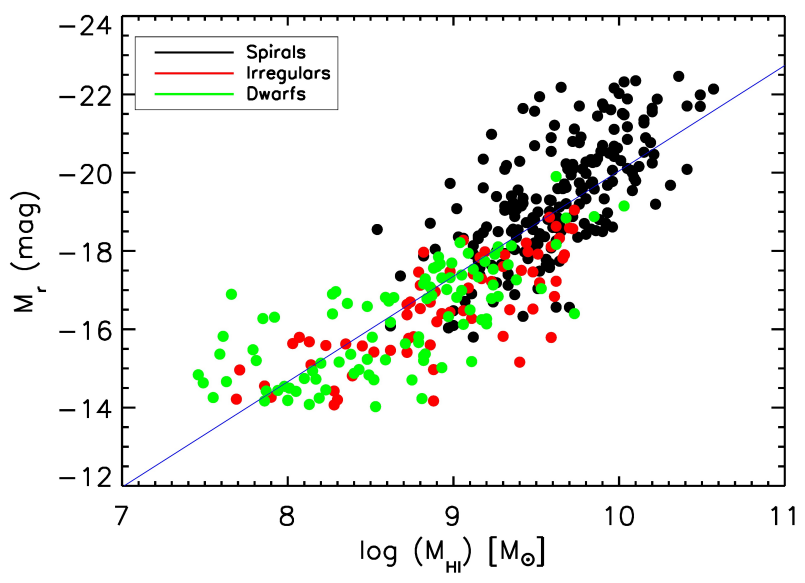

Figure 3. Absolute $r$-band magnitude corrected for Galactic extinction as a function of total $\mathrm{HI}$ mass $\left(\log \left(M_{\mathrm{HI}}\right)\right.$, in $\left.M_{\odot}\right)$ for the three morphological classes of LSB galaxies: spirals (black dots), irregulars (red dots) and dwarfs (green dots). The blue line shows the linear LSQ fit to all data. We used 206 spirals, 71 irregulars and 98 dwarfs for this plot.

\subsection{Total stellar masses}

We compared the distributions of the total stellar mass, $M_{\star}$, and the $\mathrm{HI}$ to the stellar mass ratio, $M_{\mathrm{HI}} / M_{\star}$, of all three morphological classes, since it can also tell us about their ability to convert gaseous fuel into stars.

We converted the SDSS $(g-r)$ colours into Johnson-KronCousins system $(B-V)$ colours following the standard conversion relation given by Jester et al. (2005). Using the $r$ band luminosities and $(B-V)$ colours, we estimated total stellar masses using the $r$ band $M_{\star} / L_{\mathrm{r}}$ ratio given in Bell \& de Jong (2001). Since the galaxies are non-interacting in nature, we used the closed box model for this calculations. The stellar masses obtained are listed in Table 1

Histograms of the total stellar mass distributions are given in Figure 5 The $M_{\star}$ distribution of spirals spans a wide range, $10^{6}$ to $10^{12} M_{\odot}$, with a mean value and standard deviation of $\log \left(M_{\star} / M_{\odot}\right)=9.87 \pm 0.92$. For irregulars and dwarfs their mean

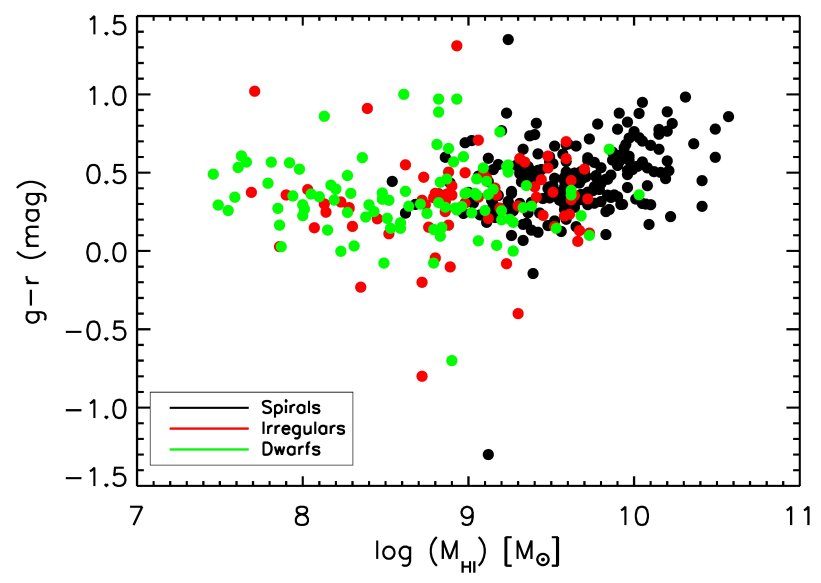

Figure 4. Integrated $(g-r)$ galaxy colour corrected for Galactic extinction as a function of total $\mathrm{HI}$ mass $\left(\log \left(M_{\mathrm{HI}}\right)\right.$, in $\left.M_{\odot}\right)$ for the three morphological classes of LSB galaxies: spirals (black dots), irregulars (red dots) and dwarfs (green dots). The number of galaxies used in this plot is similar to Fig. 3

values are similar, $8.59 \pm 1.70$ and $8.47 \pm 1.15$ respectively, and on average about 20 to 25 times lower than for spirals.

\subsection{Colour Magnitude Diagram}

For the colour magnitude diagram (CMD), a useful tool to assess the evolutionary stage of a galaxy, we plotted the integrated $(g-r)$ colours of galaxies as a function of $M_{\mathrm{r}}$ (see Fig. 6). The CMD divides SDSS galaxies in the local Universe into two main regions, the blue cloud and the red sequence (e.g., Baldry et al.|2004; Wyder et al. 2007). The blue cloud is composed of gas-rich galaxies, such as late-type spirals, that have ongoing star formation. Their sizes are usually smaller and their absolute red magnitudes are lower than for the red sequence galaxies. The red sequence is dominated by early-type (elliptical) galaxies, which usually have little or no gas, no ongoing star formation, and are dominated by an old stellar population. To compare the CMDs of LSB and HSB galaxies in the local Universe, we first constructed a CMD of 52,000 SDSS galaxies in the local Universe, which is dominated by HSB objects. We selected them on criteria similar to those of our LSBGs: $M_{\mathrm{r}}<$ -14 and $z \leqslant 0.1$. We then superimposed all 491 LSBGs from our Sample II with known SDSS colours and absolute magnitudes (375 with $\mathrm{HI}$ detections and 116 without $\mathrm{HI}$ data) on the distribution of the 52,000 predominantly HSB SDSS galaxies, see Figure 6

\subsubsection{Distribution of LSBGs in the Colour Magnitude Diagram}

In Fig. 6 the red sequence lies in the upper-right part of the galaxy distribution, and the blue cloud in the lower-left. A caveat in the interpretation of diagrams such as these, which use integrated colours, is the mixing of disc- and bulge colours. The pure disc colours can only be measured using bulge/disc decomposition on individual galaxies' luminosity profiles. Such a task is outside the scope of the present study. We would like to point out that only in case of prominent bulges will the entire galaxy appear significantly redder than its disc's colours.

The plot shows that the spiral LSBGs are distributed throughout both the blue and red regions, whereas the irregulars and dwarfs 


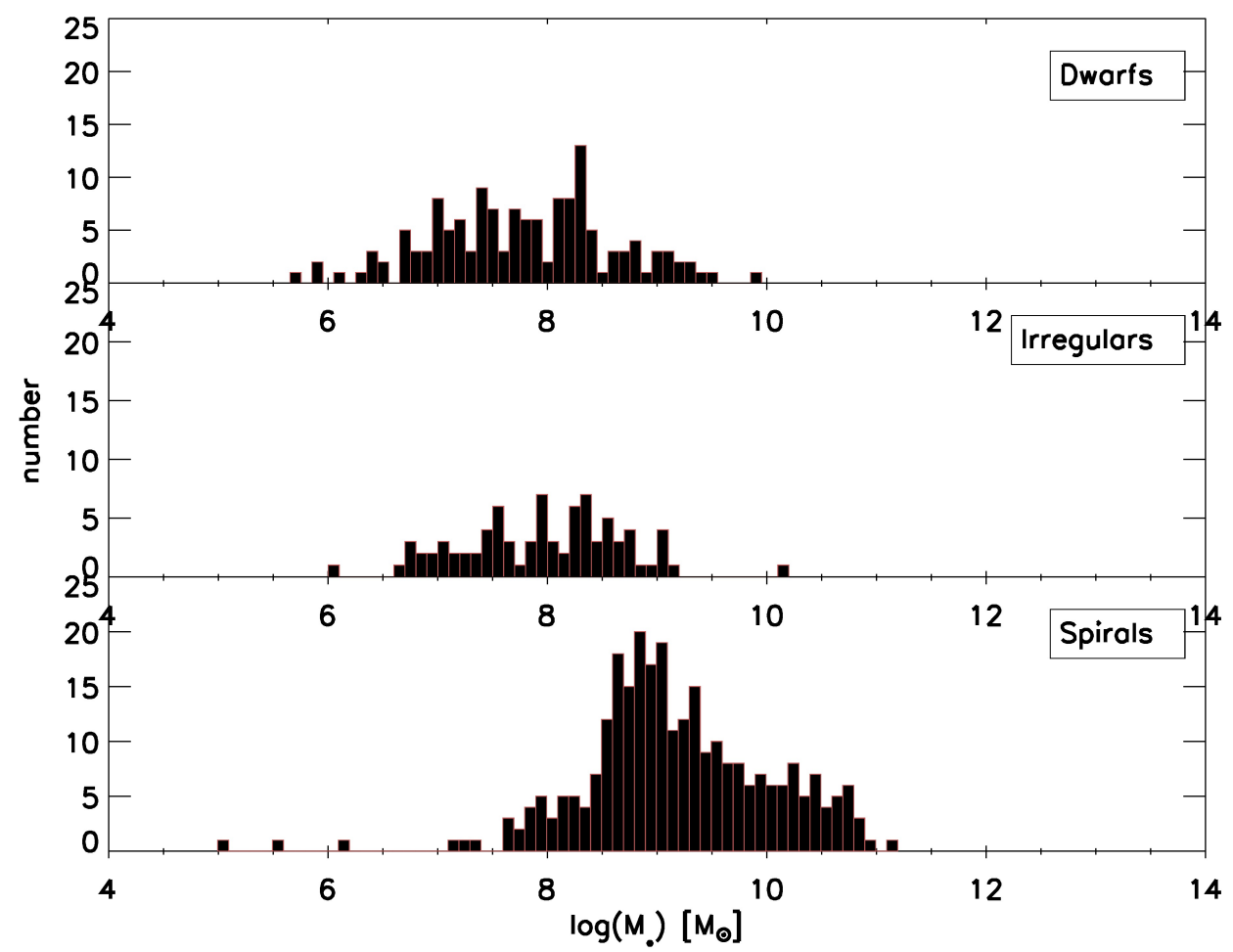

Figure 5. Histograms of the total stellar mass distributions $\left(\log \left(M_{\star}\right)\right.$, in $\left.M_{\odot}\right)$ of the three morphological classes of LSB galaxies: dwarfs, irregulars and spirals. We used 283 spirals, 83 irregulars and 142 dwarfs for this plot. The bin size in $\log \left(M_{\star}\right)=0.10$.

are predominantly found in the blue cloud. We note that a significant fraction of the gas-rich spirals are located in the red sequence region, which is usually dominated by gas-poor systems such as ellipticals, although gas-rich LSB and HSB spirals are also known to exist there (see Sect. 3.2.3. The dwarfs and irregulars are low luminosity, gas rich systems.

The difference in the distribution of spirals versus irregulars and dwarfs in the CMD suggests that both their stellar compositions and evolutionary histories are different. Large bulges could be the reason why some spiral LSBGs lie in the red part of the CMD: a large fraction of spiral LSBGs have massive bulges which sometimes host active galactic nuclei (Schombert, McGaugh \& Eder 2001, Ramya, Prabhu \& Das 2011, Subramanian et al. 2016) and faint discs that show little star formation.

\subsubsection{Gas mass fraction as a function of stellar mass}

The HI-to-stellar mass fraction, $M_{\mathrm{HI}} / M_{\star}$, is plotted as a function of the stellar mass in Figure 7 As the stellar mass increases the fraction decreases. Of the three classes, the spirals' $M_{\star}$ extends to the highest values, as expected. Overall, the irregulars and dwarfs have a larger HI mass fraction than spirals and hence a larger fraction of unused neutral hydrogen. The dwarfs show the largest scatter among the three classes, in particular towards relatively gas-poor objects with low $M_{\mathrm{HI}} / M_{\star}$ ratios. Whereas the latter can be due to gas-poor dwarf ellipticals, very high gas fractions are also expected among dwarfs as they are one of the most dark matter dominated types of galaxies known (Schombert, McGaugh \& Eder 2001), and dark matter halos can slow down their SFR by preventing the formation of disc instabilities (Mihos, McGaugh \& de Blok 1997) which can trigger the onset of star formation.
We compared our results with two samples of normal galaxies, one of HI detections only (Papastergis et al. 2012) and another, NIBLES, selected on total stellar mass (van Driel et al.|2016).

It should be noted that each of the three studies use a different method to estimate $M_{\star}$ : for NIBLES the MPA/JHU catalogues (Kauffmann et al. 2003; Brinchmann et al. 2004) were used, Papastergis et al. (2012) fitted all five SDSS photometric band magnitudes using model spectral energy distributions (see Huang et al. 2012), whereas we followed Bell \& de Jong (2001). In general, different methods for stellar mass estimates can differ systematically by as much as 0.3 dex whereas for individual galaxies the scatter can be up to 0.6 dex (Papastergis et al. 2012, Pforr, Maraston \& Tonini 2012).

We could not reduce the HI flux scales of the three studies to the same reference scale, as the HyperLeda literature data used for our survey come from many different publications. The HI flux scale used by Papastergis et al. (2012) was found to be on average a factor 1.45 higher than the scale used by NIBLES, which is based on O'Neil (2004); this factor corresponds to 0.16 in $\log \left(M_{\mathrm{HI}}\right)$.

The linear regression fit to the HI detections of the NIBLES sample has a slope of -0.54 and an intercept of 4.70 and the fit by Papastergis et al. (2012) has a slope of -0.43 and an intercept of 3.75 (see van Driel et al. 2016).

We did linear LSQ fits to our data points in Fig. 7 The spirals have a slope of $-0.71 \pm 0.03$ and an intercept of $7.00 \pm 0.24$, which is steeper than that of the irregulars and dwarfs. For irregulars the slope is $-0.49 \pm 0.08$ and the intercept $4.88 \pm 0.61$; the values are similar for the dwarfs which have a slope of $-0.50 \pm 0.07$ and intercept of $4.79 \pm 0.57$. Within the uncertainties, the fits to our LSB spirals are similar to those of the two samples which consist mainly of HSB spirals (Papastergis et al. 2012, van Driel et al. 2016). 


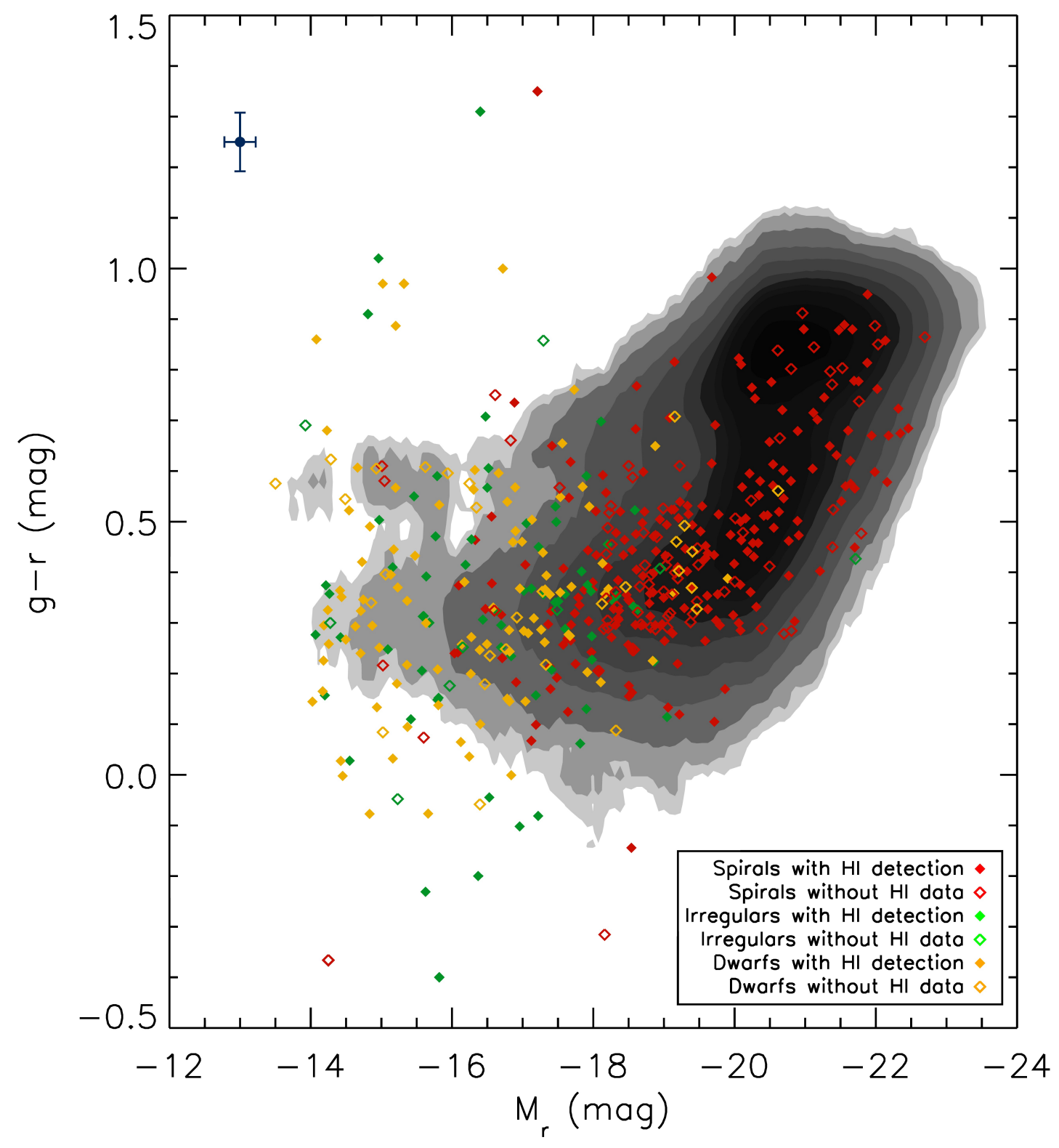

Figure 6. Colour Magnitude Diagram of all 491 LSBGs from our Sample I with known SDSS colours (375 HI detections and 116 galaxies without HI data) and of a comparison sample of 52,000 SDSS galaxies at redshifts $z<0.1$, which are predominantly HSB objects. Plotted are integrated ( $g-r$ ) colours as a function of the absolute magnitudes in the $r$-band, $M_{\mathrm{r}}$; both properties were corrected for Galactic extinction. Our LSBGs are shown as individual coloured points superimposed on a greyscale contour map of the distribution of the large comparison sample, where the darker shades represent the denser regions; the density contour levels are in units of the number of galaxies per grid unit (of size 0.078 magnitude in $M_{\mathrm{r}}$ and 0.028 magnitude in $g-r$ ): $0.05,0.1,0.2,0.5,0.7,1,2,5,10,20,30,40,50,75,100,150,200,300,400,500,600$ and 700 . The different morphological classes of LSBGs are indicated by different colours: red for spirals, green for irregulars and yellow for dwarfs. Filled symbols indicate LSBGs with HI detections, open symbols those without HI data. The typical uncertainties are represented by the blue cross in the upper left corner.

\subsection{Local environmental properties}

It is well established that the large scale galaxy environment plays an important role in shaping the morphology of galaxies (Dressler 1980), as well as in determining their colours (Bamford et al. 2009). However, the local environment around a galaxy is also very important for its evolution. Having a larger number of near-neighbours increases the possibility of a galaxy undergoing interactions and mergers, which can result in increased star formation (Park et al.
2007) associated with the tidal effects and disc instabilities such as bars and spiral arms. For isolated galaxies the possibility of interactions is lower, and for these systems slow, internal evolution - called secular evolution - becomes more important. The giant LSBGs are often found to fall into the latter category (Das 2013 see also Sect. 3.6.

Earlier studies of the local environment of LSBGs found that they are more isolated than HSB galaxies (Schombert \& Bothun 


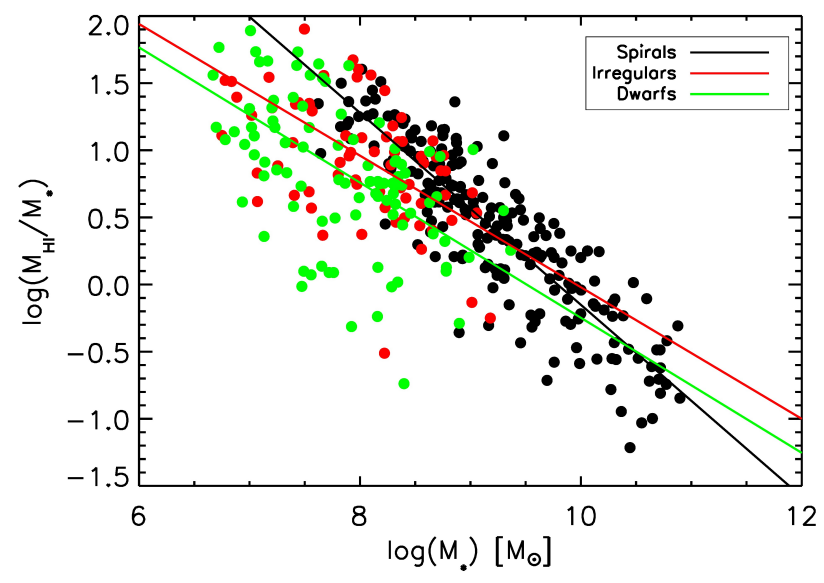

Figure 7. Gas mass fraction, $\log \left(M_{\mathrm{HI}} / M_{\star}\right)$, as a function of total stellar mass $\left(\log \left(M_{\star}\right)\right.$, in $\left.M_{\odot}\right)$. The three morphological classes of LSBGs and the linear LSQ fits to their data are indicated by different colours: red for spirals, green for irregulars and yellow for dwarfs. For the slopes and intercepts of the three fits, see Sect. 3.4.2 The number of galaxies used in this plot is similar to Fig. 3

1988, Schombert et al. 1992, Bothun et al. 1993, Galaz et al.|2011), but more recent studies show that LSB dwarfs and irregulars are found in both high- and low density environments (Javanmardi et al. 2016), whereas the larger LSB spirals are mainly located in low density regions and often close to the edges of voids (Rosenbaum et al. 2009).

We studied the local environment of each of our LSBGs by determining the number of neighbouring galaxies within $1 \mathrm{Mpc}$ radius and within $\pm 500 \mathrm{~km} \mathrm{~s}^{-1}$ of its systemic velocity. We used NED radial velocity constrained cone searches 5 for finding neighbours, which is necessarily limited to nearby galaxies with known redshifts. This means that the number of neighbours found can be a lower limit, but we assume that the missing neighbours without redshifts are evenly distributed over our LSBGs sample, which seems reasonable for our statistical analysis. The results are listed in Table 1. in the column labeled "Iso", for isolation parameter.

As we have used straightforward Hubble flow distances for all our previous calculations and plots, we also used these as input values for the NED search routine. However, in this case the routine limits the distance range for target galaxies from 10 to $150 \mathrm{Mpc}$. For this reason, the sample of galaxies for which we could determine the number of near neighbours is reduced to 468. It includes 246 spirals, 86 irregulars and 136 dwarfs. Figure 8 shows histograms of the number of near neighbours normalized by the total number of nearby galaxies found, for spirals, dwarfs and irregulars.

We find that $63 \%$ of LSB spirals have $\leqslant 3$ neighbours and $87 \%$ have $\leqslant 10$ neighbours, whereas for the irregulars and dwarfs the corresponding numbers are $42 \%$ and $71 \%$, and $31 \%$ and $61 \%$, respectively. Thus, LSB spirals are the most isolated class and dwarfs are the least isolated of LSBGs.

We compared the isolation of galaxies in our LSBG sample with that of normal galaxies using the Spitzer Infrared Nearby Galaxies Survey (SINGS, Kennicutt et al. 2003, see Fig. 8). We used 37 galaxies from this survey (at distances between 10 and 150 $\mathrm{Mpc}$ ) and estimated the number of their near neighbours in the same way as for our sample. Only $19 \%$ of the SINGS galaxies have $\leqslant 3$ neighbours and $29 \%$ have $\leqslant 10$. Thus it is clear that our LSBGs have fewer neighbours than HSB galaxies, or in other words are more isolated than normal galaxies. This is in agreement with previous studies (Schombert \& Bothun 1988, Schombert et al. 1992, Bothun et al. 1993, Rosenbaum et al. 2009, Galaz et al. 2011). The isolation of LSBGs is one of the main reasons why they have remained so poorly evolved, since they do not have interactions with other galaxies (Zaritsky \& Lorrimer 1993). Their isolated nature and high dark matter content results in a lower rate of disc instability formation, both local and global (Mayer \& Wadsley 2004, Ghosh \& $\operatorname{Jog}$ 2014), which means that the disc SFR is lower, thereby causing disc evolution to be slower (Galaz et al.2011).

\subsubsection{Gas mass fraction as a function of environment}

To examine whether interactions are important for triggering star formation in LSBGs we plotted the HI mass fraction against the number of nearby neighbours $(<1 \mathrm{Mpc})$, see Figure 9 There is a lot of scatter and there does not appear to be much dependence of $M_{\mathrm{HI}} / M_{\star}$ on the number of near neighbours. A line fitted to this distribution is almost flat, with a slope of $-0.0022 \pm 0.0020$. This suggests that the environment does not have a pronounced effect on converting $\mathrm{HI}$ mass into stellar mass in LSBGs. We found that SINGS galaxies exhibit a slightly steeper slope of $-0.014 \pm 0.010$.

The fact that LSBGs have extended HI discs indicates that they are isolated and unperturbed systems. For example, HI discs in LSB spirals are at least two times larger than their optical radii (Pickering et al. 1997, Auld et al. 2006, Das et al. 2007, Mishra et al. 2017) and in dwarfs they are even more extended (Begum et al. 2008).

\subsection{Giant LSB galaxies}

Using selection criteria of $\log \left(M_{\mathrm{HI}}\right)>9$ and $\log \left(M_{\star}\right)>10$ to define giant LSB galaxies (see e.g., Matthews, van Driel \& MonnierRagaigne 2001; Das 2013) we find that 41 out of 426 (or 9.6\%) of our LSBGs are giants; we will refer to them as GLSBGs.

In Table 3 we list the following global properties of the 41 GLSB galaxies identified in our sample, see Sect. 3 for further details:

- Galaxy name;

- $M_{\star}$ : total stellar mass (in $M_{\odot}$ );

- $M_{\mathrm{HI}}$ : total HI mass (in $M_{\odot}$ );

- Iso: isolation parameter (see Sect. 3.5), determined for galaxies with distances between 10 and $150 \mathrm{Mpc}$;

- Iso*: isolation parameter determined for galaxies at distances $>150 \mathrm{Mpc}$, using the NED methodology for determining distances, which is based on the same Hubble constant used throughout this paper but with added standard cosmological parameters;

- $D_{\mathrm{K}_{\mathrm{s}}}$ : major axis diameter in the $K_{\mathrm{s}}$ band, from 2MASS, the Two Micron All Sky Survey (in kpc); in case only $R$-band values were available these are indicated by $(R)$;

- $D_{25}$ : major axis diameter at the 25.0 magnitude $\operatorname{arcsec}^{-2}$ isophote level on blue POSS-I images, as listed in the UGC (Nilson 1973 Uppsala General Catalogue of Galaxies (UGC)), in kpc. If not available, we listed the $B$-band values given in the Third Reference Catalogue of Galaxies (de Vaucouleurs et al.|1991. RC3), indicated by $(B)$.

The mean HI mass of the GLSBGs in our sample is $\log \left(M_{\mathrm{HI}}\right)$ $=10.14 \pm 0.53$. This is about 2.3 times larger than the mean of all 

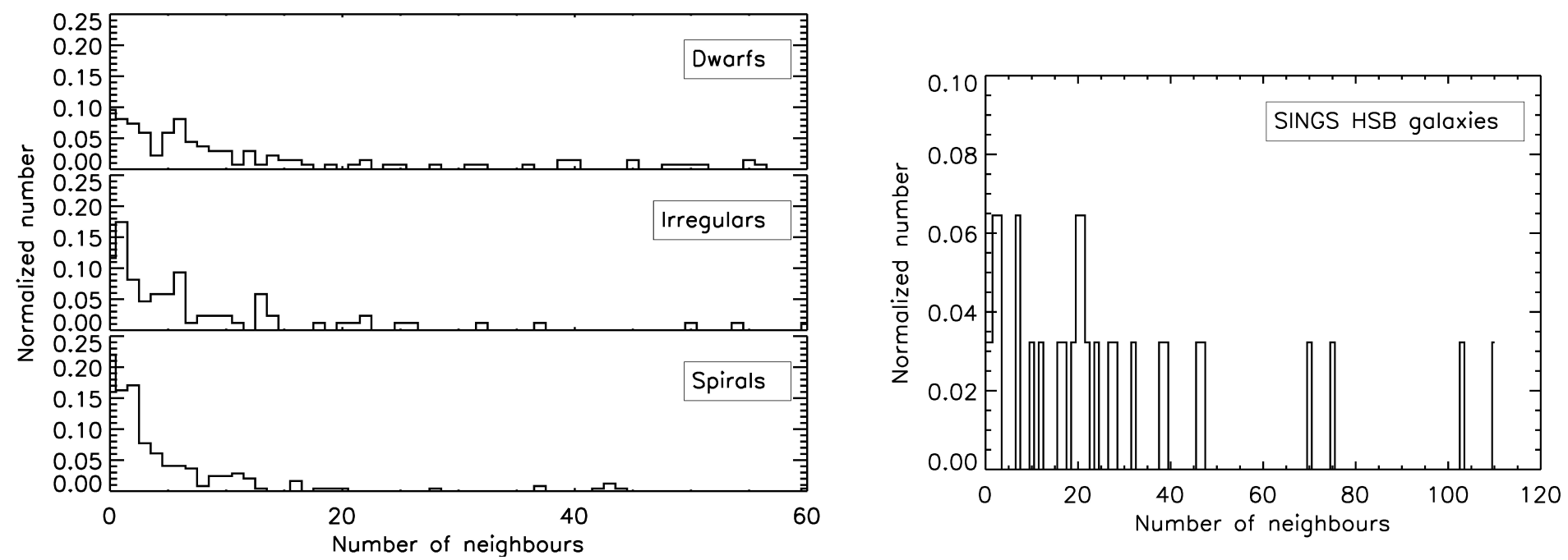

Figure 8. Histograms of the normalized distribution of the number of nearby neighbours of sample galaxies. Nearby neighbours are all known galaxies within a radius of $1 \mathrm{Mpc}$ and within $\pm 500 \mathrm{~km} \mathrm{~s}^{-1}$ of the systemic velocity of the sample galaxy. In each histogram, the distribution is normalized by the total number of galaxies in the histogram. Shown are data for LSBGs of three different morphological classes (left panel), and for HSB galaxies from the SINGS sample (right panel). We used 246 LSBG spirals, 86 irregulars and 136 dwarfs for this plot, and 37 HSB galaxies.

Table 3. Global properties of the giant LSB galaxies.

\begin{tabular}{|c|c|c|c|c|c|c|}
\hline galaxy name & $\begin{array}{c}\frac{\log \left(M_{\star}\right)}{\left(M_{\odot}\right)} \\
\text { (n) }\end{array}$ & $\begin{array}{c}\log \left(M_{\mathrm{HI}}\right) \\
\left(M_{\odot}\right)\end{array}$ & Iso & $I S O^{*}$ & $\begin{array}{c}D_{\mathrm{K}_{\mathrm{S}}} \\
(\mathrm{kpc})\end{array}$ & $\begin{array}{l}D_{25} \\
\text { (kpc) }\end{array}$ \\
\hline LSBC F611-03 & 10.12 & 10.15 & $\ldots$ & 4 & 28.6 & $\ldots$ \\
\hline LSBC F612-V02 & 10.78 & 10.36 & $\ldots$ & 2 & 66.5 & \\
\hline 0223-0033 & 10.90 & 10.05 & 5 & & 47.4 & 64.9 \\
\hline LSBC F560-05 & 11.29 & 10.11 & $\ldots$ & 2 & 38.7 & . \\
\hline LSBC F560-01 & 10.11 & 9.97 & 1 & & 38.9 & 28.8 \\
\hline IC 2409 & 10.21 & 10.02 & 4 & & 36.3 & 25.6 \\
\hline IC 2423 & 10.52 & 9.97 & 8 & & 43.2 & 40.9 \\
\hline LSBC F564-02 & 10.16 & 10.41 & $\ldots$ & 4 & $74.5(R)$ & \\
\hline IC 2454 & 10.39 & 9.51 & 38 & & 36.2 & 42.6 \\
\hline UGC 5035 & 10.70 & 10.00 & $\ldots$ & 6 & 60.2 & $\ldots$ \\
\hline $1003+0151$ & 10.51 & 11.03 & $\ldots$ & 1 & $48.6(R)$ & $\ldots$ \\
\hline LSBC F638-02 & 10.15 & 9.59 & 1 & & 25.0 & $\ldots$ \\
\hline LSBC F568-09 & 10.23 & 9.70 & 5 & & $\ldots$ & 60.9 \\
\hline LSBC F568-08 & 10.72 & 10.23 & 3 & & 60.2 & 42.3 \\
\hline LSBC F568-06 & 10.88 & 10.57 & $\ldots$ & 3 & 66.8 & \\
\hline NGC 3639 & 10.13 & 9.97 & 3 & & 37.4 & 20.3 \\
\hline UGC 6614 & 10.38 & 10.15 & 13 & & 23.7 & 87.9 \\
\hline NGC 3821 & 10.80 & 9.13 & 44 & & 36.8 & 37.7 \\
\hline NGC 3939 & 10.37 & 9.42 & 1 & & 31.7 & 28.3 \\
\hline IC 742 & 10.45 & 9.23 & 44 & & 39.0 & 36.1 \\
\hline $1213+0127$ & 10.32 & 9.76 & $\ldots$ & 3 & 39.5 & $\ldots$ \\
\hline LSBC F574-05 & 10.77 & 10.03 & $\ldots$ & 2 & 48.7 & \\
\hline $1252+0230$ & 10.31 & 10.20 & $\ldots$ & 6 & 36.1 & 33.2 \\
\hline $1300+0055$ & 10.27 & 9.49 & $\ldots$ & 2 & 49.9 & $\ldots$ \\
\hline $1300+0144$ & 10.29 & 10.05 & $\ldots$ & 3 & 44.2 & $\ldots$ \\
\hline UGC 8794 & 10.43 & 9.95 & 8 & & 35.3 & 61.1 \\
\hline UGC 8828 & 10.72 & 9.91 & 17 & & 70.7 & $57.8(B)$ \\
\hline LSBC F579-01 & 10.30 & 9.87 & 3 & & 39.2 & $\ldots$ \\
\hline LSBC F579-03 & 10.38 & 9.74 & 5 & & 31.9 & 36.8 \\
\hline IC 1021 & 10.65 & 9.65 & 2 & & 49.7 & 38.3 \\
\hline LSBC F579-V01 & 11.25 & 9.36 & 3 & & $20.6(R)$ & \\
\hline UGC 9503 & 10.28 & 9.73 & 12 & & 33.1 & $60.4(B)$ \\
\hline UGC 9634 & 10.59 & 10.49 & $\ldots$ & 2 & 44.3 & 54.4 \\
\hline UGC 9843 & 10.29 & 10.15 & $\ldots$ & 26 & 39.4 & $44.4(B)$ \\
\hline LSBC F584-01 & 10.62 & 9.90 & $\ldots$ & 7 & 36.1 & $40.1(B)$ \\
\hline LSBC F727-V04 & 10.69 & 10.20 & $\ldots$ & 7 & 44.5 & $\ldots$ \\
\hline UGC 10405 & 10.47 & 10.49 & $\ldots$ & 3 & $\ldots$ & 82.0 \\
\hline LSBC F533-03 & 10.43 & 10.30 & $\ldots$ & 1 & 82.2 & $47.0(B)$ \\
\hline LSBC F746-02 & 10.54 & 10.06 & $\ldots$ & 1 & 28.0 & $\ldots$ \\
\hline LSBC F675-01 & 10.00 & 9.96 & $\ldots$ & 2 & 26.0 & $\ldots$ \\
\hline 2327-0244 & 10.72 & 10.10 & 2 & & 63.9 & $75.2(B)$ \\
\hline
\end{tabular}

our spirals, and 8.7 and 15.5 times that of the irregulars and dwarfs, respectively. The mean stellar mass of the GLSBGs is $\log \left(M_{\star}\right)$ $=10.60 \pm 0.41$, or about 5.4 times the mean value for our spirals and about 102 and 135 times that for our irregulars and dwarfs, respectively (see Sect. 3.3 .

Giant LSB galaxies are usually redder than normal sized LSB galaxies and appear to have an evolved stellar population similar to HSB galaxies (Sprayberry et al. 1995, van den Hoek et al. 2000). They are unique not just because of their large mass and size, but also because of their high dark matter content.
They are generally isolated (Rosenbaum et al. 2009). To see if our 41 GLSB spirals are more isolated than the other LSBGs in our sample, we examined their number of nearby neighbours (see Sect. 3.5. We find that $73 \%$ (30 out of 41) GLSBs have $\leqslant 5$ neighbours, whereas it is $58 \%$ for the overall spiral LSBG sample. Thus GLSB galaxies represent the most isolated subsample of LSBGs. These giant field galaxies evolve mainly due to internal processes, since external interactions will be very rare. Hence they are the best systems in which to study the slow, secular evolution of disc galaxies, especially those with bars (Honey et al. 2016). Their evolution may thus be different from the other LSB galaxies, especially the dwarfs and irregulars.

\subsection{Are LSB spirals distinct from dwarfs and irregulars? A statistical test}

From our results presented in the earlier sections it is clear that LSB spirals are distinct in many ways from the LSB dwarfs and irregulars - for example, their mean stellar mass is about 20 times larger. To further quantify this difference we performed Kolmogorov-Smirnov (KS) statistical tests to determine whether the LSB subclasses are all derived from the same parent sample (Wall 1996). We performed the two-sample KS tests using the IDL code KSTwO.PRd ${ }^{6}$, on the HI mass, stellar mass and isolation parameter in pair-wise comparisons and summarized our results in Table 4 We found that based on the HI and stellar masses, it is virtually impossible (99.9\%) that LSB spirals arise from the same galaxy distribution as dwarfs and irregulars. The isolation parameter gives a very small probability $(0.5 \%)$ that they are from the same distribution. However, the LSB dwarfs and irregulars have a significant probability (up to 18\%) that they belong to the same distribution for all three parameters that we examined. 

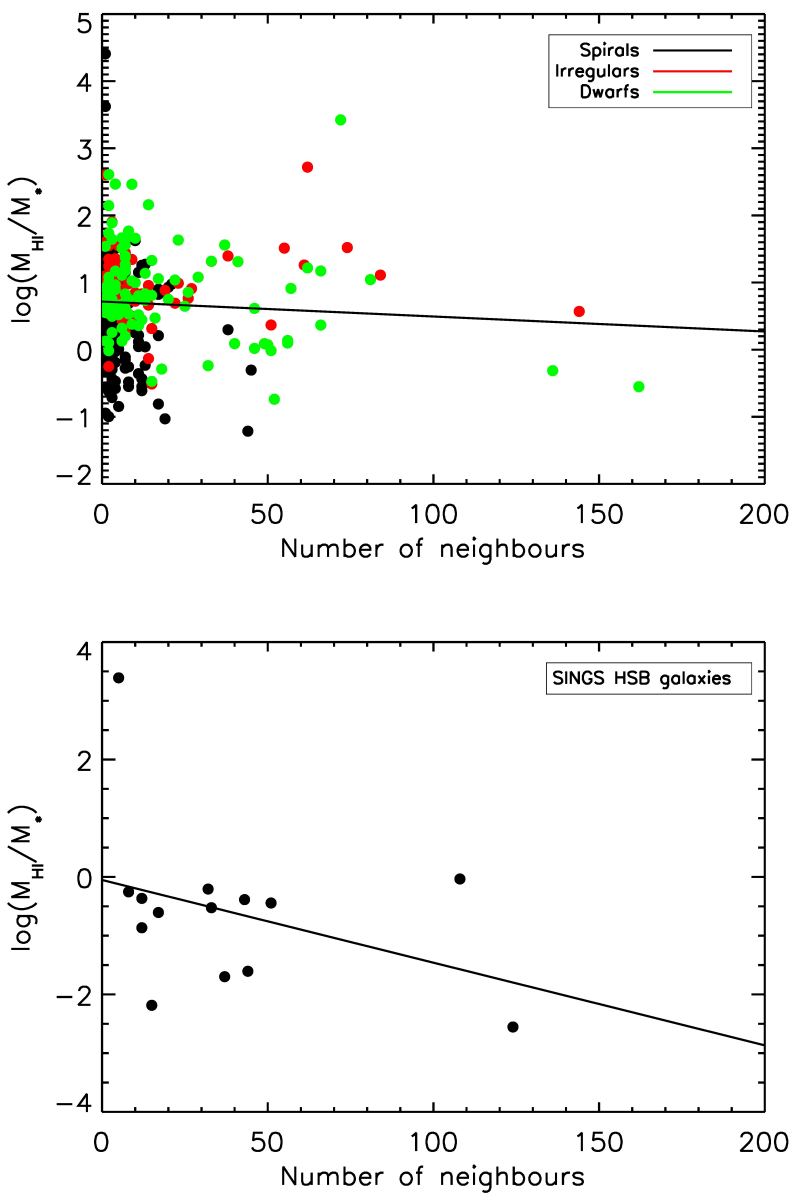

Figure 9. Gas fraction, $\log \left(M_{\mathrm{HI}} / M_{\star}\right)$, as a function of the number of near neighbours, for our LSBGs (top panel) and for SINGS HSB galaxies (bottom panel). We used 163 LSBGs spirals, 71 irregulars and 102 dwarfs for this plot, and 37 HSB galaxies. The linear LSQ fit to the LSBGs data shows a nearly flat slope $-0.0022 \pm 0.0020$ and the fit for the SINGS galaxies a steeper slope of $-0.014 \pm 0.010$.

\subsection{Implications of the statistical test for the origin of LSBGs}

One the reasons for performing the KS test on our sample is to explore the origin of the class of LSB galaxies. To date, the following hypotheses have been put forward regarding their formation: (i) major merger of two face-on disc galaxies (Mapelli \& Moore 2008), (ii) the accretion of small galaxies by a large LSBG (Kaviraj 2014), (iii) the evolution of rare $3 \sigma$ peaks in isolated regions or voids in the primordial density field of large scale structures (Hoffman, Silk \& Wyse 1992) and (iv) they are disc galaxies that formed in fast rotating halos with high specific angular momentum, resulting in low surface density discs, a common characteristic of LSBGs (Kim \& Lee 2013).

However, both major and minor mergers (scenarios i and ii) will destroy or distort the galaxy discs and lead to major star formation (Rodriguez-Gomez et al.|2016), thus transforming the LSB nature of these galaxies into HSB. Hence, scenarios (iii) and (iv) are more likely explanations for the origin of LSBGs. Of these two, the isolated $3 \sigma$ peaks in the primordial large scale structures' density field could have resulted in the formation of large, or even giant, LSBGs that are extremely isolated. However, both the smaller and
Table 4. Results of Kolmogorov-Smirnov tests on the probability that different morphological types of LSBGs originated from the same distribution.

\begin{tabular}{lccc}
\hline \multirow{2}{*}{ Pair } & \multicolumn{3}{c}{ probability of having same distribution in } \\
& HI mass & stellar mass & Iso \\
\hline spirals \& irregulars & $310^{-15}$ & $610^{-23}$ & $510^{-3}$ \\
spirals \& dwarfs & $210^{-39}$ & $410^{-40}$ & $110^{-10}$ \\
irregulars \& dwarfs & $310^{-3}$ & 0.18 & 0.06 \\
\hline
\end{tabular}

larger LSBGs may also have formed as discs in fast rotating halos; this origin scenario has no dependence on environment. Thus it appears that only the more massive, spiral LSBGs can form in isolated environments. This matches the results of our KS tests, which indicates that LSB spirals as a galaxy population are different from dwarfs and irregulars.

Although LSB dwarfs and irregulars have been found in both cluster and field environments (Pustilnik et al. 2011; Merritt, van Dokkum \& Abraham 2014, Giallongo et al. 2015, Davies, Davies \& Keenan 2016, Wittmann et al. 2017), in order to retain their LSB nature the galaxies must remain fairly isolated. Recently a population of ultra diffuse galaxies (UDGs) with stellar masses like dwarfs but radii like $L \star$ galaxies has been identified in nearby galaxy clusters and groups (e.g., Koda et al. 2015, Trujillo et al. 2017), some of which may be dwarf or irregular LSBGs (Amorisco \& Loeb 2016). On the other hand, many dwarf LSBGs have also been detected in voids (Kreckel et al.2011). The larger LSBGs are however nearly always isolated (Pickering et al. 1997).

Regarding the considerably more massive LSB spirals, they may well be disc galaxies of masses similar to those of HSB spirals that are relatively isolated and therefore free from external shocks, and thus evolving in a more quiescent manner into red and gas-rich systems.

\section{CONCLUSIONS}

The morphologies of LSBGs can be broadly classified as spirals, dwarfs and irregulars. In terms of both total $\mathrm{HI}$ and stellar mass, we find that the LSB spirals are the most massive, followed by the irregulars, and then the dwarfs.

The $r$-band luminosity increases with HI mass in all three morphological types. When taken as a whole, we find that the spirals show a different slope compared to irregulars and dwarfs in the $M_{\mathrm{HI}} / M_{\star}-M_{\star}$ plane. Within the total stellar mass estimation uncertainties, the fit parameters for our LSBGs are similar to the samples of Papastergis et al. (2012) and van Driel et al. (2016), which are dominated by HSB spirals.

The integrated $(g-r)$ galaxy colours do not show a clear dependence on HI mass in LSB spirals, dwarfs and irregulars. Only the most massive spirals appear slightly redder, which indicates that even when they have a massive HI content, LSBGs cannot form stars at a significant rate. This can be due to the low surface density of their stellar and HI discs, as well as the presence of massive dark matter halos.

The colour magnitude diagram (CMD) for LSBGs shows that spirals occur in both the blue cloud and the red sequence, indicating the variety in their evolutionary stages, with the red spirals being more massive (both $M_{\star}$ and $M_{\mathrm{HI}} \geqslant 10^{9.5} M_{\odot}$ ) and the blue ones less so $\left(M_{\star} \sim 10^{7}-10^{9} M_{\odot}, M_{\mathrm{HI}} \gtrsim 10^{8} M_{\odot}\right)$. A significant fraction of the LSB spirals are very red, similar to galaxies in which star formation is quenched. The smaller LSB dwarfs and irregulars are comparatively bluer, indicating that they support slow and continuous star formation. 
Exploring the nearby galaxy density around LSBGs, within $1 \mathrm{Mpc}$ radius and $\pm 500 \mathrm{~km} \mathrm{~s}^{-1}$ of their systemic velocity, we confirmed that LSBGs are more isolated than HSB galaxies. We also found that the LSB spirals are more isolated than dwarf and irregulars, and that giant LSBGs are the most isolated of all.

Kolmogorov-Smirnov (KS) tests using HI masses, stellar masses and isolation parameters indicate that that the LSB spirals form a distinct population from the dwarfs and irregulars. This suggests a different formation process and/or evolutionary path for spirals compared to dwarfs and irregulars.

AcKNowledgments We wish to thank the referee Greg Bothun for his valuable comments and suggestions. We thank our colleague Vaibhav Pant for helpful discussions. We have used the NASA/IPAC Extragalactic Database (NED), which is operated by the Jet Propulsion Laboratory, California Institute of Technology, under contract with the National Aeronautics and Space Administration, as well as the online HyperLeda database. This work has used SDSS-III data. Funding for SDSS-III has been provided by the Alfred P. Sloan Foundation, the Participating Institutions, the National Science Foundation, and the U.S. Department of Energy Office of Science.

\section{References}

Alam S. et al., 2015, ApJS, 219, 12

Amorisco N. C., Loeb A., 2016, MNRAS, 459, L51

Auld R., de Blok W. J. G., Bell E., Davies J. I., 2006, MNRAS, 366,1475

Baldry I. K., Glazebrook K., Brinkmann J., IvezićŽ., Lupton R. H., Nichol R. C., Szalay A. S., 2004, ApJ, 600, 681

Bamford S. P. et al., 2009, MNRAS, 393, 1324

Begum A., Chengalur J. N., Karachentsev I. D., Sharina M. E., Kaisin S. S., 2008, MNRAS, 386, 1667

Bell E. F., de Jong R. S., 2001, ApJ, 550, 212

Boissier S. et al., 2008, ApJ, 681, 244

Bothun G. D., Schombert J. M., Impey C. D., Sprayberry D., McGaugh S. S., 1993, AJ, 106, 530

Brinchmann J., Charlot S., White S. D. M., Tremonti C., Kauffmann G., Heckman T., Brinkmann J., 2004, MNRAS, 351, 1151

Burkholder V., Impey C., Sprayberry D., 2001, AJ, 122, 2318

Cornell M. E., Aaronson M., Bothun G., Mould J., 1987, ApJS, 64, 507

Das M., 2013, Journal of Astrophysics and Astronomy, 34, 19

Das M., Boone F., Viallefond F., 2010, A\&A, 523, A63

Das M., Kantharia N., Ramya S., Prabhu T. P., McGaugh S. S., Vogel S. N., 2007, MNRAS, 379, 11

Das M., O’Neil K., Vogel S. N., McGaugh S., 2006, ApJ, 651, 853

Davies J. I., Davies L. J. M., Keenan O. C., 2016, MNRAS, 456, 1607

de Blok W. J. G., McGaugh S. S., 1997, MNRAS, 290, 533

de Blok W. J. G., McGaugh S. S., van der Hulst J. M., 1996, MNRAS, 283, 18

de Vaucouleurs G., de Vaucouleurs A., Corwin, Jr. H. G., Buta R. J., Paturel G., Fouqué P., 1991, Third Reference Catalogue of Bright Galaxies. Springer, New York (RC3)

Dressler A., 1980, ApJ, 236, 351

Du W., Wu H., Lam M. I., Zhu Y., Lei F., Zhou Z., 2015, AJ, 149, 199

Freeman K. C., 1970, ApJ, 160, 811
Galaz G., Herrera-Camus R., Garcia-Lambas D., Padilla N., 2011, ApJ, 728, 74

Ghosh S., Jog C. J., 2014, MNRAS, 439, 929

Giallongo E., Menci N., Grazian A., Fassbender R., Fontana A., Paris D., Pentericci L., 2015, ApJ, 813, 68

Hinz J. L., Rieke M. J., Rieke G. H., Willmer C. N. A., Misselt K., Engelbracht C. W., Blaylock M., Pickering T. E., 2007, ApJ, 663, 895

Hoffman Y., Silk J., Wyse R. F. G., 1992, ApJL, 388, L13

Honey M., Das M., Ninan J. P., Manoj P., 2016, MNRAS, 462, 2099

Huang S., Haynes M. P., Giovanelli R., Brinchmann J., Stierwalt S., Neff S. G., 2012, AJ, 143, 133

Impey C., Bothun G., 1997, ARA\&A, 35, 267

Impey C. D., Sprayberry D., Irwin M. J., Bothun G. D., 1996, ApJS, 105, 209

Javanmardi B. et al., 2016, $A \& A, 588$, A89

Jester S. et al., 2005, $A J, 130,873$

Kauffmann G. et al., 2003, MNRAS, 341, 54

Kaviraj S., 2014, MNRAS, 440, 2944

Kennicutt, Jr. R. C. et al., 2003, PASP, 115, 928

Kim J.-h., Lee J., 2013, MNRAS, 432, 1701

Koda J., Yagi M., Yamanoi H., Komiyama Y., 2015, ApJL, 807, L2

Kreckel K., Peebles P. J. E., van Gorkom J. H., van de Weygaert R., van der Hulst J. M., 2011, AJ, 141, 204

Kuzio de Naray R., McGaugh S. S., de Blok W. J. G., 2004, MNRAS, 355, 887

Mapelli M., Moore B., 2008, Astronomische Nachrichten, 329, 948

Matthews L. D., van Driel W., Monnier-Ragaigne D., 2001, A\&A, 365,1

Mayer L., Wadsley J., 2004, MNRAS, 347, 277

McGaugh S. S., 1994, ApJ, 426, 135

McGaugh S. S., Schombert J. M., Bothun G. D., 1995, AJ, 109, 2019

Merritt A., van Dokkum P., Abraham R., 2014, ApJL, 787, L37

Mihos J. C., McGaugh S. S., de Blok W. J. G., 1997, ApJL, 477, L79

Minkowski R. L., Abell G. O., 1963, The National Geographic Society-Palomar Observatory Sky Survey. the University of Chicago Press, p. 481

Mishra A., Kantharia N. G., Das M., Omar A., Srivastava D. C., 2017, MNRAS, 464, 2741

Mishra A., Kantharia N. G., Das M., Srivastava D. C., Vogel S. N., 2015, MNRAS, 447, 3649

Nilson P., 1973, Uppsala General Catalogue of Galaxies, Nova Acta Regiae Soc. Sci. Upsaliensis Ser. V (UGC)

O'Neil K., 2004, AJ, 128, 2080

O’Neil K., Bothun G., van Driel W., Monnier Ragaigne D., 2004, $A \& A, 428,823$

O’Neil K., Bothun G. D., Schombert J., 2000, AJ, 119, 136

O’Neil K., Bothun G. D., Schombert J., Cornell M. E., Impey C. D., 1997, AJ, 114, 2448

O’Neil K., Hofner P., Schinnerer E., 2000, ApJL, 545, L99

Papastergis E., Cattaneo A., Huang S., Giovanelli R., Haynes M. P., 2012, ApJ, 759, 138

Park C., Choi Y.-Y., Vogeley M. S., Gott, III J. R., Blanton M. R., SDSS Collaboration, 2007, ApJ, 658, 898

Paturel G., Petit C., Prugniel P., Theureau G., Rousseau J., Brouty M., Dubois P., Cambrésy L., 2003a, A\&A, 412, 45 


\section{Honey et al.}

Paturel G., Theureau G., Bottinelli L., Gouguenheim L., Coudreau-

Durand N., Hallet N., Petit C., 2003b, A\&A, 412, 57

Pforr J., Maraston C., Tonini C., 2012, MNRAS, 422, 3285

Pickering T. E., Impey C. D., van Gorkom J. H., Bothun G. D., 1997, AJ, 114, 1858

Pustilnik S. A., Martin J.-M., Tepliakova A. L., Kniazev A. Y., 2011, MNRAS, 417, 1335

Rahman N., Howell J. H., Helou G., Mazzarella J. M., Buckalew B., 2007, ApJ, 663, 908

Ramya S., Prabhu T. P., Das M., 2011, MNRAS, 418, 789

Reid I. N. et al., 1991, PASP, 103, 661

Rodriguez-Gomez V. et al., 2016, MNRAS, 458, 2371

Rosenbaum S. D., Krusch E., Bomans D. J., Dettmar R.-J., 2009, $A \& A, 504,807$

Schlegel D. J., Finkbeiner D. P., Davis M., 1998, ApJ, 500, 525

Schombert J., McGaugh S., 2015, AJ, 150, 72

Schombert J., McGaugh S., Maciel T., 2013, AJ, 146, 41

Schombert J. M., Bothun G. D., 1988, AJ, 95, 1389

Schombert J. M., Bothun G. D., Schneider S. E., McGaugh S. S., 1992, AJ, 103, 1107

Schombert J. M., McGaugh S. S., Eder J. A., 2001, AJ, 121, 2420

Schommer R. A., Bothun G. D., 1983, AJ, 88, 577

Shao X., Disseau K., Yang Y. B., Hammer F., Puech M., Rodrigues

M., Liang Y. C., Deng L. C., 2015, A\&A, 579, A57

Sprayberry D., Impey C. D., Bothun G. D., Irwin M. J., 1995, AJ, 109, 558

Sprayberry D., Impey C. D., Irwin M. J., 1996, ApJ, 463, 535

Sprayberry D., Impey C. D., Irwin M. J., Bothun G. D., 1997, ApJ, 482, 104

Subramanian S., Ramya S., Das M., George K., Sivarani T., Prabhu T. P., 2016, MNRAS, 455, 3148

Trujillo I., Roman J., Filho M., Sánchez Almeida J., 2017, ApJ, 836, 191

van den Hoek L. B., de Blok W. J. G., van der Hulst J. M., de Jong T., 2000, A\&A, 357, 397

van der Hulst J. M., Skillman E. D., Kennicutt R. C., Bothun G. D., 1987, A\&A, 177, 63

van Driel W. et al., 2016, $A \& A, 595$, A118

Wall J. V., 1996, QJRAS, 37, 519

Williams R. P. et al., 2016, MNRAS, 463, 2746

Wittmann C. et al., 2017, MNRAS, 470, 1512

Wyder T. K. et al., 2009, ApJ, 696, 1834

Wyder T. K. et al., 2007, ApJS, 173, 293

York D. G. et al., 2000, AJ, 120, 1579

Young J. E., Kuzio de Naray R., Wang S. X., 2015, MNRAS, 452, 2973

Zaritsky D., Lorrimer S. J., 1993, in Evolution of Galaxies and their Environment, Shull J. M., Thronson H. A., eds., p. 82

Zhong G. H., Liang Y. C., Hammer F., Chen X. Y., Deng L. C., Flores H., 2010, A\&A, 520, A69

Zhong G. H., Liang Y. C., Liu F. S., Hammer F., Hu J. Y., Chen X. Y., Deng L. C., Zhang B., 2008, MNRAS, 391, 986 
Table 1: Global properties of the LSBGs in the initial sample of 897 galaxies-

full version.

\begin{tabular}{|c|c|c|c|c|c|c|c|c|c|c|c|}
\hline galaxy name & $\begin{array}{c}\text { RA \& DEC } \\
(\mathrm{J} 2000.0)\end{array}$ & $\begin{array}{r}D \\
(\mathrm{Mpc}) \\
\end{array}$ & $\begin{array}{l}\text { morphology } \\
{[\mathrm{NED}]}\end{array}$ & class & $\begin{array}{c}\text { HI flux } \\
(\mathrm{Jy} \mathrm{km} / \mathrm{s})\end{array}$ & $\begin{array}{c}\log \left(M_{\mathrm{HI}}\right) \\
\left(M_{\odot}\right) \\
\end{array}$ & $\begin{array}{c}M_{\mathrm{r}} \\
(\mathrm{mag})\end{array}$ & $\begin{array}{r}(g-r) \\
(\mathrm{mag}) \\
\end{array}$ & $\begin{array}{r}\log \left(M_{\star}\right) \\
\left(M_{\odot}\right)\end{array}$ & Iso & Flag* \\
\hline \multicolumn{12}{|c|}{ 1. With HI detections: } \\
\hline LSBC F539-V01 & $00: 11: 29.00+21: 25: 52.0$ & 113.3 & $\mathrm{Sm}$ & spiral & 2.37 & 9.86 & -18.52 & 0.34 & 8.75 & 1 & good \\
\hline LSBC F608-V01 & $00: 12: 48.25+14: 31: 31.1$ & 26.1 & $\mathrm{Sd}$ & dwarf & 3.47 & 8.75 & -14.71 & 0.24 & 7.09 & 10 & good \\
\hline $0012+0218$ & $00: 14: 59.97+02: 34: 48.3$ & 256.3 & dI & dwarf & 0.69 & 10.03 & -19.15 & 0.36 & 9.02 & $\ldots$ & good \\
\hline $0014+0210$ & $00: 16: 41.72+02: 27: 34.4$ & 59.1 & Sm: & star & 0.75 & 8.79 & -15.62 & 1.34 & 8.91 & 1 & not used \\
\hline LSBC F608-01 & $00: 17: 15.90+17: 31: 23.0$ & 14.3 & Im: & irregular & 2.18 & 8.02 & -13.99 & 0.92 & 7.71 & 15 & not used \\
\hline LSBC F473-V01 & $00: 17: 18.30+26: 51: 41.0$ & 127.3 & Im & irregular & 1.36 & 9.72 & -18.57 & 0.33 & 8.76 & 1 & good \\
\hline LSBC F608-V02 & $00: 23: 06.06+15: 08: 25.6$ & 78.8 & $\mathrm{Sd}$ & irregular & 0.85 & 9.09 & -17.05 & 0.50 & 8.37 & 10 & good \\
\hline LSBC F539-02 & $00: 23: 15.76+20: 15: 59.1$ & 81.7 & Im: & spiral & 1.56 & 9.39 & -19.56 & 0.42 & 9.27 & 11 & good \\
\hline LSBC F473-01 & $00: 25: 56.90+23: 55: 24.0$ & 80.5 & $\operatorname{Im}$ & irregular & 0.95 & 9.16 & -17.83 & 0.40 & 8.56 & 3 & good \\
\hline LSBC F473-V02 & $00: 26: 21.00+24: 38: 35.0$ & 51.1 & Irr & irregular & 1.40 & 8.93 & -16.40 & 1.31 & 9.18 & 2 & good \\
\hline $0023+0044$ & $00: 26: 24.98+01: 01: 12.0$ & 75.7 & $\mathrm{Sd}$ & spiral & 1.51 & 9.31 & -19.04 & 0.49 & 9.16 & 3 & good \\
\hline $0025+0221$ & $00: 27: 46.98+02: 38: 23.5$ & 58.1 & dI & dwarf & 0.49 & 8.59 & -16.81 & 0.14 & 7.81 & 13 & good \\
\hline $0029+0037$ & $00: 31: 43.27+00: 54: 02.6$ & 76.6 & & spiral & 1.09 & 9.18 & -18.47 & 0.36 & 8.75 & 3 & good \\
\hline $0029+0226$ & $00: 31: 45.35+02: 42: 53.3$ & 34.0 & dI & dwarf & 1.11 & 8.48 & -14.38 & -0.50 & 5.87 & 2 & bad \\
\hline LSBC F473-V03 & $00: 34: 46.10+22: 46: 46.0$ & 83.4 & $\mathrm{Sm}$ & spiral & 1.19 & 9.29 & -17.66 & 0.55 & 8.68 & 1 & good \\
\hline $0049+0105$ & $00: 52: 01.86+01: 21: 42.9$ & 184.0 & $\mathrm{Sm}$ & spiral & 1.15 & 9.96 & -18.61 & 0.41 & 8.87 & $\ldots$ & good \\
\hline 0051-0227 & $00: 54: 21.40-02: 11: 45.1$ & 77.7 & Sd pec sp & spiral & 2.65 & 9.58 & -17.69 & 0.30 & 8.36 & 1 & good \\
\hline LSBC F682-V01 & $00: 56: 41.10+10: 20: 23.0$ & 148.6 & $\mathrm{Sc}$ & spiral & 1.35 & 9.85 & -19.58 & 0.26 & 9.07 & 1 & good \\
\hline LSBC F682-01 & $00: 57: 31.89+10: 21: 48.2$ & 39.4 & $\mathrm{Sm}$ & spiral & 2.53 & 8.97 & -16.03 & 0.24 & 7.62 & 1 & good \\
\hline $0056+0044$ & $00: 58: 55.46+01: 00: 17.7$ & 76.5 & Irr & irregular & 3.38 & 9.67 & -17.90 & 0.13 & 8.22 & 7 & good \\
\hline $0056+0020$ & $00: 58: 55.89+00: 36: 27.9$ & 77.6 & $\mathrm{dI}$ & dwarf & 2.38 & 9.53 & -17.04 & 0.14 & 7.90 & 7 & good \\
\hline LSBC F682-V02 & $01: 01: 51.57+10: 16: 21.8$ & 163.2 & $\mathrm{Sm}$ & spiral & 0.75 & 9.67 & -19.71 & 0.43 & 9.35 & $\ldots$ & good \\
\hline $0103+0030$ & $01: 06: 07.17+00: 46: 33.7$ & 74.3 & $\mathrm{Sd}$ & spiral & 1.40 & 9.26 & -17.99 & 0.38 & 8.59 & 5 & good \\
\hline $0108+0242$ & $01: 11: 21.26+02: 58: 22.8$ & 143.3 & $\mathrm{Sc}$ & spiral & 1.30 & 9.80 & -19.98 & 0.32 & 9.30 & 1 & good \\
\hline $0110+0046$ & $01: 12: 50.69+01: 02: 48.8$ & 15.8 & $\mathrm{dI}$ & dwarf & 6.23 & 8.56 & -13.65 & -0.10 & 6.10 & 9 & not used \\
\hline $0110+0034$ & $01: 13: 10.02+00: 50: 12.1$ & 139.8 & & spiral & 0.92 & 9.63 & -18.85 & 0.36 & 8.91 & 2 & good \\
\hline LSBC F611-03 & $01: 13: 20.17+14: 43: 39.8$ & 186.0 & $\mathrm{Sc}(\mathrm{r}) / \mathrm{LSB}$ disk & spiral & 1.75 & 10.15 & -20.52 & 0.78 & 10.12 & $\ldots$ & good \\
\hline $0111+0036$ & $01: 13: 39.40+00: 52: 27.9$ & 16.6 & dI & dwarf & 4.80 & 8.49 & -14.83 & 0.08 & 6.72 & 8 & good \\
\hline 0111-0019 & $01: 14: 31.62-00: 04: 02.5$ & 73.6 & $\mathrm{dEn}$ & dwarf & 0.53 & 8.83 & -17.29 & 0.44 & 8.39 & 12 & good \\
\hline $0114+0056$ & $01: 16: 35.88+01: 12: 08.1$ & 72.7 & $\mathrm{Sd}$ & spiral & 1.06 & 9.12 & -17.92 & 0.44 & 8.65 & 4 & good \\
\hline $0114+0204$ & $01: 16: 48.84+02: 20: 42.6$ & 140.1 & dI & spiral & 1.36 & 9.80 & -19.33 & 0.53 & 9.33 & 2 & good \\
\hline 0116-0158 & 01:19:28.98 -01:42:06.0 & 68.3 & $\mathrm{SB}(\mathrm{s}) \mathrm{m}$ & spiral & 3.51 & 9.59 & -18.08 & 0.20 & 8.39 & 2 & good \\
\hline LSBC F611-01 & $01: 19: 47.37+16: 47: 24.6$ & 30.9 & $\mathrm{dI} / \mathrm{Im}$ & dwarf & 1.45 & 8.51 & -15.80 & 0.21 & 7.49 & 9 & good \\
\hline $0117+0027$ & $01: 19: 58.70+00: 43: 20.3$ & 62.8 & $\mathrm{Sd}$ & dwarf & 0.92 & 8.93 & -17.31 & 0.26 & 8.16 & 1 & good \\
\hline LSBC F683-V01 & $01: 19: 59.50+08: 51: 54.0$ & 137.9 & $\mathrm{Sm}$ & spiral & 1.24 & 9.75 & -18.35 & 0.38 & 8.73 & $\ldots$ & good \\
\hline 0117-0013 & $01: 20: 23.42+00: 01: 49.1$ & 52.0 & S & irregular & 0.65 & 8.62 & -15.46 & 0.55 & 7.80 & 3 & good \\
\hline 0118-0004 & $01: 21: 13.16+00: 11: 13.5$ & 54.8 & $\mathrm{Sdm}$ & spiral & 2.43 & 9.24 & -16.70 & 0.32 & 7.99 & 7 & good \\
\hline LSBC F683-V02 & $01: 22: 05.73+09: 25: 16.6$ & 81.1 & $\operatorname{Im}$ & position is off & 0.31 & 8.68 & -16.26 & 0.24 & 7.72 & 3 & not used \\
\hline LSBC F683-V04 & $01: 22: 39.70+09: 08: 58.0$ & 194.8 & $\mathrm{Sm} / \mathrm{Im}$ & spiral & 0.76 & 9.83 & -19.71 & 0.10 & 8.91 & $\ldots$ & good \\
\hline
\end{tabular}


Table 1:-continued.

\begin{tabular}{|c|c|c|c|c|c|c|c|c|c|c|c|}
\hline galaxy name & $\begin{array}{c}\text { RA \& DEC } \\
(\mathrm{J} 2000.0)\end{array}$ & $\begin{array}{r}D \\
(\mathrm{Mpc})\end{array}$ & $\begin{array}{l}\text { morphology } \\
{[\mathrm{NED}]}\end{array}$ & class & $\begin{array}{c}\text { HI flux } \\
(\mathrm{Jy} \mathrm{km} / \mathrm{s})\end{array}$ & $\begin{array}{c}\log \left(M_{\mathrm{HI}}\right) \\
\left(M_{\odot}\right)\end{array}$ & $\begin{array}{c}M_{\mathrm{r}} \\
(\mathrm{mag})\end{array}$ & $\begin{array}{r}(g-r) \\
(\mathrm{mag})\end{array}$ & $\begin{array}{r}\log \left(M_{\star}\right) \\
\left(M_{\odot}\right)\end{array}$ & Iso & Flag $^{*}$ \\
\hline LSBC F683-V06 & $01: 23: 05.30+09: 20: 35.0$ & 72.7 & $\mathrm{Sd}$ & spiral & 1.04 & 9.11 & -16.91 & 0.18 & 7.90 & 2 & good \\
\hline LSBC F683-V07 & $01: 25: 06.11+10: 00: 24.0$ & $\ldots$ & $\mathrm{Sm}$ & no SDSS galaxy & 1.54 & $\ldots$ & & & & & not used \\
\hline $0123+0055$ & $01: 25: 39.73+01: 10: 41.1$ & 83.6 & $\mathrm{Sb}$ & spiral & 3.11 & 9.71 & -19.94 & 0.47 & 9.49 & 11 & good \\
\hline LSBC F683-V08 & $01: 25: 47.30+09: 35: 01.0$ & 209.7 & $\mathrm{Sb}$ & spiral & 1.28 & 10.12 & -20.16 & 0.51 & 9.62 & $\ldots$ & good \\
\hline $0123+0017$ & $01: 26: 29.28+00: 32: 55.5$ & 77.8 & Im: & irregular & 0.46 & 8.82 & -17.97 & 0.36 & 8.56 & 7 & good \\
\hline LSBC F611-V03 & $01: 27: 56.87+14: 30: 07.5$ & 91.5 & $\mathrm{SBm}$ & irregular & 1.51 & 9.48 & -16.52 & 0.61 & 8.30 & 5 & good \\
\hline LSBC F612-01 & $01: 30: 15.42+14: 40: 39.2$ & 34.9 & $\mathrm{Sm}$ & dwarf & 5.55 & 9.20 & -16.14 & 0.26 & 7.69 & 6 & good \\
\hline $0127+0234$ & $01: 30: 29.05+02: 49: 55.3$ & 30.2 & $S$ & irregular & 0.55 & 8.07 & -15.79 & 0.15 & 7.41 & 14 & good \\
\hline LSBC F683-V10 & $01: 30: 31.90+11: 29: 25.0$ & 13.9 & dI & dwarf & 1.26 & 7.76 & -13.82 & 0.26 & 6.76 & 10 & not used \\
\hline $0128+0036$ & $01: 30: 35.79+00: 51: 28.2$ & 115.3 & $\mathrm{Sb}$ & spiral & 1.16 & 9.56 & -17.79 & 0.35 & 8.47 & 2 & good \\
\hline $0132+0146$ & $01: 35: 31.54+02: 01: 53.7$ & 37.3 & $\mathrm{Sdm}$ & irregular & 1.93 & 8.80 & -17.12 & 0.37 & 8.23 & 2 & good \\
\hline LSBC F612-V01 & $01: 37: 25.41+14: 39: 47.2$ & 37.0 & Irr & irregular & 1.96 & 8.80 & -16.53 & 0.04 & 7.44 & 4 & good \\
\hline LSBC F612-V02 & $01: 38: 19.63+15: 24: 02.7$ & 307.5 & S/Malin-like & spiral & 1.04 & 10.36 & -22.46 & 0.68 & 10.78 & $\ldots$ & good \\
\hline LSBC F612-V03 & $01: 41: 22.40+17: 29: 49.0$ & 71.5 & $\mathrm{dI} / \mathrm{Im}$ & dwarf & 0.87 & 9.02 & -16.82 & 0.24 & 7.94 & 2 & good \\
\hline $0139+0240$ & $01: 42: 34.06+02: 55: 46.0$ & 25.2 & dI & dwarf & 8.53 & 9.11 & -15.18 & 0.45 & 7.55 & 7 & good \\
\hline $0142-0033$ & 01:45:03.28 -00:18:00.0 & 77.2 & dIn & spiral & 1.62 & 9.36 & -19.02 & 0.43 & 9.08 & 3 & good \\
\hline $0143+0200$ & $01: 46: 34.67+02: 15: 26.0$ & 25.5 & $\mathrm{Sm}$ & dwarf & 0.67 & 8.01 & -14.50 & 0.27 & 7.04 & 4 & good \\
\hline LSBC F613-V04 & $01: 50: 03.60+16: 26: 21.0$ & 71.1 & Scd: & spiral & 2.62 & 9.49 & -18.21 & 0.41 & 8.72 & 4 & good \\
\hline $0147+0203$ & $01: 50: 10.72+02: 18: 37.2$ & 24.2 & dIn & spiral & 3.49 & 8.68 & -17.36 & 0.30 & 8.23 & 5 & good \\
\hline LSBC F613-V05 & $01: 53: 57.00+13: 28: 03.5$ & 88.6 & $\mathrm{Sm}$ & spiral & 1.61 & 9.47 & -17.07 & 0.55 & 8.45 & 6 & bad \\
\hline LSBC F477-V02 & $01: 54: 30.70+22: 52: 14.0$ & 72.0 & dI & dwarf & 1.08 & 9.12 & -17.53 & 0.36 & 8.38 & 3 & good \\
\hline LSBC F477-01 & $01: 54: 34.15+23: 12: 17.4$ & 68.3 & $\operatorname{Im}$ & irregular & 2.30 & 9.40 & -15.16 & 0.41 & 7.50 & 3 & good \\
\hline LSBC F477-V01 & $01: 59: 19.30+27: 00: 44.0$ & 75.8 & dI & dwarf & 1.13 & 9.19 & -17.73 & 0.76 & 8.99 & 7 & good \\
\hline LSBC F544-01 & $02: 01: 20.90+19: 58: 51.0$ & 33.4 & $\mathrm{Sb}$ & dwarf & 4.79 & 9.10 & -16.49 & 0.26 & 7.83 & 7 & good \\
\hline LSBC F544-02 & $02: 07: 50.80+18: 59: 01.0$ & 62.4 & $\mathrm{Sm}$ & spiral & 4.17 & 9.58 & -17.68 & 0.27 & 8.31 & 1 & good \\
\hline LSBC F544-V01 & $02: 12: 27.60+18: 29: 24.0$ & 75.9 & Sm: & spiral & 1.27 & 9.24 & -17.21 & 1.35 & 9.55 & 1 & good \\
\hline $0212-0031$ & $02: 15: 31.96-00: 17: 27.4$ & 110.2 & $\mathrm{Sc}$ & spiral & 1.08 & 9.49 & -18.79 & 0.34 & 8.86 & 3 & good \\
\hline LSBC F614-01 & $02: 15: 43.81+17: 03: 30.8$ & 117.7 & $\mathrm{Sm}$ & irregular & 1.53 & 9.70 & -18.59 & 0.52 & 9.02 & 2 & good \\
\hline $0217+0031$ & $02: 20: 00.98+00: 45: 24.2$ & 239.9 & dI & no SDSS galaxy & 0.27 & 9.57 & & & & & not used \\
\hline LSBC F614-V02 & $02: 21: 45.70+16: 28: 14.0$ & 56.6 & dI & dwarf & 0.56 & 8.62 & $\ldots$ & $\ldots$ & $\ldots$ & 10 & bad \\
\hline LSBC F614-V03 & $02: 22: 40.60+17: 13: 34.0$ & 57.8 & $\mathrm{dI}$ & dwarf & 1.53 & 9.08 & $\ldots$ & $\ldots$ & $\ldots$ & 8 & bad \\
\hline $0221+0034$ & $02: 24: 23.80+00: 48: 15.0$ & 128.5 & $\mathrm{Sd}$ & no SDSS galaxy & 0.46 & 9.25 & & & & & not used \\
\hline 0223-0033 & 02:26:06.71 -00:19:55.0 & 91.7 & $\mathrm{SB}(\mathrm{rs}) \mathrm{bc}$ & spiral & 5.65 & 10.05 & -21.88 & 0.95 & 10.90 & 5 & good \\
\hline $0224+0238$ & $02: 26: 47.06+02: 51: 55.0$ & 411.1 & dI & no SDSS galaxy & 0.16 & 9.81 & & & & & not used \\
\hline $0225-0134$ & $02: 28: 12.38-01: 20: 56.3$ & 25.3 & $\mathrm{SB}(\mathrm{s}) \mathrm{dm}:$ & spiral & 2.29 & 8.54 & -18.55 & 0.44 & 8.90 & 11 & good \\
\hline 0225-0049 & $02: 28: 18.80-00: 36: 30.1$ & 20.9 & $\mathrm{IAB}(\mathrm{s}) \mathrm{m}:$ & irregular & 0.50 & 7.71 & -14.96 & 1.02 & 8.22 & 15 & good \\
\hline $0227+0009$ & $02: 29: 33.89+00: 22: 23.2$ & 91.8 & $\mathrm{Sc}$ & spiral & 0.64 & 9.11 & -17.79 & 0.44 & 8.59 & 8 & bad \\
\hline $0227+0040$ & $02: 29: 35.33+00: 54: 14.9$ & 121.5 & dI & no SDSS galaxy & 0.97 & 9.53 & & & & & not used \\
\hline $0229+0255$ & $02: 32: 12.92+03: 08: 35.7$ & 59.0 & dEn & dwarf & 1.93 & 9.20 & -16.27 & 0.20 & 7.66 & 1 & good \\
\hline LSBC F415-03 & $02: 32: 45.24+28: 50: 26.9$ & 14.1 & Im & irregular & 11.0 & 8.71 & $\ldots$ & $\ldots$ & $\ldots$ & 14 & bad \\
\hline LSBC F687-01 & $02: 40: 24.53+10: 56: 44.4$ & 52.3 & Sm: & spiral & 2.99 & 9.29 & $\ldots$ & $\ldots$ & $\cdots$ & 3 & bad \\
\hline LSBC F687-V01 & $02: 40: 38.30+08: 54: 43.0$ & 82.1 & $\mathrm{SBm}$ & $\ldots$ & 0.51 & 8.91 & $\ldots$ & $\ldots$ & $\ldots$ & 10 & not used \\
\hline
\end{tabular}


Table 1:-continued

\begin{tabular}{|c|c|c|c|c|c|c|c|c|c|c|c|}
\hline galaxy name & $\begin{array}{c}\text { RA \& DEC } \\
(\mathrm{J} 2000.0)\end{array}$ & $\begin{array}{r}D \\
(\mathrm{Mpc})\end{array}$ & $\begin{array}{l}\text { morphology } \\
\text { [NED] }\end{array}$ & class & $\begin{array}{c}\text { HI flux } \\
(\mathrm{Jy} \mathrm{km} / \mathrm{s})\end{array}$ & $\begin{array}{c}\log \left(M_{\mathrm{HI}}\right) \\
\left(M_{\odot}\right)\end{array}$ & $\begin{array}{c}M_{\mathrm{r}} \\
(\mathrm{mag})\end{array}$ & $\begin{array}{r}(g-r) \\
(\mathrm{mag})\end{array}$ & $\begin{array}{r}\log \left(M_{\star}\right) \\
\left(M_{\odot}\right)\end{array}$ & Iso & Flag $^{*}$ \\
\hline LSBC F615-01 & $02: 43: 25.50+16: 44: 00.0$ & 11.7 & dI & dwarf & 2.94 & 7.98 & $\ldots$ & $\ldots$ & $\ldots$ & 7 & bad \\
\hline LSBC F687-02 & $02: 46: 06.40+08: 26: 20.0$ & 109.1 & $\mathrm{~S}(\mathrm{r}) /$ Malin-like & spiral & 1.67 & 9.67 & $\ldots$ & $\ldots$ & $\ldots$ & 2 & bad \\
\hline 0244-0039 & $02: 46: 52.88-00: 27: 16.9$ & 93.6 & $\mathrm{Sm}$ & too bright & 0.29 & 8.77 & -17.24 & 0.07 & 7.87 & 7 & not used \\
\hline LSBC F615-02 & $02: 47: 01.01+14: 52: 43.7$ & 106.3 & $\mathrm{Sc}(\mathrm{r}) / \mathrm{LSB}$ arms & spiral & 1.32 & 9.55 & $\ldots$ & $\ldots$ & $\ldots$ & 3 & bad \\
\hline $0246-0033$ & $02: 48: 52.73-00: 21: 03.5$ & 38.3 & $\mathrm{dI}$ & irregular & 1.52 & 8.72 & -16.37 & -0.20 & 7.17 & 5 & good \\
\hline $0246+0145$ & $02: 49: 08.25+01: 57: 55.9$ & 41.9 & $\mathrm{dIn}$ & dwarf & 2.28 & 8.97 & -16.32 & 0.60 & 8.22 & 1 & good \\
\hline LSBC F480-V01 & $02: 49: 51.80+26: 39: 32.0$ & 101.7 & $\mathrm{Sm} / \mathrm{Im}$ & spiral & 1.12 & 9.44 & $\ldots$ & $\ldots$ & $\ldots$ & 2 & bad \\
\hline LSBC F480-01 & $02: 51: 23.10+26: 34: 58.0$ & 106.9 & $\mathrm{Sd}$ & spiral & 3.19 & 9.93 & $\ldots$ & $\ldots$ & $\ldots$ & 2 & bad \\
\hline $0249+0146$ & $02: 52: 20.04+01: 58: 34.9$ & 61.3 & dI & dwarf & 0.85 & 8.88 & -17.56 & 0.65 & 8.78 & 2 & good \\
\hline LSBC F480-V03 & $02: 54: 42.40+23: 22: 41.0$ & 86.7 & $\mathrm{SBm}$ & spiral & 1.76 & 9.49 & $\ldots$ & $\ldots$ & $\ldots$ & 1 & bad \\
\hline LSBC F480-V04 & $03: 02: 54.43+26: 00: 24.3$ & 151.7 & $\mathrm{Sb}$ & spiral & 1.73 & 9.97 & $\ldots$ & $\ldots$ & $\ldots$ & $\ldots$ & bad \\
\hline LSBC F480-V07 & $03: 08: 21.80+27: 16: 08.6$ & 154.6 & S/Irr & no SDSS galaxy & 1.16 & 9.81 & & & & & not used \\
\hline $0314+0005$ & $03: 17: 06.12+00: 16: 52.1$ & 116.0 & dI & dwarf & 0.64 & 9.31 & -15.31 & 0.54 & 7.72 & 1 & bad \\
\hline $0319+0015$ & $03: 21: 48.18+00: 25: 43.2$ & 93.5 & dIn & dwarf & 0.84 & 9.24 & -17.13 & 0.50 & 8.41 & 7 & good \\
\hline $0332+0058$ & $03: 35: 08.32+01: 08: 34.5$ & 99.6 & $\mathrm{Sc}$ & spiral & 1.38 & 9.51 & -17.04 & 0.41 & 8.25 & 2 & good \\
\hline 0339-0209 & 03:41:44.45 -02:00:08.8 & 48.9 & $\mathrm{Sc}$ & spiral & 7.54 & 9.63 & $\ldots$ & $\ldots$ & $\ldots$ & 1 & bad \\
\hline $0343+0200$ & $03: 45: 45.41+02: 09: 51.2$ & 60.8 & $\mathrm{Sm}$ & spiral & 3.32 & 9.46 & $\ldots$ & $\ldots$ & $\ldots$ & 1 & bad \\
\hline LSBC F549-V01 & $03: 46: 58.40+21: 20: 14.0$ & 82.5 & $\mathrm{Sm}$ & spiral & 1.82 & 9.46 & $\ldots$ & $\ldots$ & $\ldots$ & 1 & bad \\
\hline $0346+0101$ & $03: 48: 59.72+01: 10: 17.0$ & 59.2 & $\mathrm{SAB}(\mathrm{s}) \mathrm{dm}$ & spiral & 4.69 & 9.59 & -18.45 & 0.32 & 8.70 & 3 & bad \\
\hline 0349-0139 & 03:52:14.11 -01:30:29.4 & 71.1 & $\mathrm{Sb}$ & spiral & 5.50 & 9.82 & $\ldots$ & $\ldots$ & $\ldots$ & 2 & bad \\
\hline $0352+0152$ & $03: 55: 37.7+02: 02: 49.0$ & 158.2 & & $\ldots$ & 1.53 & 9.96 & $\ldots$ & $\ldots$ & $\ldots$ & $\ldots$ & not used \\
\hline $0357+0036$ & 04:00:10.62+00:44:38.3 & 50.6 & $\mathrm{SAB}(\mathrm{s}) \mathrm{dm}:$ & spiral & 8.70 & 9.72 & -18.88 & 0.30 & 8.83 & 2 & good \\
\hline 0358-0051 & 04:01:02.51 -00:43:03.7 & 60.9 & $\mathrm{SB}(\mathrm{rs}) \mathrm{dm} ?$ & spiral & 4.66 & 9.61 & -21.21 & 0.40 & 9.91 & 3 & good \\
\hline LSBC F549-01 & $04: 02: 13.70+21: 51: 34.0$ & 93.7 & $\mathrm{Sm}$ & spiral & 2.83 & 9.77 & $\ldots$ & $\ldots$ & $\ldots$ & 8 & bad \\
\hline $0400+0149$ & $04: 02: 48.19+01: 57: 57.7$ & 54.4 & $\mathrm{SB}(\mathrm{s}) \mathrm{d}$ & spiral & 9.42 & 9.82 & $\ldots$ & $\ldots$ & $\ldots$ & 1 & bad \\
\hline LSBC F549-V02 & $04: 04: 32.60+21: 22: 44.0$ & 91.5 & $\operatorname{Im}$ & irregular & 1.64 & 9.51 & $\ldots$ & $\ldots$ & $\ldots$ & 5 & bad \\
\hline $0405+0259$ & $04: 08: 35.09+03: 07: 22.3$ & 104.6 & $\mathrm{Sm}$ & spiral & 4.81 & 10.09 & $\ldots$ & $\ldots$ & $\ldots$ & 1 & bad \\
\hline $0411+0243$ & $04: 14: 28.20+02: 50: 41$ & 49.2 & & $\cdots$ & 0.90 & 8.71 & $\ldots$ & $\ldots$ & $\ldots$ & 12 & not used \\
\hline UGC 3616 & $06: 57: 52.35+22: 51: 52.6$ & 79.7 & Sd: & spiral & 4.24 & 9.80 & $\ldots$ & $\ldots$ & $\ldots$ & 1 & bad \\
\hline UGC 3658 & $07: 04: 40.10+17: 35: 00.0$ & 16.8 & Im: & irregular & 5.81 & 8.59 & $\ldots$ & $\ldots$ & $\ldots$ & 2 & bad \\
\hline NGC 2342 & 07:09:18.08 +20:38:09.5 & 75.4 & S pec & spiral & 8.81 & 10.07 & $\ldots$ & $\ldots$ & $\ldots$ & 2 & bad \\
\hline LSBC F560-05 & $07: 39: 55.98+17: 15: 09.9$ & 186.7 & $\mathrm{Sd}$ & spiral & 1.57 & 10.11 & -22.12 & 1.17 & 11.29 & $\ldots$ & bad \\
\hline LSBC F560-01 & $07: 43: 30.38+22: 55: 49.9$ & 103.7 & $\mathrm{Sc}$ & spiral & 3.71 & 9.97 & -20.68 & 0.72 & 10.11 & 1 & good \\
\hline LSBC F561-01 & $08: 09: 41.32+22: 33: 37.0$ & 68.7 & $\mathrm{Sm}$ & spiral & 0.96 & 9.03 & -18.36 & 0.31 & 8.64 & 9 & good \\
\hline LSBC F561-02 & $08: 15: 21.34+21: 33: 29.4$ & 61.0 & Scd & spiral & 1.19 & 9.02 & -19.08 & 0.70 & 9.45 & 12 & good \\
\hline LSBC F495-01 & $08: 16: 45.22+23: 21: 59.7$ & 61.0 & S/Malin-like & spiral & 1.66 & 9.16 & -17.57 & 0.26 & 8.26 & 17 & good \\
\hline LSBC F704-01 & $08: 23: 30.66+10: 02: 43.9$ & 60.5 & $\mathrm{SBm}(\mathrm{r})$ & spiral & 2.92 & 9.40 & -18.02 & 1.08 & 9.52 & 1 & bad \\
\hline LSBC F704-V01 & $08: 24: 51.70+09: 13: 29.0$ & 86.0 & S/Malin-like & spiral & 2.27 & 9.60 & -18.60 & 0.68 & 9.23 & 3 & good \\
\hline LSBC F495-V01 & $08: 28: 18.10+25: 47: 18.1$ & 32.4 & dI & dwarf & 0.55 & 8.13 & -14.08 & 0.86 & 7.66 & 16 & good \\
\hline LSBC F495-02 & $08: 29: 08.30+26: 52: 05.0$ & 30.9 & $\mathrm{Sd}$ & dwarf & 1.80 & 8.61 & -16.72 & 1.00 & 8.90 & 18 & good \\
\hline LSBC F562-V02 & $08: 32: 40.35+19: 30: 41.1$ & 90.9 & S & spiral & 2.49 & 9.68 & -19.62 & 0.33 & 9.17 & 3 & good \\
\hline LSBC F562-V01 & $08: 36: 50.50+19: 40: 06.0$ & 66.4 & Irr & irregular & 2.64 & 9.44 & -18.20 & 0.46 & 8.77 & 7 & good \\
\hline
\end{tabular}


Table 1:-continued.

\begin{tabular}{|c|c|c|c|c|c|c|c|c|c|c|c|}
\hline galaxy name & $\begin{array}{c}\text { RA \& DEC } \\
(\mathrm{J} 2000.0)\end{array}$ & $\begin{array}{r}D \\
(\mathrm{Mpc})\end{array}$ & $\begin{array}{l}\text { morphology } \\
\text { [NED] }\end{array}$ & class & $\begin{array}{c}\text { HI flux } \\
(\mathrm{Jy} \mathrm{km} / \mathrm{s})\end{array}$ & $\begin{array}{c}\log \left(M_{\mathrm{HI}}\right) \\
\left(M_{\odot}\right)\end{array}$ & $\begin{array}{c}M_{\mathrm{r}} \\
(\mathrm{mag})\end{array}$ & $\begin{array}{r}(g-r) \\
(\mathrm{mag})\end{array}$ & $\begin{array}{r}\log \left(M_{\star}\right) \\
\left(M_{\odot}\right)\end{array}$ & Iso & Flag $^{*}$ \\
\hline LSBC F563-V01 & $08: 46: 37.90+18: 53: 23.7$ & 55.6 & dI & dwarf & 0.95 & 8.84 & -16.78 & 0.15 & 7.80 & 22 & good \\
\hline IC 2409 & $08: 48: 24.66+18: 19: 52.1$ & 90.4 & $\mathrm{SAB}(\mathrm{s}) \mathrm{a}$ & spiral & 5.44 & 10.02 & -21.51 & 0.54 & 10.21 & 4 & good \\
\hline LSBC F633-01 & $08: 48: 27.78+16: 11: 31.7$ & 84.4 & Sc & spiral & 1.69 & 9.45 & -17.80 & 0.33 & 8.46 & 3 & good \\
\hline LSBC F563-V02 & 08:53:03.83 + 18:26:09.4 & 61.6 & Irr & irregular & 3.66 & 9.51 & -17.92 & 0.38 & 8.55 & 14 & good \\
\hline IC 2423 & $08: 54: 47.08+20: 13: 13.0$ & 130.0 & $\mathrm{SAB}(\mathrm{s}) \mathrm{b}$ & spiral & 2.35 & 9.97 & -22.16 & 0.58 & 10.52 & 8 & good \\
\hline UGC 4669 & $08: 55: 06.87+18: 56: 04.3$ & 58.5 & Sdm: & spiral & 3.06 & 9.39 & -18.54 & -0.10 & 8.12 & 13 & good \\
\hline LSBC F563-01 & $08: 55: 07.20+19: 45: 02.4$ & 50.0 & $\mathrm{Sm} / \mathrm{Irr}$ & interacting & 5.81 & 9.53 & -17.22 & 0.34 & 8.23 & 6 & not used \\
\hline LSBC F564-V03 & 09:02:53.80 +20:04:32.0 & 6.9 & dI & dwarf & 1.89 & 7.33 & -12.63 & 0.34 & 6.39 & $\ldots$ & not used \\
\hline NGC 2744 & 09:04:38.90 +18:27:37.0 & 48.9 & SB(s)ab: pec & merger & 7.88 & 9.65 & -20.46 & 0.57 & 9.83 & 12 & not used \\
\hline LSBC F564-V02 & $09: 05: 22.00+21: 37: 23.0$ & 43.9 & dI & dwarf & 3.13 & 9.15 & -17.34 & 0.39 & 8.35 & 11 & good \\
\hline LSBC F564-02 & 09:06:04.06 + 17:02:21.9 & 242.4 & $\mathrm{Sc}(\mathrm{r}) / \mathrm{LSB}$ arms & spiral & 1.84 & 10.41 & -21.70 & 0.45 & 10.16 & $\ldots$ & good \\
\hline LSBC F564-V01 & 09:08:11.70 +22:00:06.0 & 147.4 & & $\ldots$ & 1.35 & 9.84 & -21.78 & 0.73 & 10.56 & 9 & not used \\
\hline NGC 2764 & 09:08:17.47 +21:26:36.0 & 38.7 & S0: & lenticular & 5.58 & 9.29 & -20.39 & 0.61 & 9.86 & 13 & good \\
\hline LSBC F564-01 & 09:10:29.40 +20:33:53.0 & 121.6 & & $\ldots$ & 1.63 & 9.75 & -20.57 & 0.78 & 10.15 & 6 & not used \\
\hline LSBC F634-V02 & 09:11:06.12 + 13:07:17.9 & 127.1 & S/Malin-like & spiral & 3.14 & 10.08 & -19.99 & 0.42 & 9.44 & 3 & good \\
\hline IC 2454 & 09:16:01.77 + 17:49:14.5 & 123.2 & $\mathrm{Sa} ?$ & spiral & 0.90 & 9.51 & -21.90 & 0.56 & 10.39 & 38 & bad \\
\hline LSBC F635-V01 & $09: 16: 55.60+14: 42: 52.0$ & 53.9 & $\operatorname{Im}$ & irregular & 1.39 & 8.98 & -16.44 & 0.31 & 7.87 & 4 & good \\
\hline $0915+0115$ & $09: 17: 45.30+01: 03: 19.5$ & 116.9 & $\mathrm{Sc}$ & spiral & 0.47 & 9.18 & -19.61 & 0.35 & 9.20 & 2 & good \\
\hline LSBC F565-V01 & $09: 19: 30.36+21: 36: 12.4$ & 7.1 & dI & dwarf & 0.30 & 6.55 & -12.69 & 0.30 & 6.37 & $\ldots$ & not used \\
\hline 0917-0022 & 09:19:55.18 -00:35:28.8 & 123.5 & $\mathrm{Sm}$ & spiral & 0.74 & 9.42 & -19.22 & 0.12 & 8.74 & 2 & good \\
\hline $0918+0147$ & $09: 21: 33.48+01: 35: 04.6$ & 71.1 & Irr & irregular & 0.64 & 8.88 & -16.94 & 1.01 & 9.01 & 14 & good \\
\hline LSBC F565-01 & $09: 22: 35.50+20: 51: 06.4$ & 134.7 & Sc & spiral & 1.82 & 9.89 & -20.54 & 0.61 & 9.92 & 4 & good \\
\hline $0921+0258$ & $09: 23: 46.37+02: 45: 10.7$ & 72.3 & $\mathrm{Sm}$ & spiral & 1.14 & 9.15 & -18.32 & 0.30 & 8.61 & 5 & good \\
\hline UGC 5005 & $09: 24: 29.38+22: 16: 29.3$ & 54.7 & $\operatorname{Im}$ & irregular & 6.40 & 9.66 & -17.81 & 0.06 & 8.10 & 1 & good \\
\hline UGC 5009 & 09:24:44.64 +20:01:45.2 & 61.1 & Scd: & spiral & 3.01 & 9.42 & -19.35 & 0.51 & 9.31 & 2 & good \\
\hline $0922+0233$ & $09: 25: 34.73+02: 20: 31.1$ & 103.2 & $\mathrm{Sm}$ & dwarf & 0.69 & 9.24 & -17.53 & 0.55 & 8.63 & 7 & good \\
\hline UGC 5035 & $09: 27: 10.18+21: 35: 38.1$ & 158.4 & $(\mathrm{R}) \mathrm{SB}(\mathrm{s}) \mathrm{a}$ & spiral & 1.69 & 10.00 & -22.02 & 0.76 & 10.71 & $\ldots$ & good \\
\hline LSBC F565-V04 & $09: 30: 12.80+19: 59: 26.0$ & 8.0 & $\mathrm{dE}:$ & dwarf & 0.80 & 7.08 & -13.09 & 0.27 & 6.50 & $\ldots$ & not used \\
\hline $0929+0246$ & $09: 32: 23.08+02: 32: 52.1$ & 74.6 & dIn & dwarf & 1.62 & 9.33 & -17.65 & 0.28 & 8.32 & 2 & good \\
\hline LSBC F565-V03 & $09: 32: 48.82+21: 27: 56.3$ & 6.4 & Im: & dwarf & 5.01 & 7.68 & $\ldots$ & $\ldots$ & $\ldots$ & $\ldots$ & bad \\
\hline $0931+0036$ & $09: 34: 04.13+00: 23: 01.1$ & 100.4 & $\mathrm{Sm}$ & spiral & 0.55 & 9.12 & -18.14 & 0.59 & 8.93 & 1 & good \\
\hline LSBC F636-01 & $09: 35: 14.43+17: 06: 56.6$ & 61.5 & $\mathrm{Sm}$ & spiral & 2.61 & 9.37 & -16.88 & 0.74 & 8.62 & 3 & good \\
\hline LSBC F565-V02 & $09: 37: 29.88+21: 45: 40.4$ & 52.6 & dI & dwarf & 1.04 & 8.83 & -15.37 & 0.09 & 7.16 & 6 & good \\
\hline $0949+0036$ & $09: 51: 38.82+00: 22: 11.3$ & 27.1 & $\operatorname{Im}$ & irregular & 0.80 & 8.14 & -15.09 & 0.25 & 7.26 & 19 & good \\
\hline LSBC F709-01 & $09: 52: 58.83+08: 01: 44.4$ & 37.7 & $\mathrm{Sd}$ & irregular & 3.81 & 9.11 & -16.28 & 0.47 & 8.02 & 5 & good \\
\hline $0951+0214$ & $09: 53: 59.15+02: 00: 17.4$ & 25.1 & dI & dwarf & 0.49 & 7.86 & -14.17 & 0.16 & 6.78 & 29 & good \\
\hline $0951+0146$ & $09: 54: 04.50+01: 32: 25.7$ & 19.6 & dI & irregular & 0.93 & 7.93 & -12.71 & 0.90 & 7.16 & 26 & not used \\
\hline $0955+0155$ & $09: 58: 28.85+01: 41: 40.8$ & 25.9 & $\mathrm{dI}$ & dwarf & 5.31 & 8.93 & -15.02 & 0.97 & 8.18 & 20 & good \\
\hline $0956+0235$ & $09: 58: 46.84+02: 20: 51.4$ & 24.7 & $\mathrm{dI}$ & dwarf & 0.87 & 8.10 & -14.74 & 0.35 & 7.25 & 26 & good \\
\hline LSBC F637-03 & $10: 00: 50.96+17: 24: 35.3$ & 151.2 & $\mathrm{Sb}(\mathrm{r})$ & spiral & 3.46 & 10.27 & -19.30 & -0.50 & 7.83 & $\ldots$ & bad \\
\hline UGC 5401 & $10: 02: 31.34+19: 01: 58.5$ & 28.6 & Im: & irregular & 3.73 & 8.86 & -16.69 & 0.25 & 7.90 & 3 & good \\
\hline $1003+0151$ & $10: 05: 43.16+01: 36: 54.7$ & 681.6 & Scd & high redshift & 0.97 & 11.03 & -21.33 & 0.82 & 10.51 & $\ldots$ & not used \\
\hline
\end{tabular}


Table 1:-continued

\begin{tabular}{|c|c|c|c|c|c|c|c|c|c|c|c|}
\hline galaxy name & $\begin{array}{c}\text { RA \& DEC } \\
(\mathrm{J} 2000.0)\end{array}$ & $\begin{array}{r}D \\
(\mathrm{Mpc})\end{array}$ & $\begin{array}{l}\text { morphology } \\
\text { [NED] }\end{array}$ & class & $\begin{array}{c}\text { HI flux } \\
(\mathrm{Jy} \mathrm{km} / \mathrm{s})\end{array}$ & $\begin{array}{c}\log \left(M_{\mathrm{HI}}\right) \\
\left(M_{\odot}\right)\end{array}$ & $\begin{array}{c}M_{\mathrm{r}} \\
(\mathrm{mag})\end{array}$ & $\begin{array}{r}(g-r) \\
(\mathrm{mag})\end{array}$ & $\begin{array}{r}\log \left(M_{\star}\right) \\
\left(M_{\odot}\right)\end{array}$ & Iso & Flag $^{*}$ \\
\hline $1013+0256$ & $10: 15: 50.65+02: 41: 39.5$ & 18.5 & $\mathrm{Sc}$ & dwarf & 8.03 & 8.81 & -14.23 & 0.68 & 7.48 & 15 & good \\
\hline LSBC F567-02 & $10: 17: 56.30+21: 03: 41.0$ & 81.1 & $\mathrm{Sm}$ & position is off & 1.15 & 9.25 & & & & & not used \\
\hline $1015+0148$ & $10: 18: 02.51+01: 33: 43.2$ & 195.1 & $\mathrm{Sm}$ & spiral & 0.77 & 9.84 & -19.76 & 0.36 & 9.27 & $\ldots$ & good \\
\hline LSBC F638-01 & $10: 18: 23.53+13: 16: 42.1$ & 78.2 & $\mathrm{Sc}$ & spiral & 2.26 & 9.51 & -19.00 & 0.35 & 8.95 & 6 & good \\
\hline $1016+0229$ & $10: 18: 53.84+02: 14: 37.1$ & 195.9 & interacting & spiral & 0.30 & 9.44 & -20.21 & 0.24 & 9.29 & $\ldots$ & bad \\
\hline LSBC F567-01 & $10: 19: 01.50+21: 17: 01.3$ & 15.5 & $E / p$ & dwarf & 1.24 & 7.85 & -16.27 & 0.27 & 7.76 & 49 & good \\
\hline $1017+0145$ & $10: 20: 11.34+01: 30: 46.0$ & 193.7 & $\mathrm{Sm}$ & spiral & 0.86 & 9.88 & -18.80 & 0.36 & 8.89 & $\ldots$ & good \\
\hline LSBC F638-02 & $10: 21: 52.96+13: 56: 16.2$ & 122.3 & Sb-p- & spiral & 1.10 & 9.59 & -20.89 & 0.68 & 10.15 & 1 & good \\
\hline NGC 3227 & $10: 23: 30.58+19: 51: 54.2$ & 16.5 & $\mathrm{SAB}(\mathrm{s})$ pec & spiral & 12.2 & 8.90 & -18.95 & 0.24 & 8.78 & 43 & bad \\
\hline UGC 5629 & $10: 24: 13.09+21: 02: 59.0$ & 17.7 & Sm: & dwarf & 3.08 & 8.36 & -16.66 & 0.60 & 8.34 & 46 & good \\
\hline LSBC F568-01 & $10: 26: 06.36+22: 26: 00.9$ & 93.2 & $\mathrm{Sc}$ & spiral & 1.85 & 9.58 & -18.85 & 0.47 & 9.05 & 2 & good \\
\hline LSBC F568-03 & $10: 27: 20.23+22: 14: 24.4$ & 84.4 & $\mathrm{Sd}$ & spiral & 1.80 & 9.48 & -18.85 & 0.40 & 8.96 & 3 & good \\
\hline LSBC F568-09 & $10: 28: 12.02+18: 36: 23.5$ & 115.2 & SBc-p- & spiral & 1.60 & 9.70 & -21.17 & 0.66 & 10.23 & 5 & bad \\
\hline UGC 5675 & $10: 28: 30.00+19: 33: 44.6$ & 15.7 & Sm: & dwarf & 3.47 & 8.31 & -15.16 & 0.03 & 7.00 & 41 & good \\
\hline LSBC F568-07 & $10: 29: 53.72+20: 48: 05.3$ & 42.5 & $\mathrm{Sc} / \mathrm{p}$ & spiral & 3.22 & 9.14 & -17.40 & 0.32 & 8.28 & 1 & good \\
\hline LSBC F568-05 & $10: 30: 36.71+21: 51: 18.0$ & 94.0 & Sb-p- & spiral & 0.98 & 9.31 & -20.09 & 0.50 & 9.59 & 7 & good \\
\hline UGC 5709 & $10: 31: 16.24+19: 22: 58.8$ & 88.7 & Sd: & spiral & 3.26 & 9.78 & -19.62 & 0.44 & 9.32 & 1 & good \\
\hline LSBC F638-03 & $10: 32: 30.98+14: 39: 02.1$ & 45.1 & $\mathrm{Sm}$ & spiral & 2.10 & 9.00 & -16.47 & 0.33 & 7.91 & 6 & good \\
\hline $1030+0141$ & $10: 33: 21.66+01: 25: 48.1$ & 124.7 & $\mathrm{dE}$ & dwarf & 1.14 & 9.62 & -19.90 & 0.39 & 9.36 & 3 & good \\
\hline LSBC F568-08 & $10: 34: 08.68+19: 42: 15.5$ & 145.9 & $\mathrm{Sb}$ & spiral & 3.40 & 10.23 & -21.88 & 0.81 & 10.72 & 3 & good \\
\hline LSBC F638-04 & $10: 34: 43.75+16: 13: 42.5$ & 83.7 & Sm: & irregular & 1.23 & 9.31 & -17.90 & 0.59 & 8.83 & 11 & good \\
\hline $1032-0121$ & $10: 35: 23.17-01: 37: 11.3$ & 102.3 & Irr & irregular & 0.91 & 9.35 & -18.60 & 0.35 & 8.79 & 2 & bad \\
\hline UGC 5750 & $10: 35: 45.12+20: 59: 24.9$ & 59.5 & SBdm: & spiral & 2.48 & 9.31 & -17.94 & 0.30 & 8.47 & 3 & good \\
\hline NGC 3303 & $10: 36: 59.80+18: 08: 12.0$ & 89.7 & Pec & $\cdots$ & 2.78 & 9.72 & -21.45 & 0.86 & 10.61 & 5 & not used \\
\hline UGC 5769 & $10: 37: 02.75+20: 25: 53.2$ & 185.2 & & spiral & 2.52 & 10.31 & -19.68 & 0.98 & 10.06 & $\ldots$ & good \\
\hline $1035+0238$ & $10: 37: 52.50+02: 23: 20.4$ & 80.5 & Irr & irregular & 0.51 & 8.89 & -16.96 & -0.10 & 7.54 & 2 & good \\
\hline $1035+0014$ & $10: 38: 25.51-00: 01: 04.3$ & 82.0 & $\mathrm{SBc}$ & spiral & 1.42 & 9.35 & -18.50 & 0.18 & 8.53 & 17 & good \\
\hline $1036+0207$ & $10: 39: 16.99+01: 51: 40.3$ & 120.1 & Irr & spiral & 0.69 & 9.37 & -18.04 & 0.52 & 8.79 & 1 & good \\
\hline LSBC F568-06 & $10: 39: 52.48+20: 50: 49.4$ & 197.6 & $\mathrm{Sd} / \mathrm{p}$ GLSBG & spiral & 4.02 & 10.57 & -22.14 & 0.86 & 10.88 & $\ldots$ & good \\
\hline $1041-0041$ & $10: 44: 05.87-00: 57: 44.5$ & 113.6 & $\mathrm{Sc}$ & spiral & 1.40 & 9.63 & -18.60 & 0.48 & 8.96 & 6 & good \\
\hline $1042+0231$ & $10: 44: 40.07+02: 15: 32.3$ & 81.0 & $\mathrm{Sd}$ & dwarf & 1.54 & 9.38 & -17.26 & 0.29 & 8.18 & 7 & good \\
\hline $1042+0154$ & $10: 45: 01.18+01: 38: 55.4$ & 121.0 & $\mathrm{Sm}$ & spiral & 0.75 & 9.41 & -19.15 & 0.82 & 9.63 & 1 & good \\
\hline LSBC F568-V01 & $10: 45: 02.07+22: 03: 15.7$ & 82.4 & $\mathrm{Sd}$ & spiral & 3.65 & 9.77 & -18.54 & 0.57 & 9.06 & 13 & bad \\
\hline $1042+0214$ & $10: 45: 22.21+01: 59: 07.2$ & 81.7 & $\mathrm{dE}$ & dwarf & 0.60 & 8.98 & -17.32 & 0.37 & 8.30 & 6 & good \\
\hline $1043+0221$ & $10: 45: 49.59+02: 05: 23.4$ & 80.9 & $\mathrm{Sm}$ & irregular & 0.40 & 8.79 & -17.46 & 0.34 & 8.33 & 6 & good \\
\hline $1043+0250$ & $10: 45: 56.49+02: 35: 12.0$ & 82.0 & dI & dwarf & 0.42 & 8.82 & -15.32 & 0.97 & 8.30 & 5 & good \\
\hline $1043+0202$ & $10: 46: 34.31+01: 46: 27.9$ & 93.9 & dIn & dwarf & 1.08 & 9.35 & -18.13 & 0.42 & 8.70 & 1 & good \\
\hline $1047+0131$ & $10: 50: 08.92+01: 15: 53.3$ & 22.9 & dI & dwarf & 0.70 & 7.94 & -15.25 & 0.38 & 7.49 & 5 & bad \\
\hline $1050+0245$ & $10: 53: 03.03+02: 29: 37.4$ & 15.0 & dIn & dwarf & 6.33 & 8.53 & -14.02 & 0.14 & 6.37 & 14 & good \\
\hline $1051+0227$ & $10: 54: 21.65+02: 11: 36.5$ & 112.0 & Irr & irregular & 0.96 & 9.45 & -17.98 & 0.23 & 8.38 & 1 & good \\
\hline LSBC F640-V01 & $10: 56: 13.91+12: 00: 40.7$ & 14.1 & $\mathrm{Im} / \mathrm{Sm}$ & irregular & 1.54 & 7.86 & -14.55 & 0.03 & 6.75 & 84 & good \\
\hline LSBC F640-V02 & $10: 57: 38.15+13: 58: 44.5$ & 17.4 & Irr & irregular & 2.83 & 8.30 & -14.20 & 0.16 & 6.78 & 74 & good \\
\hline
\end{tabular}


Table 1:-continued.

\begin{tabular}{|c|c|c|c|c|c|c|c|c|c|c|c|}
\hline galaxy name & $\begin{array}{c}\text { RA \& DEC } \\
(\mathrm{J} 2000.0)\end{array}$ & $\begin{array}{r}D \\
(\mathrm{Mpc})\end{array}$ & $\begin{array}{l}\text { morphology } \\
\text { [NED] }\end{array}$ & class & $\begin{array}{c}\text { HI flux } \\
(\mathrm{Jy} \mathrm{km} / \mathrm{s})\end{array}$ & $\begin{array}{c}\log \left(M_{\mathrm{HI}}\right) \\
\left(M_{\odot}\right)\end{array}$ & $\begin{array}{c}M_{\mathrm{r}} \\
(\mathrm{mag})\end{array}$ & $\begin{array}{r}(g-r) \\
(\mathrm{mag})\end{array}$ & $\begin{array}{r}\log \left(M_{\star}\right) \\
\left(M_{\odot}\right)\end{array}$ & Iso & Flag* \\
\hline LSBC F640-01 & $10: 58: 52.40+14: 07: 47.0$ & 9.8 & S/Malin-like & irregular & 0.38 & 6.93 & -13.48 & 0.38 & 6.79 & $\ldots$ & not used \\
\hline $1100+0200$ & $11: 02: 38.70+01: 44: 46.6$ & 166.3 & $\mathrm{Sc}$ & spiral & 0.58 & 9.58 & -19.01 & 0.26 & 8.84 & $\ldots$ & good \\
\hline LSBC F640-02 & $11: 03: 26.35+16: 00: 58.2$ & 17.6 & S/smooth & dwarf & 0.89 & 7.81 & -15.20 & 0.57 & 7.72 & 40 & good \\
\hline $1101+0211$ & $11: 04: 19.74+01: 55: 12.6$ & 108.3 & dI & dwarf & 0.53 & 9.17 & -16.24 & 0.04 & 7.44 & 2 & good \\
\hline $1102+0019$ & $11: 04: 40.08+00: 03: 29.6$ & 11.6 & $\mathrm{dE}$ & dwarf & 0.06 & 6.27 & -13.19 & -0.20 & 6.74 & 15 & not used \\
\hline $1103-0135$ & $11: 05: 34.59-01: 51: 47.6$ & 10.6 & $\mathrm{Im}$ & irregular & 3.01 & 7.90 & -14.27 & 0.36 & 7.07 & 12 & good \\
\hline $1103+0010$ & 11:05:40.99 -00:06:01.8 & 48.0 & dIn & dwarf & 9.88 & 9.73 & -16.40 & 0.10 & 7.59 & 2 & good \\
\hline $1103+0007$ & $11: 05: 46.62-00: 08: 13.6$ & 134.2 & dIn & spiral & 1.37 & 9.76 & -19.74 & 0.30 & 9.19 & 6 & good \\
\hline UGC 6151 & $11: 05: 56.29+19: 49: 34.6$ & 19.1 & Sm: & dwarf & 5.11 & 8.64 & -16.81 & 0.29 & 7.99 & 25 & good \\
\hline $1104-0002$ & $11: 06: 55.16-00: 18: 46.1$ & 134.0 & $\mathrm{Sm}$ & spiral & 0.92 & 9.59 & -19.29 & 0.33 & 9.04 & 5 & good \\
\hline UGC 6181 & $11: 07: 46.70+19: 32: 57.4$ & 16.7 & Im: & irregular & 3.43 & 8.35 & -15.63 & -0.20 & 6.84 & 55 & good \\
\hline $1108+0128$ & $11: 10: 50.11+01: 12: 32.3$ & 162.4 & Irr & spiral & 1.89 & 10.07 & -20.06 & 0.30 & 9.31 & $\ldots$ & good \\
\hline $1108+0121$ & $11: 10: 54.95+01: 05: 35.1$ & 14.2 & dIn & dwarf & 5.08 & 8.38 & -15.36 & 0.22 & 7.32 & 17 & good \\
\hline LSBC F640-03 & $11: 12: 15.70+16: 45: 15.0$ & 17.2 & $\mathrm{dI} / \mathrm{dE}$ & dwarf & 0.80 & 7.75 & -13.70 & 0.77 & 7.38 & 66 & not used \\
\hline $1110-0017$ & $11: 12: 47.75-00: 34: 06.9$ & 121.7 & $\mathrm{Sm}$ & irregular & 1.11 & 9.59 & -18.11 & 0.70 & 9.06 & 2 & good \\
\hline LSBC F570-07 & $11: 18: 21.40+17: 41: 51.0$ & 15.0 & dI & dwarf & 1.87 & 8.00 & -14.19 & 0.30 & 6.96 & 81 & good \\
\hline $1118+0217$ & $11: 20: 55.22+02: 01: 32.1$ & 103.8 & Scd & spiral & 1.26 & 9.51 & -18.18 & 0.56 & 8.90 & 2 & good \\
\hline NGC 3639 & $11: 21: 35.68+18: 27: 30.9$ & 77.7 & $\mathrm{~S} ?$ & spiral & 6.49 & 9.97 & -21.11 & 0.60 & 10.13 & 3 & good \\
\hline $1119+0241$ & $11: 21: 45.87+02: 25: 14.6$ & 36.9 & $\mathrm{Sd}$ & dwarf & 3.53 & 9.05 & -16.99 & 0.46 & 8.30 & 3 & good \\
\hline LSBC F570-03 & $11: 22: 58.87+19: 28: 38.8$ & 48.1 & dI: & dwarf & 1.58 & 8.94 & -18.10 & 0.83 & 9.23 & $\ldots$ & bad \\
\hline LSBC F570-V01 & $11: 22: 59.32+17: 28: 26.5$ & 19.7 & dI & dwarf & 0.47 & 7.63 & -14.66 & 0.61 & 7.56 & 50 & good \\
\hline $1122+0126$ & $11: 24: 37.70+01: 10: 06.5$ & 84.2 & $\mathrm{Sm}$ & dwarf & 0.54 & 8.96 & -17.02 & 0.28 & 8.07 & 2 & good \\
\hline LSBC F570-05 & $11: 25: 17.69+17: 48: 30.2$ & 70.3 & $\mathrm{Sbc}$ & spiral & 4.52 & 9.72 & -20.21 & 0.60 & 9.76 & 2 & good \\
\hline LSBC F571-V01 & $11: 26: 19.08+18: 50: 09.3$ & 81.7 & $\mathrm{Sd}$ & spiral & 0.91 & 9.16 & -17.38 & 0.21 & 8.13 & 7 & good \\
\hline LSBC F571-04 & $11: 26: 19.09+21: 03: 17.9$ & 180.4 & Scd & spiral & 2.03 & 10.19 & -20.77 & 0.46 & 9.81 & $\ldots$ & good \\
\hline $1125+0025$ & $11: 28: 29.57+00: 08: 39.5$ & 214.9 & $\mathrm{dEn}$ & spiral & 0.19 & 9.32 & -20.18 & 0.44 & 9.55 & $\ldots$ & good \\
\hline LSBC F571-10 & $11: 28: 51.01+18: 17: 03.3$ & 18.6 & $\mathrm{dE}:$ & dwarf & 1.37 & 8.05 & -14.41 & 0.36 & 7.14 & 57 & good \\
\hline IC 700 & $11: 29: 15.48+20: 35: 05.7$ & 21.0 & S0? & lenticular & 5.50 & 8.76 & -17.19 & 0.25 & 8.09 & 14 & good \\
\hline UGC 6495 & $11: 29: 45.20+22: 07: 35.6$ & 92.9 & $\mathrm{SAB}(\mathrm{s}) \mathrm{b}:$ & spiral & 2.91 & 9.77 & -20.91 & 0.47 & 9.88 & 7 & good \\
\hline LSBC F571-05 & $11: 30: 22.19+20: 35: 08.0$ & 60.8 & $\mathrm{Sm}$ & spiral & 2.46 & 9.33 & -17.39 & 0.17 & 8.07 & 12 & good \\
\hline LSBC F571-06 & $11: 31: 00.68+20: 28: 08.2$ & 87.7 & $\mathrm{SB}(\mathrm{rs}) \mathrm{dm}$ pec & spiral & 3.20 & 9.76 & -20.77 & 0.39 & 9.72 & 13 & good \\
\hline $1129+0013$ & $11: 31: 58.62-00: 03: 01.2$ & 170.0 & SA(s)cd: & spiral & 1.43 & 9.99 & -20.79 & 0.42 & 9.77 & $\ldots$ & bad \\
\hline $1130-0027$ & $11: 32: 45.43-00: 44: 27.8$ & 95.7 & $\mathrm{SB}(\mathrm{s}) \mathrm{m}$ & spiral & 1.47 & 9.50 & -19.33 & 0.40 & 9.15 & 2 & good \\
\hline LSBC F571-08 & $11: 33: 55.12+19: 21: 36.1$ & 53.3 & $\mathrm{Sc}$ & spiral & 2.36 & 9.20 & -18.61 & 0.77 & 9.35 & 7 & good \\
\hline $1132-0028$ & $11: 34: 57.11-00: 45: 14.6$ & 83.0 & $\mathrm{Sm}$ & spiral & 1.16 & 9.27 & -18.49 & 0.26 & 8.63 & 5 & good \\
\hline LSBC F571-V02 & $11: 37: 28.30+18: 24: 34.4$ & 13.7 & $\mathrm{dI} / \mathrm{Sm}:$ & dwarf & 2.19 & 7.98 & $\ldots$ & $\ldots$ & $\ldots$ & 40 & bad \\
\hline UGC 6597 & $11: 37: 43.62+22: 00: 35.4$ & 128.9 & $\mathrm{SB}(\mathrm{r}) \mathrm{b}$ & spiral & 0.85 & 9.52 & -21.94 & 0.67 & 10.55 & 19 & bad \\
\hline UGC 6614 & $11: 39: 14.87+17: 08: 37.2$ & 90.7 & (R)SA(r)a GLSBG & spiral & 7.24 & 10.15 & -21.27 & 0.75 & 10.38 & 13 & good \\
\hline NGC 3801 & $11: 40: 16.94+17: 43: 41.0$ & 47.4 & S0/a & lenticular & 3.40 & 9.26 & -21.31 & 0.93 & 10.64 & 36 & good \\
\hline NGC 3808 & $11: 40: 44.40+22: 26: 16.0$ & 101.6 & DBL SYS & merger & 2.54 & 9.79 & -21.31 & 0.57 & 10.17 & 11 & not used \\
\hline NGC 3821 & $11: 42: 09.11+20: 18: 56.4$ & 82.3 & (R)SAB(s)ab & spiral & 0.85 & 9.13 & -21.65 & 0.95 & 10.8 & 44 & bad \\
\hline NGC 3939 & $11: 49: 19.85+74: 18: 07.9$ & 97.3 & S? & spiral & 1.18 & 9.42 & -21.64 & 0.62 & 10.37 & 1 & good \\
\hline
\end{tabular}


Table 1:-continued

\begin{tabular}{|c|c|c|c|c|c|c|c|c|c|c|c|}
\hline galaxy name & $\begin{array}{c}\text { RA \& DEC } \\
(\text { J2000.0) }\end{array}$ & $\begin{array}{r}D \\
(\mathrm{Mpc})\end{array}$ & $\begin{array}{l}\text { morphology } \\
\text { [NED] }\end{array}$ & class & $\begin{array}{c}\text { HI flux } \\
(\mathrm{Jy} \mathrm{km} / \mathrm{s})\end{array}$ & $\begin{array}{c}\log \left(M_{\mathrm{HI}}\right) \\
\left(M_{\odot}\right)\end{array}$ & $\begin{array}{c}M_{\mathrm{r}} \\
(\mathrm{mag})\end{array}$ & $\begin{array}{r}(g-r) \\
(\mathrm{mag})\end{array}$ & $\begin{array}{r}\log \left(M_{\star}\right) \\
\left(M_{\odot}\right)\end{array}$ & Iso & Flag* \\
\hline IC 742 & $11: 51: 02.25+20: 47: 59.0$ & 91.8 & SBab & spiral & 0.85 & 9.23 & -20.98 & 0.88 & 10.44 & 44 & good \\
\hline UGC 6881 & $11: 54: 44.90+20: 03: 23.3$ & 8.7 & Im: & irregular & 2.76 & 7.69 & -14.22 & 0.37 & 7.07 & $\ldots$ & good \\
\hline LSBC F572-02 & $11: 55: 44.76+17: 53: 17.3$ & 90.7 & S0: & spiral & 3.52 & 9.83 & -20.33 & 0.46 & 9.63 & 3 & good \\
\hline $1154+0203$ & $11: 57: 22.22+01: 46: 54.9$ & 28.3 & dI & dwarf & 0.75 & 8.15 & -14.94 & 0.13 & 7.04 & 6 & good \\
\hline $1156+0254$ & $11: 58: 54.00+02: 37: 23.1$ & 46.2 & $\mathrm{Sc}$ & irregular & 1.04 & 8.72 & -16.63 & 0.32 & 7.97 & 3 & good \\
\hline UGC 6976 & $11: 59: 02.33+21: 48: 29.6$ & 92.1 & S0: & lenticular & 3.66 & 9.86 & -21.77 & 0.70 & 10.53 & 10 & good \\
\hline $1156-0218$ & $11: 59: 10.28-02: 35: 27.2$ & 22.1 & (R)SB(s)m: & irregular & 4.63 & 8.73 & -15.77 & 0.47 & 7.82 & 27 & good \\
\hline $1204+0056$ & $12: 06: 57.12+00: 39: 46.5$ & 24.8 & $\mathrm{Sm}$ & dwarf & 0.60 & 7.94 & -14.44 & 0.35 & 7.13 & 15 & good \\
\hline LSBC F573-03 & $12: 09: 42.57+20: 02: 51.6$ & 35.6 & dwarf & dwarf & 1.40 & 8.62 & -16.02 & 0.39 & 7.81 & 8 & bad \\
\hline $1209+0305$ & $12: 12: 25.59+02: 48: 38.0$ & 12.6 & dIn & dwarf & 7.12 & 8.43 & -14.97 & 0.25 & 7.21 & 62 & good \\
\hline $1210+0142$ & $12: 13: 30.93+01: 25: 39.4$ & 41.8 & dI & dwarf & 0.61 & 8.40 & -14.87 & 0.29 & 7.23 & $\ldots$ & good \\
\hline UGC 7237 & $12: 14: 01.19+17: 53: 57.7$ & 32.5 & $\mathrm{Sm}$ & dwarf & 2.91 & 8.86 & -17.08 & 0.28 & 8.09 & 11 & good \\
\hline UGC 7270 & $12: 15: 34.39+21: 49: 56.1$ & 96.4 & $\mathrm{Sa}$ & spiral & 4.92 & 10.03 & -21.48 & 0.88 & 10.64 & 12 & good \\
\hline $1213+0221$ & $12: 15: 45.66+02: 04: 59.8$ & 332.2 & $\mathrm{Sbc}$ & spiral & 0.47 & 10.09 & -19.86 & 0.17 & 9.06 & $\ldots$ & good \\
\hline $1213+0127$ & $12: 16: 04.48+01: 10: 49.5$ & 214.9 & $\left(\mathrm{R}^{\prime}\right) \mathrm{SB}(\mathrm{s}) \mathrm{b}$ : & spiral & 0.53 & 9.76 & -21.70 & 0.57 & 10.32 & $\ldots$ & good \\
\hline LSBC F573-07 & $12: 16: 15.46+17: 48: 04.4$ & 126.9 & $\mathrm{Sc}$ & spiral & 0.81 & 9.49 & -20.69 & 0.60 & 9.96 & 4 & good \\
\hline LSBC F573-04 & $12: 18: 15.22+20: 00: 40.0$ & 124.9 & $\mathrm{Sb}$ & spiral & 3.90 & 10.16 & -20.89 & 0.50 & 9.91 & 10 & good \\
\hline LSBC F573-02 & $12: 18: 59.05+21: 18: 21.3$ & 125.1 & Sc & spiral & 1.34 & 9.69 & -20.10 & 0.46 & 9.54 & 1 & good \\
\hline $1216+0029$ & $12: 19: 25.86+00: 12: 45.1$ & 12.3 & dIn & dwarf & 0.99 & 7.55 & -14.26 & 0.26 & 6.94 & 46 & good \\
\hline $1217+0103$ & $12: 20: 33.75+00: 47: 17.0$ & 30.1 & $\mathrm{SB}(\mathrm{s}) \mathrm{d}: \mathrm{sp}$ & spiral & 3.63 & 8.89 & -18.04 & 0.43 & 8.68 & 17 & good \\
\hline $1221+0001$ & $12: 23: 42.16-00: 15: 26.1$ & 107.3 & $\mathrm{dEn}$ & dwarf & 0.46 & 9.09 & -17.94 & 0.53 & 8.77 & 6 & good \\
\hline $1221+0128$ & $12: 24: 04.89+01: 11: 23.3$ & 102.0 & Sm;WR & spiral & 0.62 & 9.18 & -20.35 & 0.55 & 9.76 & 4 & good \\
\hline $1221+0020$ & $12: 24: 30.87+00: 04: 15.5$ & 66.4 & Irr & irregular & 2.49 & 9.41 & -17.50 & 0.34 & 8.35 & 1 & good \\
\hline $1223-0101$ & $12: 26: 12.03-01: 18: 13.3$ & 28.9 & IBm pec: & irregular & 6.70 & 9.12 & -17.41 & 0.21 & 8.13 & 23 & good \\
\hline $1223+0117$ & $12: 26: 19.29+01: 01: 10.6$ & 21.0 & $\mathrm{Sm}$ & dwarf & 0.37 & 7.59 & -15.36 & 0.34 & 7.49 & 56 & good \\
\hline $1223-0058$ & $12: 26: 22.71-01: 15: 12.3$ & 29.0 & dIn & dwarf & 5.82 & 9.06 & -16.13 & 0.06 & 7.43 & 23 & good \\
\hline $1225+0152$ & $12: 27: 46.30+01: 36: 00.5$ & 18.5 & dIn & dwarf & 27.1 & 9.34 & -12.71 & 0.05 & 5.92 & 72 & not used \\
\hline LSBC F573-01 & $12: 28: 04.81+22: 17: 24.6$ & 8.6 & dI & dwarf & 0.91 & 7.20 & -13.27 & 0.10 & 6.34 & $\ldots$ & not used \\
\hline LSBC F574-03 & $12: 28: 08.67+20: 10: 46.3$ & 96.8 & $\mathrm{Sc}$ & spiral & 3.75 & 9.92 & -20.25 & 0.51 & 9.66 & 2 & bad \\
\hline LSBC F574-05 & $12: 28: 36.15+19: 28: 12.5$ & 193.5 & $\mathrm{Sb} / \mathrm{p}$ & spiral & 1.20 & 10.03 & -22.32 & 0.72 & 10.77 & $\cdots$ & good \\
\hline $1226+0022$ & $12: 29: 03.86+00: 06: 13.7$ & 16.3 & $\mathrm{dE}$ & dwarf & 0.99 & 7.79 & -15.48 & 0.43 & 7.65 & 56 & good \\
\hline $1226+0119$ & $12: 29: 21.64+01: 03: 25.0$ & 99.3 & $\mathrm{SB}(\mathrm{rs}) \mathrm{bc}$ pec & spiral & 2.25 & 9.72 & -20.80 & 0.58 & 9.98 & 8 & good \\
\hline LSBC F573-09 & $12: 30: 05.18+17: 23: 41.6$ & 36.5 & $\mathrm{I} ?$ & irregular & 3.66 & 9.06 & -16.48 & 0.71 & 8.42 & 7 & good \\
\hline $1227+0254$ & $12: 30: 13.75+02: 37: 28.9$ & 23.3 & SdmIII-IV & irregular & 4.07 & 8.72 & -15.41 & -0.80 & 6.00 & 62 & good \\
\hline $1228+0157$ & $12: 31: 03.82+01: 40: 32.5$ & 15.8 & $\mathrm{IAB}(\mathrm{s}) \mathrm{m}$ pec: & irregular & 2.29 & 8.13 & -15.68 & 0.30 & 7.56 & 144 & good \\
\hline $1228+0116$ & $12: 31: 16.69+00: 59: 39.3$ & 32.7 & dI & dwarf & 0.63 & 8.20 & -15.13 & 0.40 & 7.47 & 13 & good \\
\hline IC 3473 & $12: 32: 19.12+18: 14: 38.9$ & 11.7 & Sd: & $\ldots$ & 0.28 & 6.95 & -16.10 & 0.52 & 8.01 & 123 & not used \\
\hline LSBC F574-01 & $12: 38: 07.03+22: 18: 49.2$ & 98.4 & $\mathrm{Sd}$ & irregular & 1.75 & 9.60 & -18.89 & 0.44 & 9.03 & 1 & good \\
\hline LSBC F574-11 & $12: 38: 20.95+19: 32: 28.8$ & 19.5 & $\mathrm{Sd} / \mathrm{Irr}$ & spiral & 4.66 & 8.62 & -16.08 & 0.24 & 7.64 & 21 & good \\
\hline LSBC F574-02 & $12: 46: 43.50+21: 49: 52.0$ & 90.3 & Sm: & dwarf & 0.97 & 9.27 & -18.11 & 0.18 & 8.38 & 4 & good \\
\hline $1247+0002$ & 12:50:04.75 -00:13:57.7 & 10.8 & $\mathrm{dE}$ & dwarf & 0.09 & 6.40 & -13.65 & 0.29 & 6.95 & 162 & not used \\
\hline LSBC F574-10 & $12: 50: 31.28+17: 28: 15.9$ & 12.1 & Sd: & spiral & 5.61 & 8.28 & -14.42 & 0.27 & 7.02 & 61 & good \\
\hline
\end{tabular}


Table 1:-continued.

\begin{tabular}{|c|c|c|c|c|c|c|c|c|c|c|c|}
\hline galaxy name & $\begin{array}{c}\text { RA \& DEC } \\
(\mathrm{J} 2000.0)\end{array}$ & $\begin{array}{r}D \\
(\mathrm{Mpc})\end{array}$ & $\begin{array}{l}\text { morphology } \\
{[\mathrm{NED}]}\end{array}$ & class & $\begin{array}{c}\text { HI flux } \\
\text { (Jy km/s) }\end{array}$ & $\begin{array}{c}\log \left(M_{\mathrm{HI}}\right) \\
\left(M_{\odot}\right)\end{array}$ & $\begin{array}{c}M_{\mathrm{r}} \\
(\mathrm{mag})\end{array}$ & $\begin{array}{r}(g-r) \\
(\mathrm{mag})\end{array}$ & $\begin{array}{r}\log \left(M_{\star}\right) \\
\left(M_{\odot}\right)\end{array}$ & Iso & Flag* $^{*}$ \\
\hline LSBC F575-02 & $12: 51: 46.10+21: 44: 06.7$ & 8.3 & Sm/Irr: & dwarf & 2.23 & 7.56 & -13.96 & 0.25 & 6.80 & $\ldots$ & not used \\
\hline UGC 8011 & $12: 52: 21.03+21: 37: 46.0$ & 11.1 & $\operatorname{Im}$ & irregular & 6.55 & 8.28 & -14.07 & 0.28 & 6.88 & 38 & good \\
\hline $1249+0233$ & $12: 52: 23.04+02: 17: 16.6$ & 98.7 & dI & dwarf & 0.35 & 8.91 & -17.85 & 0.57 & 8.78 & 1 & good \\
\hline LSBC F646-01 & $12: 52: 59.08+14: 24: 01.9$ & 14.6 & dwarf & dwarf & 3.06 & 8.19 & -14.24 & 0.33 & 7.02 & 66 & good \\
\hline $1251+0122$ & $12: 54: 32.32+01: 06: 32.3$ & 42.0 & $\mathrm{Sdm}$ & dwarf & 1.23 & 8.71 & -15.63 & 0.30 & 7.54 & 7 & good \\
\hline $1252+0214$ & $12: 54: 57.64+01: 58: 41.6$ & 15.4 & Irr & irregular & 0.59 & 7.52 & -13.86 & 1.28 & 8.12 & 157 & not used \\
\hline $1252+0230$ & $12: 55: 25.95+02: 13: 52.4$ & 205.5 & $\mathrm{Sc}$ & spiral & 1.58 & 10.20 & -21.64 & 0.57 & 10.31 & $\ldots$ & good \\
\hline LSBC F575-03 & $12: 55: 41.04+19: 12: 32.7$ & 6.0 & dI & dwarf & 3.95 & 7.52 & -12.46 & -0.10 & 5.65 & $\ldots$ & not used \\
\hline $1254+0117$ & $12: 57: 00.32+01: 01: 43.2$ & 39.5 & $\mathrm{SBc}$ & spiral & 3.87 & 9.15 & -17.75 & 0.22 & 8.28 & 6 & good \\
\hline $1257+0219$ & $12: 59: 58.12+02: 02: 57.3$ & 12.7 & dIn & dwarf & 1.08 & 7.61 & -15.82 & 0.53 & 7.92 & 136 & good \\
\hline $1258+0014$ & 13:00:58.66 -00:01:39.4 & 16.9 & $\mathrm{SB}(\mathrm{s}) \mathrm{cd}$ & spiral & 10.8 & 8.86 & -18.71 & 0.60 & 9.16 & 45 & good \\
\hline $1300+0055$ & $13: 02: 43.53+00: 39: 49.8$ & 174.5 & $\mathrm{Sc}$ & spiral & 0.43 & 9.49 & -21.57 & 0.57 & 10.27 & $\ldots$ & good \\
\hline $1300+0144$ & $13: 03: 16.00+01: 28: 07.0$ & 175.2 & $\mathrm{Sc}(\mathrm{f})$ & spiral & 1.56 & 10.05 & -21.17 & 0.70 & 10.29 & $\ldots$ & good \\
\hline $1301+0218$ & $13: 03: 44.22+02: 02: 23.2$ & 13.9 & $\mathrm{dE}$ & dwarf & 0.63 & 7.46 & -14.84 & 0.49 & 7.47 & 51 & good \\
\hline LSBC F508-V01 & $13: 04: 34.06+26: 46: 27.1$ & 27.6 & $\mathrm{dI} / \mathrm{Im}$ & dwarf & 3.40 & 8.79 & -15.66 & 0.08 & 7.06 & 2 & good \\
\hline LSBC F646-03 & $13: 09: 53.98+17: 09: 53.7$ & 51.2 & $\mathrm{Sd} / \mathrm{Irr}$ & spiral & 3.42 & 9.33 & -17.12 & 0.07 & 7.83 & 3 & good \\
\hline LSBC F575-05 & $13: 09: 53.98+17: 09: 53.7$ & 51.2 & $\mathrm{Sd} / \mathrm{Irr}$ & spiral & 3.42 & 9.33 & -17.12 & 0.07 & 7.83 & 3 & good \\
\hline $1307+0112$ & $13: 10: 04.67+00: 56: 55.7$ & 78.5 & dI & dwarf & 0.75 & 9.04 & -18.21 & 0.37 & 8.66 & 9 & good \\
\hline LSBC F576-03 & $13: 10: 42.68+21: 22: 01.5$ & 96.4 & Scd & spiral & 1.37 & 9.48 & -18.55 & 0.16 & 8.53 & 4 & good \\
\hline $1309+0051$ & $13: 12: 01.95+00: 35: 32.8$ & 81.4 & Irr & irregular & 0.99 & 9.19 & -17.98 & 0.27 & 8.44 & 4 & good \\
\hline UGC 8291 & $13: 12: 55.92+21: 47: 22.3$ & 45.0 & Im: & irregular & 2.00 & 8.98 & -17.48 & 0.50 & 8.54 & 6 & good \\
\hline $1310+0118$ & $13: 13: 14.15+01: 03: 00.4$ & 206.2 & Sc & spiral & 0.84 & 9.93 & -19.68 & 0.61 & 9.57 & $\ldots$ & good \\
\hline LSBC F576-01 & $13: 13: 41.28+22: 37: 32.5$ & 46.5 & Sc: & spiral & 2.75 & 9.15 & -18.38 & 0.52 & 8.93 & 3 & good \\
\hline LSBC F508-03 & $13: 18: 07.58+24: 44: 32.4$ & 39.9 & $\mathrm{Sd}$ & spiral & 2.67 & 9.00 & -16.1 & 0.37 & 7.82 & 1 & good \\
\hline LSBC F508-04 & $13: 24: 15.27+25: 22: 05.0$ & 71.4 & $\mathrm{Sm} / \mathrm{Im}$ & irregular & 1.41 & 9.23 & -17.22 & 0.08 & 7.67 & $\ldots$ & good \\
\hline $1323+0243$ & $13: 26: 16.30+02: 27: 34.2$ & 14.7 & dI & dwarf & 1.99 & 8.00 & -14.18 & 0.23 & 6.86 & 13 & good \\
\hline $1325+0232$ & $13: 28: 12.12+02: 16: 46.0$ & 14.6 & dIn & dwarf & 2.94 & 8.17 & -14.73 & 0.42 & 7.34 & 13 & good \\
\hline $1325+0109$ & $13: 28: 14.88+00: 53: 55.2$ & 146.9 & $\mathrm{Sd}$ & spiral & 0.72 & 9.56 & -17.64 & 0.12 & 8.11 & 3 & good \\
\hline $1326+0109$ & $13: 29: 26.41+00: 54: 11.9$ & 46.8 & dI & dwarf & 1.61 & 8.92 & -17.67 & 0.27 & 8.32 & 3 & good \\
\hline $1327+0148$ & $13: 29: 56.03+01: 32: 41.6$ & 15.0 & dIn & dwarf & 0.58 & 7.49 & -14.63 & 0.29 & 7.13 & 11 & good \\
\hline $1329+0226$ & $13: 31: 34.02+02: 11: 18.6$ & 19.3 & $\mathrm{dEn}$ & dwarf & 1.08 & 7.98 & -14.54 & 0.52 & 7.40 & 6 & good \\
\hline $1331-0002$ & $13: 34: 15.57-00: 17: 17.9$ & 53.8 & dI & dwarf & 0.47 & 8.51 & $\ldots$ & $\ldots$ & $\ldots$ & 9 & bad \\
\hline LSBC F648-V01 & $13: 40: 37.79+17: 05: 40.9$ & 58.5 & $\mathrm{Sm}$ & spiral & 1.64 & 9.12 & -15.80 & -1.30 & 5.49 & 1 & good \\
\hline LSBC F648-V02 & $13: 42: 41.48+15: 36: 30.3$ & 110.9 & S/Malin-like & spiral & 1.91 & 9.74 & -18.93 & 0.33 & 8.90 & 3 & bad \\
\hline LSBC F577-V01 & $13: 50: 10.17+18: 16: 07.7$ & 111.3 & Sd: & spiral & 1.53 & 9.65 & -18.50 & 0.16 & 8.50 & 11 & good \\
\hline LSBC F577-02 & $13: 52: 15.46+17: 17: 34.6$ & 110.2 & $\mathrm{Sb}$ & spiral & 3.19 & 9.96 & -20.56 & 0.49 & 9.76 & 3 & good \\
\hline UGC 8794 & $13: 52: 57.68+20: 55: 01.3$ & 122.6 & $\mathrm{Sb}$ & spiral & 2.49 & 9.95 & -21.61 & 0.68 & 10.43 & 8 & good \\
\hline LSBC F721-V01 & $13: 53: 14.55+09: 40: 51.1$ & 161.9 & ring & no SDSS galaxy & 1.04 & 9.81 & & & & & not used \\
\hline $1350+0230$ & $13: 53: 32.16+02: 15: 35.6$ & 64.4 & dI & dwarf & 0.43 & 8.62 & -16.18 & 0.38 & 7.87 & 8 & good \\
\hline LSBC F578-02 & $13: 54: 17.60+19: 25: 18.7$ & 117.4 & $\mathrm{Sbc}$ & spiral & 1.96 & 9.80 & -20.27 & 0.43 & 9.57 & 6 & good \\
\hline UGC 8828 & $13: 54: 26.86+21: 49: 48.2$ & 119.1 & $\mathrm{~S} ?$ & spiral & 2.44 & 9.91 & -21.67 & 0.88 & 10.72 & 17 & good \\
\hline UGC 8839 & $13: 55: 24.96+17: 47: 41.8$ & 13.7 & $\operatorname{Im}$ & irregular & 17.3 & 8.88 & -14.97 & 0.50 & 7.54 & 7 & good \\
\hline
\end{tabular}


Table 1:-continued

\begin{tabular}{|c|c|c|c|c|c|c|c|c|c|c|c|}
\hline galaxy name & $\begin{array}{c}\text { RA \& DEC } \\
(\mathrm{J} 2000.0)\end{array}$ & $\begin{array}{r}D \\
(\mathrm{Mpc})\end{array}$ & $\begin{array}{l}\text { morphology } \\
\text { [NED] }\end{array}$ & class & $\begin{array}{c}\text { HI flux } \\
(\mathrm{Jy} \mathrm{km} / \mathrm{s})\end{array}$ & $\begin{array}{c}\log \left(M_{\mathrm{HI}}\right) \\
\left(M_{\odot}\right)\end{array}$ & $\begin{array}{c}M_{\mathrm{r}} \\
(\mathrm{mag})\end{array}$ & $\begin{array}{r}(g-r) \\
(\mathrm{mag})\end{array}$ & $\begin{array}{r}\log \left(M_{\star}\right) \\
\left(M_{\odot}\right)\end{array}$ & Iso & Flag* \\
\hline LSBC F721-V02 & $13: 55: 56.70+09: 00: 51.0$ & 17.4 & dI & star & 0.28 & 7.31 & -14.17 & 0.67 & 7.44 & 5 & not used \\
\hline UGC 8850 & $13: 56: 02.87+18: 22: 19.5$ & 215.7 & Merger & merger & 0.21 & 9.37 & -22.65 & 0.45 & 10.54 & $\ldots$ & not used \\
\hline $1353+0202$ & $13: 56: 10.46+01: 47: 51.3$ & 67.7 & dI & dwarf & 0.84 & 8.96 & -15.67 & 2.01 & 9.81 & 4 & bad \\
\hline UGC 8910 & $13: 59: 25.87+17: 28: 07.2$ & 158.5 & SB? & spiral & 1.58 & 9.97 & -20.41 & 0.51 & 9.73 & $\ldots$ & good \\
\hline $1357-0017$ & $13: 59: 43.53-00: 31: 32.8$ & 60.8 & $\mathrm{Sm}$ & irregular & 0.63 & 8.74 & -16.70 & 0.30 & 7.96 & 2 & good \\
\hline LSBC F721-V03 & $14: 00: 32.94+08: 59: 40.4$ & 59.3 & $\operatorname{Im}$ & irregular & 0.95 & 8.90 & -16.19 & 0.41 & 7.92 & 8 & good \\
\hline $1358+0212$ & $14: 01: 27.54+01: 58: 22.6$ & 104.3 & dIn & spiral & 3.29 & 9.93 & -18.97 & 0.30 & 8.87 & 6 & good \\
\hline LSBC F721-V04 & $14: 02: 43.56+09: 59: 29.4$ & 83.0 & S/Malin-like & spiral & 1.04 & 9.23 & -17.63 & 0.27 & 8.30 & 20 & good \\
\hline LSBC F721-01 & $14: 03: 13.84+09: 45: 03.8$ & 103.0 & $\mathrm{Sm}$ & spiral & 1.74 & 9.64 & $\ldots$ & 0.50 & $\ldots$ & $\ldots$ & good \\
\hline $1401+0205$ & $14: 03: 34.50+01: 51: 27.1$ & 103.9 & Sdm & irregular & 0.79 & 9.30 & -17.60 & 0.29 & 8.31 & 2 & good \\
\hline UGC 9024 & $14: 06: 40.54+22: 04: 12.4$ & 33.2 & S? & spiral & 8.32 & 9.33 & -17.42 & 0.65 & 8.72 & 1 & good \\
\hline $1405+0122$ & $14: 07: 50.40+01: 08: 12.9$ & 212.4 & dIn & dwarf & 0.45 & 9.68 & -18.84 & 0.23 & 8.73 & $\ldots$ & good \\
\hline LSBC F579-01 & $14: 11: 49.10+21: 22: 34.9$ & 121.0 & $\mathrm{Sbc}$ & spiral & 2.17 & 9.87 & -21.44 & 0.63 & 10.30 & 3 & good \\
\hline LSBC F579-03 & $14: 13: 53.75+20: 58: 44.6$ & 123.1 & $\mathrm{SB} / \mathrm{p}$ & spiral & 1.54 & 9.74 & -21.63 & 0.63 & 10.38 & 5 & bad \\
\hline $1411-0247$ & $14: 14: 22.55-03: 01: 55.5$ & 27.2 & Scd & spiral & 4.46 & 8.89 & -17.32 & 0.16 & 8.03 & 14 & bad \\
\hline LSBC F579-02 & $14: 14: 58.71+21: 01: 37.0$ & 123.8 & Sc: & spiral & 1.32 & 9.68 & -20.23 & 0.36 & 9.46 & 4 & good \\
\hline LSBC F650-V01 & $14: 15: 22.22+14: 15: 01.3$ & 75.0 & $\mathrm{Sd} / \mathrm{Im}$ & spiral & 2.05 & 9.43 & -17.97 & 0.24 & 8.40 & 7 & good \\
\hline UGC 9282 & $14: 28: 41.38+21: 20: 24.2$ & 16.2 & $\mathrm{Im}:$ & irregular & 2.71 & 8.23 & -15.59 & 0.31 & 7.54 & 7 & good \\
\hline IC 1021 & $14: 29: 17.13+20: 39: 16.3$ & 126.7 & $\mathrm{SBa}$ & spiral & 1.18 & 9.65 & -22.18 & 0.67 & 10.65 & 2 & good \\
\hline LSBC F650-V02 & $14: 30: 05.43+15: 39: 34.3$ & 118.8 & $\mathrm{Sm} / \mathrm{Im}$ & spiral & 1.77 & 9.77 & -19.52 & 0.48 & 9.33 & 1 & good \\
\hline UGC 9316 & $14: 30: 18.10+21: 44: 48.4$ & 76.0 & S0? & spiral & 1.86 & 9.40 & -20.29 & 0.74 & 9.99 & 2 & good \\
\hline LSBC F650-V03 & $14: 31: 29.74+17: 12: 07.6$ & 125.8 & $\mathrm{Im}$ & irregular & 1.17 & 9.64 & -18.33 & 0.35 & 8.69 & 1 & good \\
\hline LSBC F723-V01 & $14: 32: 31.06+11: 33: 11.4$ & 31.0 & $\mathrm{Im} / \mathrm{SBm}:$ & dwarf & 3.52 & 8.90 & -17.60 & -0.70 & 7.00 & 3 & good \\
\hline LSBC F579-V01 & $14: 32: 49.90+22: 45: 40.6$ & 89.9 & $\mathrm{Sd}$ & spiral & 1.21 & 9.36 & -19.28 & 2.01 & 11.25 & 3 & good \\
\hline LSBC F512-01 & $14: 33: 20.31+26: 59: 52.9$ & 11.9 & $\mathrm{Sm}$ & dwarf & 2.21 & 7.87 & -14.43 & 0.03 & 6.70 & 4 & good \\
\hline $1430+0005$ & $14: 33: 27.16-00: 07: 08.2$ & 149.9 & dIn & spiral & 2.37 & 10.10 & -19.79 & 0.30 & 9.20 & 3 & good \\
\hline $1431+0146$ & $14: 34: 14.49+01: 33: 27.5$ & 122.6 & $\mathrm{Sm}$ & spiral & 0.32 & 9.06 & -18.32 & 0.48 & 8.85 & 3 & good \\
\hline $1431+0149$ & $14: 34: 21.41+01: 36: 26.5$ & 131.5 & $\mathrm{SBc}$ & spiral & 0.50 & 9.31 & -19.14 & 0.52 & 9.24 & 2 & good \\
\hline LSBC F723-01 & $14: 35: 23.30+09: 30: 05.1$ & 29.7 & $\operatorname{Im}$ & irregular & 2.81 & 8.76 & -15.81 & 0.15 & 7.42 & 9 & good \\
\hline $1433+0249$ & $14: 35: 50.11+02: 36: 19.7$ & 22.2 & $\operatorname{Irr}(f)$ & irregular & 0.92 & 8.03 & -15.64 & 0.39 & 7.66 & 51 & good \\
\hline LSBC F723-V02 & $14: 36: 40.94+11: 34: 36.8$ & 25.6 & $\mathrm{Sb}$ & dwarf & 1.19 & 8.27 & -16.39 & 0.25 & 7.77 & 3 & good \\
\hline LSBC F580-02 & $14: 36: 44.72+21: 04: 21.9$ & 78.0 & $\mathrm{Sc}(\mathrm{r})$ & spiral & 7.80 & 10.05 & -20.11 & 0.57 & 9.68 & 4 & good \\
\hline LSBC F651-01 & $14: 37: 36.80+13: 19: 06.5$ & 93.9 & $\mathrm{Sd}$ & spiral & 2.08 & 9.64 & -17.74 & 0.32 & 8.41 & 1 & good \\
\hline $1436+0011$ & 14:38:46.83-00:01:39.4 & 26.2 & $\mathrm{Sd}$ & dwarf & 1.04 & 8.23 & -14.45 & -0.00 & 6.67 & 37 & good \\
\hline $1436+0043$ & $14: 39: 07.14+00: 30: 31.1$ & 142.4 & $\mathrm{Sm}$ & spiral & 2.16 & 10.01 & -20.31 & 0.33 & 9.45 & 4 & good \\
\hline $1437-0005$ & 14:39:40.67-00:18:09.2 & 25.8 & $\mathrm{Sm}$ & irregular & 2.10 & 8.52 & -15.42 & 0.11 & 7.20 & 33 & good \\
\hline $1437+0001$ & 14:39:59.88 -00:11:10.2 & 26.6 & dI & dwarf & 1.99 & 8.52 & -14.71 & 0.32 & 7.20 & 33 & good \\
\hline $1438+0049$ & $14: 41: 03.48+00: 37: 09.5$ & 39.1 & dIn & dwarf & 0.51 & 8.27 & -16.90 & 0.48 & 8.29 & 2 & good \\
\hline $1439-0135$ & $14: 41: 44.37-01: 48: 25.3$ & 26.2 & $\mathrm{IAB}(\mathrm{s}) \mathrm{m}:$ & irregular & 4.55 & 8.87 & -17.02 & 0.36 & 8.18 & 22 & good \\
\hline $1439+0053$ & $14: 41: 48.68+00: 41: 13.1$ & 26.9 & SB(rs)dm pec: & spiral & 3.88 & 8.82 & -17.87 & 0.37 & 8.52 & 38 & good \\
\hline $1440-0010$ & $14: 43: 00.18-00: 23: 00.2$ & 24.9 & $\mathrm{dI}$ & dwarf & 0.57 & 7.92 & -16.31 & 0.56 & 8.16 & 32 & good \\
\hline LSBC F651-V01 & $14: 44: 27.50+12: 30: 19.0$ & 127.1 & $\operatorname{Im}$ & irregular & 1.09 & 9.62 & -18.63 & 0.33 & 8.77 & 10 & good \\
\hline
\end{tabular}


Table 1:-continued.

\begin{tabular}{|c|c|c|c|c|c|c|c|c|c|c|c|}
\hline galaxy name & $\begin{array}{c}\text { RA \& DEC } \\
(\mathrm{J} 2000.0)\end{array}$ & $\begin{array}{r}D \\
(\mathrm{Mpc})\end{array}$ & $\begin{array}{l}\text { morphology } \\
{[\mathrm{NED}]}\end{array}$ & class & $\begin{array}{c}\text { HI flux } \\
(\mathrm{Jy} \mathrm{km} / \mathrm{s})\end{array}$ & $\begin{array}{c}\log \left(M_{\mathrm{HI}}\right) \\
\left(M_{\odot}\right)\end{array}$ & $\begin{array}{c}M_{\mathrm{r}} \\
(\mathrm{mag})\end{array}$ & $\begin{array}{r}(g-r) \\
(\mathrm{mag}) \\
\end{array}$ & $\begin{array}{r}\log \left(M_{\star}\right) \\
\left(M_{\odot}\right)\end{array}$ & Iso & Flag $^{*}$ \\
\hline $1441+0144$ & $14: 44: 30.90+01: 31: 21.9$ & 21.1 & Sbc & dwarf & 0.44 & 7.66 & -16.89 & 0.57 & 8.40 & 52 & good \\
\hline $1442+0137$ & $14: 45: 00.22+01: 24: 30.7$ & 144.9 & $\mathrm{Sc}$ & spiral & 1.60 & 9.90 & -20.70 & 0.55 & 9.89 & 5 & good \\
\hline $1442+0026$ & $14: 45: 25.35+00: 14: 04.3$ & 161.8 & $\mathrm{Sbc}$ & spiral & 1.19 & 9.87 & -20.36 & 0.58 & 9.80 & $\ldots$ & good \\
\hline UGC 9503 & $14: 45: 26.34+19: 27: 56.6$ & 134.2 & $\mathrm{Sb}$ & spiral & 1.27 & 9.73 & -21.12 & 0.72 & 10.28 & 12 & good \\
\hline LSBC F512-V01 & $14: 45: 32.88+25: 41: 05.8$ & 60.9 & $\mathrm{Sm}$ & spiral & 3.54 & 9.49 & -17.99 & 0.37 & 8.57 & 6 & good \\
\hline LSBC F651-02 & $14: 46: 24.30+14: 12: 45.0$ & 25.6 & $\mathrm{dI} / \mathrm{Im}$ & dwarf & 4.25 & 8.82 & -15.20 & 0.89 & 8.14 & 4 & good \\
\hline $1446-0031$ & $14: 48: 56.40-00: 43: 38.0$ & 120.2 & $\mathrm{SBc}$ & spiral & 0.70 & 9.38 & -19.06 & 0.13 & 8.69 & 8 & good \\
\hline $1446+0231$ & $14: 48: 59.03+02: 18: 53.2$ & 145.5 & $\mathrm{Sm}$ & spiral & 0.84 & 9.62 & -18.60 & 0.30 & 8.72 & 4 & good \\
\hline LSBC F723-V04 & $14: 50: 33.67+08: 22: 09.1$ & 149.0 & $\mathrm{SBc}$ & irregular & 1.04 & 9.73 & -19.04 & 0.11 & 8.66 & 2 & good \\
\hline LSBC F723-02 & $14: 52: 28.33+10: 11: 35.1$ & 99.6 & $\mathrm{SBm}$ & spiral & 2.87 & 9.83 & -18.56 & 0.25 & 8.65 & 3 & good \\
\hline $1452+0121$ & $14: 54: 43.16+01: 09: 43.3$ & 26.1 & $\mathrm{dE}$ & dwarf & 0.58 & 7.97 & -15.28 & 0.34 & 7.46 & 41 & bad \\
\hline UGC 9634 & $14: 58: 57.88+20: 03: 09.9$ & 183.1 & $\mathrm{SB}(\mathrm{s}) \mathrm{b}$ & spiral & 3.86 & 10.49 & -21.69 & 0.78 & 10.60 & $\ldots$ & good \\
\hline UGC 9672 & $15: 02: 41.66+19: 49: 35.0$ & 70.6 & $\mathrm{Sm}$ & spiral & 3.53 & 9.62 & -18.26 & 0.27 & 8.55 & 3 & good \\
\hline UGC 9680 & $15: 04: 01.51+18: 38: 57.9$ & 208.2 & Scd & spiral & 2.52 & 10.41 & -20.08 & 0.29 & 9.30 & $\ldots$ & good \\
\hline LSBC F581-V01 & $15: 06: 34.78+20: 29: 17.6$ & 89.0 & Sd: & spiral & 1.28 & 9.38 & -18.35 & 0.31 & 8.64 & 2 & good \\
\hline UGC 9738 & $15: 08: 56.65+19: 17: 24.6$ & 89.6 & Scd: & spiral & 2.27 & 9.63 & -19.59 & 0.43 & 9.29 & 8 & good \\
\hline LSBC F513-V01 & $15: 10: 45.24+26: 01: 53.6$ & 142.8 & S/Malin-like & spiral & 0.99 & 9.68 & -19.21 & 0.51 & 9.24 & 3 & good \\
\hline UGC 9763 & $15: 12: 02.18+21: 17: 54.1$ & 67.2 & S? & spiral & 5.62 & 9.78 & -20.09 & 0.81 & 10.00 & 2 & good \\
\hline LSBC F514-01 & $15: 19: 54.05+26: 17: 39.8$ & 134.1 & $\mathrm{dI} / \mathrm{dE}$ & dwarf & 0.99 & 9.62 & -18.17 & 0.36 & 8.63 & 2 & good \\
\hline LSBC F725-V01 & $15: 23: 04.97+11: 45: 53.6$ & 104.0 & $\mathrm{Sm}$ & spiral & 2.46 & 9.80 & -18.43 & 0.43 & 8.84 & 2 & good \\
\hline UGC 9843 & $15: 25: 39.82+20: 47: 16.6$ & 169.8 & $\mathrm{SB}(\mathrm{s}) \mathrm{b}: \mathrm{pec}$ & spiral & 2.05 & 10.15 & -21.35 & 0.65 & 10.29 & $\ldots$ & good \\
\hline LSBC F582-V01 & $15: 27: 39.99+21: 29: 45.1$ & 166.9 & Ring & spiral & 1.32 & 9.94 & -20.49 & 0.66 & 9.96 & $\ldots$ & good \\
\hline LSBC F507-01 & $15: 33: 34.75+25: 14: 19.0$ & 150.9 & $\mathrm{Sc}$ & spiral & 1.81 & 9.99 & -20.63 & 0.52 & 9.83 & $\ldots$ & good \\
\hline LSBC F582-02 & $15: 33: 57.63+21: 47: 23.8$ & 100.6 & $\mathrm{Sbc}$ & spiral & 5.05 & 10.08 & -19.54 & 0.53 & 9.41 & 6 & good \\
\hline LSBC F726-V01 & $15: 35: 09.52+07: 32: 24.9$ & 184.4 & ring & lenticular & 0.58 & 9.67 & -20.02 & 0.73 & 9.87 & $\ldots$ & good \\
\hline LSBC F583-02 & $15: 37: 00.57+20: 47: 41.6$ & 24.6 & $\mathrm{Sd}$ & irregular & 5.12 & 8.86 & -15.60 & 0.31 & 7.57 & 4 & good \\
\hline LSBC F582-03 & $15: 37: 13.42+19: 53: 12.0$ & 181.4 & $\mathrm{Sc}$ & spiral & 0.51 & 9.59 & -20.54 & 0.57 & 9.86 & $\ldots$ & good \\
\hline LSBC F726-V02 & $15: 39: 48.50+08: 26: 46.0$ & 57.9 & $\mathrm{Sm}$ & irregular & 1.88 & 9.17 & -17.29 & 0.36 & 8.28 & 1 & good \\
\hline LSBC F726-V03 & $15: 41: 55.11+10: 27: 02.8$ & 80.4 & S/Malin-like & spiral & 1.79 & 9.44 & -18.73 & 0.52 & 9.07 & 1 & good \\
\hline UGC 10017 & $15: 45: 33.70+21: 25: 18.6$ & 63.0 & Im: & irregular & 2.82 & 9.42 & -18.39 & 0.13 & 8.42 & 3 & bad \\
\hline UGC 10015 & $15: 45: 39.23+21: 01: 10.3$ & 63.5 & Sdm: & spiral & 3.73 & 9.55 & -18.36 & 0.32 & 8.67 & 3 & good \\
\hline LSBC F583-05 & $15: 45: 44.09+17: 18: 51.4$ & 46.6 & $\mathrm{Sm}$ & spiral & 5.17 & 9.42 & -16.33 & 0.46 & 8.05 & 7 & good \\
\hline NGC 5996 & $15: 46: 58.88+17: 53: 03.1$ & 47.1 & $\mathrm{SBc} ; \mathrm{Sbr}$ & too bright & 14.9 & 9.89 & -20.14 & 0.51 & 9.62 & 6 & not used \\
\hline LSBC F583-V02 & $15: 48: 40.72+20: 41: 19.8$ & 157.8 & $\mathrm{Sbc}$ & spiral & 1.22 & 9.86 & -20.28 & 0.48 & 9.64 & $\ldots$ & good \\
\hline LSBC F583-V01 & $15: 50: 19.73+20: 45: 43.1$ & 156.2 & $\mathrm{Sbc}$ & spiral & 1.20 & 9.84 & -20.26 & 0.46 & 9.60 & $\ldots$ & good \\
\hline LSBC F583-04 & $15: 52: 09.33+18: 47: 52.0$ & 51.7 & $\mathrm{Sc}$ & spiral & 1.47 & 8.97 & -13.89 & 0.68 & 7.35 & 10 & not used \\
\hline LSBC F583-01 & $15: 57: 27.48+20: 39: 59.1$ & 32.3 & $\mathrm{Sm} / \mathrm{Irr}$ & irregular & 8.14 & 9.30 & -15.82 & -0.40 & 6.69 & 1 & good \\
\hline LSBC F727-01 & $16: 02: 18.08+12: 16: 31.2$ & 150.6 & $\mathrm{Sc}$ & spiral & 2.96 & 10.20 & -20.25 & 0.76 & 10.00 & $\ldots$ & good \\
\hline LSBC F727-V02 & $16: 04: 32.01+10: 57: 15.7$ & 70.9 & $\mathrm{Sb}$ & spiral & 3.54 & 9.62 & -16.56 & 0.38 & 8.02 & 3 & good \\
\hline LSBC F727-V03 & $16: 05: 12.17+11: 02: 30.1$ & 72.7 & $\mathrm{Sm}$ & irregular & 2.41 & 9.48 & -17.46 & 0.53 & 8.58 & 6 & good \\
\hline LSBC F584-01 & $16: 05: 36.80+22: 11: 11.0$ & 171.6 & $\mathrm{~S} ?$ & spiral & 1.13 & 9.90 & -21.76 & 0.78 & 10.62 & $\ldots$ & good \\
\hline LSBC F727-V04 & $16: 12: 54.09+11: 07: 23.1$ & 173.6 & S/Malin-like & spiral & 2.22 & 10.20 & -21.56 & 0.89 & 10.69 & $\ldots$ & good \\
\hline
\end{tabular}


Table 1:-continued

\begin{tabular}{|c|c|c|c|c|c|c|c|c|c|c|c|}
\hline galaxy name & $\begin{array}{c}\text { RA \& DEC } \\
(\mathrm{J} 2000.0)\end{array}$ & $\begin{array}{r}D \\
(\mathrm{Mpc})\end{array}$ & $\begin{array}{l}\text { morphology } \\
\text { [NED] }\end{array}$ & class & $\begin{array}{c}\text { HI flux } \\
(\mathrm{Jy} \mathrm{km} / \mathrm{s})\end{array}$ & $\begin{array}{c}\log \left(M_{\mathrm{HI}}\right) \\
\left(M_{\odot}\right)\end{array}$ & $\begin{array}{c}M_{\mathrm{r}} \\
(\mathrm{mag})\end{array}$ & $\begin{array}{r}(g-r) \\
(\mathrm{mag})\end{array}$ & $\begin{array}{r}\log \left(M_{\star}\right) \\
\left(M_{\odot}\right)\end{array}$ & Iso & Flag $^{*}$ \\
\hline LSBC F728-V01 & 16:13:00.64 +10:17:52.9 & 138.2 & S/Malin-like & spiral & 0.84 & 9.58 & -19.30 & 0.45 & 9.20 & 1 & good \\
\hline LSBC F585-03 & $16: 21: 23.61+20: 51: 57.2$ & 44.3 & $\mathrm{Sm}$ & spiral & 8.14 & 9.58 & -17.58 & 0.41 & 8.46 & 2 & good \\
\hline LSBC F728-01 & $16: 23: 46.67+11: 22: 24.8$ & 71.1 & $\mathrm{Sc}$ & no SDSS galaxy & 2.19 & 9.42 & & & & & not used \\
\hline UGC 10405 & $16: 28: 54.13+17: 53: 27.5$ & 155.3 & Scd: & spiral & 5.41 & 10.49 & -21.99 & 0.60 & 10.48 & $\ldots$ & good \\
\hline UGC 10440 & $16: 32: 45.23+19: 25: 42.3$ & 62.9 & $\mathrm{Sd}$ & spiral & 2.33 & 9.34 & -19.11 & 0.52 & 9.23 & 1 & good \\
\hline NGC 6186 & $16: 34: 25.48+21: 32: 27.2$ & 42.0 & $\left(\mathrm{R}^{\prime}\right) \mathrm{SB}(\mathrm{s}) \mathrm{a}$ & spiral & 2.30 & 8.98 & -19.73 & 0.69 & 9.69 & 3 & good \\
\hline LSBC F740-01 & $20: 19: 47.33+09: 38: 05.8$ & 78.5 & $\mathrm{Sm}$ & spiral & 1.64 & 9.38 & $\ldots$ & $\ldots$ & $\ldots$ & 3 & bad \\
\hline LSBC F597-02 & $20: 44: 16.71+18: 43: 48.6$ & 98.3 & $\mathrm{SBc}$ & spiral & 2.96 & 9.83 & $\ldots$ & $\ldots$ & $\ldots$ & 2 & bad \\
\hline LSBC F530-01 & $21: 07: 32.85+26: 27: 00.8$ & 204.7 & $\mathrm{~S}(\mathrm{r})$ & spiral & 2.00 & 10.30 & $\ldots$ & $\ldots$ & $\ldots$ & $\ldots$ & bad \\
\hline LSBC F743-01 & $21: 18: 45.40+08: 22: 02.0$ & 42.3 & $\mathrm{Sd}$ & spiral & 2.78 & 9.07 & -16.71 & 0.23 & 7.88 & 1 & good \\
\hline LSBC F530-03 & $21: 21: 01.48+23: 24: 06.3$ & 68.1 & $\mathrm{Sc}$ & no SDSS galaxy & 3.02 & 9.52 & & & & & not used \\
\hline LSBC F744-01 & $21: 47: 37.31+12: 11: 08.7$ & 66.6 & $\mathrm{Sd}$ & spiral & 3.16 & 9.52 & -17.48 & 0.19 & 8.14 & 1 & good \\
\hline LSBC F673-01 & $21: 52: 27.51+15: 47: 14.6$ & 104.7 & $\mathrm{Sb}$ & spiral & 3.52 & 9.96 & -19.77 & 0.51 & 9.48 & 3 & good \\
\hline LSBC F745-V01 & $21: 57: 19.70+08: 19: 34.0$ & 49.8 & Irr & irregular & 3.76 & 9.34 & -16.50 & 0.57 & 8.24 & 1 & good \\
\hline LSBC F674-V01 & $22: 11: 30.58+15: 43: 55.6$ & 86.4 & $\mathrm{Im} / \mathrm{dI}$ & spiral & 1.04 & 9.26 & -17.19 & 0.10 & 7.90 & 1 & good \\
\hline LSBC F533-03 & $22: 17: 13.16+25: 12: 47.6$ & 180.9 & $\mathrm{SBc}(\mathrm{r}) / \mathrm{LSB}$ arms & spiral & 2.60 & 10.30 & -21.99 & 0.56 & 10.43 & $\ldots$ & bad \\
\hline LSBC F602-V01 & $22: 17: 23.20+19: 59: 16.0$ & 103.4 & $\mathrm{Sm}$ & irregular & 1.53 & 9.59 & -15.79 & 0.59 & 7.98 & 1 & good \\
\hline LSBC F674-01 & $22: 19: 09.79+15: 01: 54.6$ & 98.2 & $\mathrm{Sm}$ & spiral & 1.64 & 9.57 & -17.68 & 0.62 & 8.78 & 1 & good \\
\hline LSBC F746-01 & $22: 20: 50.67+12: 49: 51.2$ & 112.1 & Irr & spiral & 2.78 & 9.92 & -18.70 & 0.30 & 8.76 & 7 & good \\
\hline LSBC F746-02 & $22: 24: 08.65+08: 42: 03.3$ & 172.1 & S/Malin-like & spiral & 1.64 & 10.06 & -20.96 & 0.96 & 10.54 & $\ldots$ & bad \\
\hline LSBC F533-01 & $22: 28: 06.63+23: 22: 28.6$ & 18.3 & $\operatorname{Im}$ & irregular & 3.10 & 8.39 & -14.81 & 0.91 & 8.02 & 7 & good \\
\hline LSBC F746-03 & $22: 28: 34.20+08: 12: 10.0$ & 108.9 & Irr & irregular & 1.50 & 9.62 & -17.23 & 0.45 & 8.38 & 2 & good \\
\hline LSBC F602-V02 & $22: 31: 17.30+21: 25: 39.0$ & 103.5 & $\mathrm{Sm}$ & spiral & 3.13 & 9.90 & -18.50 & 0.35 & 8.75 & 1 & good \\
\hline LSBC F602-01 & $22: 34: 46.00+22: 33: 48.0$ & 108.8 & $\mathrm{Sdm}$ & spiral & 1.89 & 9.72 & -20.08 & 0.38 & 9.42 & 1 & good \\
\hline LSBC F675-01 & $22: 40: 35.28+13: 58: 38.3$ & 157.4 & S/ring & spiral & 1.57 & 9.96 & -20.06 & 0.82 & 10.00 & $\ldots$ & good \\
\hline LSBC F675-V01 & $22: 41: 20.26+16: 42: 57.2$ & 45.8 & Irr & spiral & 0.27 & 8.12 & -18.09 & 0.55 & 8.86 & 1 & bad \\
\hline LSBC F675-V02 & $22: 47: 37.40+15: 14: 39.0$ & 160.7 & $\mathrm{Sm}$ & spiral & 1.34 & 9.91 & -19.33 & 0.57 & 9.38 & $\ldots$ & good \\
\hline $2247+0036$ & $22: 50: 23.29+00: 52: 39.2$ & 106.1 & dIn & dwarf & 2.65 & 9.85 & -18.88 & 0.65 & 9.30 & 1 & good \\
\hline $2251+0124$ & $22: 53: 33.48+01: 40: 25.8$ & 70.9 & $\mathrm{Sm}$ & irregular & 0.67 & 8.90 & -17.60 & 0.36 & 8.40 & 9 & good \\
\hline $2252+0156$ & $22: 54: 51.68+02: 12: 22.4$ & 110.4 & $\mathrm{Sm}$ & spiral & 0.81 & 9.37 & -18.88 & 0.47 & 9.07 & 2 & good \\
\hline LSBC F469-01 & $22: 55: 06.25+32: 11: 04.9$ & 93.4 & E-p-/shells & lenticular & 1.32 & 9.44 & -21.61 & 0.80 & 10.59 & 13 & not used \\
\hline LSBC F469-02 & $22: 57: 19.50+27: 59: 04.0$ & 42.1 & $\mathrm{Sm}$ & position is off & 3.02 & 9.10 & -15.49 & 0.43 & 7.66 & 1 & not used \\
\hline 2254-0246 & $22: 57: 32.65-02: 30: 02.9$ & 42.9 & $\mathrm{Sm}$ & spiral & 11.4 & 9.70 & -16.56 & 0.51 & 8.19 & 4 & good \\
\hline $2300+0137$ & $23: 03: 21.49+01: 53: 12.0$ & 76.6 & Scd & spiral & 1.31 & 9.26 & -19.39 & 0.37 & 9.13 & 5 & good \\
\hline LSBC F535-02 & $23: 08: 18.00+27: 42: 59.0$ & 41.2 & $\mathrm{SBm}$ & dwarf & 4.23 & 9.23 & -16.78 & 0.54 & 8.32 & 1 & good \\
\hline LSBC F677-V02 & $23: 12: 12.51+17: 34: 55.3$ & 71.0 & $\mathrm{Im} / \mathrm{dI}$ & dwarf & 0.56 & 8.82 & -17.16 & 0.31 & 8.16 & 1 & good \\
\hline LSBC F677-V01 & $23: 12: 50.09+14: 03: 49.2$ & 67.2 & $\mathrm{Im}$ & irregular & 3.73 & 9.60 & -14.73 & 4.69 & 7.47 & 14 & bad \\
\hline LSBC F535-V01 & $23: 15: 09.97+25: 45: 57.9$ & 112.8 & $\mathrm{Im} / \mathrm{Sm}$ & irregular & 1.27 & 9.58 & -18.86 & 0.22 & 8.73 & 6 & good \\
\hline $2315-0003$ & $23: 18: 06.76+00: 13: 11.4$ & 123.9 & $\mathrm{Sb}$ & spiral & 0.91 & 9.52 & -18.44 & 0.46 & 8.88 & 5 & good \\
\hline LSBC F677-02 & $23: 19: 09.42+15: 43: 37.3$ & 63.5 & Irr & irregular & 1.20 & 9.06 & -18.28 & 0.34 & 8.66 & 7 & good \\
\hline 2317-0034 & $23: 20: 21.17-00: 18: 19.2$ & 107.9 & $\mathrm{Sc}$ & spiral & 1.59 & 9.64 & -19.12 & 0.28 & 8.91 & 2 & good \\
\hline $2318+0033$ & $23: 20: 41.15+00: 49: 34.1$ & 130.4 & Scd & spiral & 0.93 & 9.57 & -18.81 & 0.31 & 8.83 & 10 & good \\
\hline
\end{tabular}


Table 1:-continued.

\begin{tabular}{|c|c|c|c|c|c|c|c|c|c|c|c|}
\hline galaxy name & $\begin{array}{c}\text { RA \& DEC } \\
(\mathrm{J} 2000.0)\end{array}$ & $\begin{array}{r}D \\
(\mathrm{Mpc})\end{array}$ & $\begin{array}{l}\text { morphology } \\
{[\mathrm{NED}]}\end{array}$ & class & $\begin{array}{c}\text { HI flux } \\
(\mathrm{Jy} \mathrm{km} / \mathrm{s})\end{array}$ & $\begin{array}{c}\log \left(M_{\mathrm{HI}}\right) \\
\left(M_{\odot}\right)\end{array}$ & $\begin{array}{c}M_{\mathrm{r}} \\
(\mathrm{mag})\end{array}$ & $\begin{array}{r}(g-r) \\
(\mathrm{mag}) \\
\end{array}$ & $\begin{array}{r}\log \left(M_{\star}\right) \\
\left(M_{\odot}\right)\end{array}$ & Iso & Flag* \\
\hline $2318+0214$ & $23: 20: 49.80+02: 30: 48.5$ & 57.5 & Sm: & irregular & 5.24 & 9.61 & -16.84 & 0.23 & 7.94 & 2 & good \\
\hline $2319+0010$ & $23: 21: 34.22+00: 26: 51.6$ & 150.2 & $\mathrm{Sc}$ & spiral & 3.04 & 10.21 & -20.47 & 0.51 & 9.76 & $\ldots$ & good \\
\hline LSBC F677-03 & $23: 21: 45.80+16: 47: 26.0$ & 101.9 & $\mathrm{Sm}$ & spiral & 1.75 & 9.63 & -18.29 & 0.33 & 8.64 & 2 & good \\
\hline LSBC F677-V03 & $23: 24: 10.93+15: 53: 05.1$ & 61.5 & $\mathrm{dI} /$ double? & dwarf & 0.83 & 8.87 & -16.86 & 0.46 & 8.24 & 4 & good \\
\hline $2322-0216$ & $23: 24: 37.91-01: 59: 51.6$ & 73.6 & $\operatorname{Im} ?$ & spiral & 4.55 & 9.76 & -19.20 & 0.41 & 9.11 & 3 & good \\
\hline LSBC F677-V04 & $23: 25: 17.64+12: 42: 55.9$ & 52.4 & dI & dwarf & 0.47 & 8.48 & -16.58 & 0.33 & 7.96 & 11 & good \\
\hline LSBC F677-V05 & $23: 26: 13.65+15: 04: 36.5$ & 59.9 & $\mathrm{dI} / \mathrm{Im}$ & dwarf & 0.73 & 8.79 & -15.81 & 0.14 & 7.40 & 7 & good \\
\hline LSBC F677-V06 & $23: 27: 37.29+13: 43: 57.1$ & 55.5 & $\mathrm{Sm} / \mathrm{Im}$ & dwarf & 1.34 & 8.99 & -17.69 & 0.37 & 8.46 & 8 & good \\
\hline $2327-0244$ & $23: 30: 32.29-02: 27: 45.1$ & 143.2 & $\mathrm{SB}(\mathrm{r}) \mathrm{b}$ pec & spiral & 2.58 & 10.10 & -22.35 & 0.67 & 10.72 & 2 & good \\
\hline $2329+0145$ & $23: 31: 58.31+02: 02: 27.8$ & 305.2 & $\mathrm{Sc}$ & spiral & 0.51 & 10.05 & -20.85 & 0.30 & 9.63 & $\ldots$ & good \\
\hline $2329+0050$ & $23: 32: 05.98+01: 07: 07.4$ & 73.4 & $\mathrm{dE}$ & dwarf & 0.88 & 9.05 & -17.39 & 0.36 & 8.32 & 2 & good \\
\hline $2329+0148$ & $23: 32: 11.75+02: 05: 10.5$ & 124.5 & $\mathrm{dEn}$ & spiral & 1.06 & 9.59 & -18.94 & 0.50 & 9.14 & 1 & good \\
\hline $2331-0003$ & $23: 34: 00.50+00: 12: 53.5$ & 150.5 & $\mathrm{Sm}$ & spiral & 3.13 & 10.22 & -19.19 & 0.22 & 8.86 & $\ldots$ & good \\
\hline $2331+0118$ & $23: 34: 04.50+01: 35: 03.0$ & 189.4 & $\mathrm{Sd}$ & merger & 1.61 & 10.13 & -21.35 & 0.53 & 10.13 & $\ldots$ & not used \\
\hline $2332+0055$ & $23: 34: 53.31+01: 12: 24.8$ & 37.2 & dIn & dwarf & 1.19 & 8.59 & -15.22 & 0.18 & 6.10 & 7 & good \\
\hline $2333+0025$ & $23: 35: 56.57+00: 42: 13.9$ & 96.1 & $\mathrm{Sm}$ & spiral & 1.06 & 9.36 & -18.56 & 0.24 & 8.64 & 2 & good \\
\hline $2334+0128$ & $23: 36: 44.77+01: 44: 43.5$ & 103.4 & dIn & dwarf & 0.70 & 9.25 & -17.92 & 0.20 & 8.33 & 1 & good \\
\hline LSBC F678-01 & $23: 36: 45.60+17: 36: 54.0$ & 59.8 & Irr & irregular & 3.98 & 9.52 & -17.19 & 0.16 & 7.97 & 2 & good \\
\hline $2334+0020$ & $23: 36: 46.84+00: 37: 24.5$ & 37.6 & LSBG;Sm & dwarf & 0.59 & 8.29 & -16.96 & 0.37 & 8.16 & 6 & good \\
\hline $2335+0101$ & $23: 37: 47.29+01: 18: 01.2$ & 120.4 & $\mathrm{SBc}$ & spiral & 1.34 & 9.66 & -19.59 & 0.45 & 9.32 & $\ldots$ & good \\
\hline LSBC F750-02 & $23: 40: 09.39+07: 18: 37.0$ & 52.8 & $\mathrm{Sc}$ & dwarf & 2.84 & 9.27 & -16.84 & 0.00 & 7.63 & 3 & good \\
\hline 2341-0012 & $23: 43: 55.19+00: 04: 32.8$ & 114.0 & $\mathrm{Sd}$ & spiral & 1.08 & 9.52 & -18.35 & 0.38 & 8.73 & 4 & good \\
\hline LSBC F750-04 & $23: 44: 20.20+10: 07: 05.0$ & 21.5 & $\mathrm{Sc}(\mathrm{r})$ : & irregular & 2.60 & 8.45 & -15.57 & 0.21 & 7.39 & 5 & good \\
\hline $2341-0010$ & $23: 44: 22.18+00: 05: 46.9$ & 94.2 & $\mathrm{Sc}$ & spiral & 1.08 & 9.35 & -19.40 & 0.49 & 9.30 & 11 & good \\
\hline LSBC F750-05 & $23: 45: 35.40+11: 34: 37.0$ & 76.7 & $\mathrm{Sc}(\mathrm{r})$ & spiral & 4.48 & 9.79 & -18.70 & 0.39 & 8.89 & 1 & good \\
\hline \multicolumn{12}{|l|}{ 2. Without HI data: } \\
\hline $0012+0227$ & $00: 14: 53.02+02: 44: 08.0$ & $\ldots$ & $\mathrm{Sc}$ & spiral & & & ... & 0.30 & $\ldots$ & $\ldots$ & good \\
\hline LSBC F539-V02 & $00: 16: 02.79+18: 32: 22.1$ & $\ldots$ & $\mathrm{Sb}$ & no SDSS galaxy & & & & & & & not used \\
\hline LSBC F539-01 & $00: 17: 20.48+20: 19: 51.7$ & $\ldots$ & $\mathrm{Sc}(\mathrm{r})$ & no SDSS galaxy & & & & & & & not used \\
\hline $0016+0001$ & $00: 18: 44.02+00: 18: 29.5$ & $\ldots$ & Sc & spiral & & & $\ldots$ & 0.28 & $\ldots$ & $\ldots$ & good \\
\hline 0016-0052 & $00: 19: 30.68-00: 36: 06.3$ & 140.7 & Irr & irregular & & & -18.95 & 0.41 & 9.01 & 3 & good \\
\hline $0017+0115$ & $00: 20: 22.90+01: 31: 43.0$ & $\ldots$ & $\mathrm{Sbc}$ & dwarf & & & $\ldots$ & 0.51 & $\ldots$ & $\ldots$ & good \\
\hline 0018-0011 & $00: 20: 38.17+00: 04: 57.6$ & $\ldots$ & $\mathrm{dI}$ & dwarf & & & $\ldots$ & -0.10 & $\ldots$ & $\ldots$ & bad \\
\hline 0019-0036 & $00: 21: 49.76-00: 19: 29.4$ & 187.1 & Sc & spiral & & & -18.99 & 0.53 & 9.18 & $\ldots$ & good \\
\hline $0026+0200$ & $00: 28: 47.84+02: 17: 23.7$ & $\ldots$ & dI & dwarf & & & $\ldots$ & 0.22 & $\ldots$ & $\ldots$ & good \\
\hline 0026-0052 & $00: 28: 55.36-00: 35: 36.0$ & $\ldots$ & dI & no SDSS galaxy & & & & & & & not used \\
\hline 0028-0151 & $00: 30: 48.20-01: 35: 14.0$ & $\ldots$ & $\mathrm{dE}$ & no SDSS galaxy & & & & & & & not used \\
\hline 0048-0219 & 00:51:19.11-02:02:51.5 & $\ldots$ & dwarf & dwarf & & & $\ldots$ & 0.15 & $\ldots$ & $\ldots$ & not used \\
\hline 0049-0031 & $00: 52: 11.46-00: 14: 48.4$ & $\ldots$ & Scd & no SDSS galaxy & & & & & & & not used \\
\hline $0052+0029$ & $00: 54: 39.86+00: 45: 19.3$ & $\ldots$ & Scd & spiral & & & $\ldots$ & 0.42 & $\ldots$ & $\ldots$ & good \\
\hline $0101+0124$ & $01: 03: 36.94+01: 40: 23.4$ & $\ldots$ & $\mathrm{dI}$ & dwarf & & & $\ldots$ & 1.05 & $\ldots$ & $\ldots$ & good \\
\hline 0104-0001 & $01: 06: 46.84+00: 14: 37.8$ & $\ldots$ & $\mathrm{Sc}$ & dwarf & & & $\ldots$ & 0.28 & $\ldots$ & $\ldots$ & good \\
\hline
\end{tabular}


Table 1:-continued

\begin{tabular}{|c|c|c|c|c|c|c|c|c|c|c|c|}
\hline galaxy name & $\begin{array}{c}\text { RA \& DEC } \\
(\mathrm{J} 2000.0)\end{array}$ & $\begin{array}{r}D \\
(\mathrm{Mpc})\end{array}$ & $\begin{array}{l}\text { morphology } \\
\text { [NED] }\end{array}$ & class & $\begin{array}{c}\text { HI flux } \\
(\mathrm{Jy} \mathrm{km} / \mathrm{s})\end{array}$ & $\begin{array}{c}\log \left(M_{\mathrm{HI}}\right) \\
\left(M_{\odot}\right)\end{array}$ & $\begin{array}{c}M_{\mathrm{r}} \\
(\mathrm{mag})\end{array}$ & $\begin{array}{r}(g-r) \\
(\mathrm{mag})\end{array}$ & $\begin{array}{r}\log \left(M_{\star}\right) \\
\left(M_{\odot}\right)\end{array}$ & Iso & Flag* \\
\hline 0104-0101 & $01: 06: 56.67-00: 45: 21.4$ & ... & Sbc & dwarf & & & $\ldots$ & 0.49 & $\ldots$ & $\ldots$ & good \\
\hline $0104+0044$ & 01:07:23.89+01:00:08.1 & $\ldots$ & dI & dwarf & & & $\ldots$ & 0.38 & $\ldots$ & $\ldots$ & good \\
\hline 0105-0214 & 01:08:07.84 -01:58:32.7 & $\ldots$ & dI & dwarf & & & $\ldots$ & 0.24 & $\ldots$ & $\ldots$ & good \\
\hline $0108+0243$ & $01: 11: 25.16+02: 58: 56.7$ & $\ldots$ & $\mathrm{Sc}$ & spiral & & & $\ldots$ & 0.31 & $\ldots$ & $\ldots$ & bad \\
\hline $0110+0023$ & $01: 12: 44.80+00: 39: 35.2$ & 277.7 & Sc & spiral & & & -21.39 & 0.45 & 10.04 & $\ldots$ & good \\
\hline $0110-0251$ & 01:13:07.02-02:36:02.1 & $\ldots$ & $\mathrm{Sbc}$ & spiral & & & $\ldots$ & 0.33 & $\ldots$ & $\ldots$ & good \\
\hline LSBC F611-02 & $01: 14: 17.28+15: 25: 51.8$ & $\ldots$ & $\mathrm{E} / \mathrm{S} 0 /$ shells & no SDSS galaxy & & & & & & & not used \\
\hline LSBC F611-V01 & $01: 16: 20.04+16: 15: 54.6$ & $\ldots$ & S/Malin-like & spiral & & & $\ldots$ & 0.85 & $\ldots$ & $\ldots$ & good \\
\hline $0115-0125$ & 01:18:02.88 -01:09:58.5 & $\ldots$ & $\mathrm{Sdm}$ & spiral & & & $\ldots$ & 0.16 & $\ldots$ & $\ldots$ & good \\
\hline LSBC F542-V01 & $01: 19: 27.34+19: 48: 44.5$ & $\ldots$ & Sb: & no SDSS galaxy & & & & & & & not used \\
\hline $0117+0231$ & $01: 19: 55.50+02: 47: 08.8$ & $\ldots$ & Scd & spiral & & & $\ldots$ & 0.34 & $\ldots$ & $\ldots$ & good \\
\hline $0118+0026$ & $01: 21: 27.62+00: 42: 37.4$ & $\ldots$ & Scd & spiral & & & $\ldots$ & 0.26 & $\ldots$ & $\ldots$ & good \\
\hline LSBC F683-V03 & $01: 22: 24.40+09: 26: 58.0$ & $\ldots$ & Im/real? & spiral & & & $\ldots$ & 0.85 & $\ldots$ & $\ldots$ & good \\
\hline LSBC F683-01 & $01: 22: 32.47+08: 45: 33.9$ & $\ldots$ & dI:/real? & no SDSS galaxy & & & & & & & not used \\
\hline LSBC F683-V05 & $01: 22: 43.00+09: 25: 06.0$ & $\ldots$ & $\mathrm{Sm} / \mathrm{Im}$ & spiral & & & $\ldots$ & 0.59 & $\ldots$ & $\ldots$ & good \\
\hline LSBC F611-V02 & $01: 25: 15.09+14: 03: 23.7$ & $\ldots$ & $\operatorname{Im}$ & no SDSS galaxy & & & & & & & not used \\
\hline $0122+0134$ & $01: 25: 22.11+01: 50: 29.0$ & $\ldots$ & $\mathrm{Sbc}$ & spiral & & & $\ldots$ & 0.15 & $\ldots$ & $\ldots$ & good \\
\hline 0123-0029 & $01: 25: 53.70-00: 14: 08.3$ & $\ldots$ & $\mathrm{dE}$ & no SDSS galaxy & & & & & & & not used \\
\hline 0124-0109 & $01: 27: 11.26-00: 53: 53.5$ & $\ldots$ & Scd & spiral & & & $\ldots$ & 0.49 & $\ldots$ & $\ldots$ & good \\
\hline LSBC F683-V09 & $01: 27: 31.70+09: 38: 15.0$ & $\ldots$ & $\mathrm{Sm}$ & spiral & & & $\ldots$ & 0.25 & $\ldots$ & $\ldots$ & good \\
\hline $0125-0006$ & $01: 27: 42.97+00: 09: 23.8$ & $\ldots$ & $\mathrm{dE}$ & no SDSS galaxy & & & & & & & not used \\
\hline 0126-0157 & $01: 28: 53.96-01: 41: 58.7$ & $\ldots$ & $\mathrm{Sb}$ & $\ldots$ & & & $\ldots$ & 0.30 & $\ldots$ & $\ldots$ & not used \\
\hline LSBC F542-01 & $01: 31: 48.88+18: 35: 50.1$ & 183.5 & SB0/LSB arms & lenticular & & & -22.90 & 0.75 & 11.04 & $\ldots$ & not used \\
\hline 0129-0029 & $01: 31: 50.59-00: 13: 55.0$ & $\ldots$ & dI & dwarf & & & $\ldots$ & 0.80 & $\ldots$ & $\ldots$ & good \\
\hline $0130-0235$ & $01: 33: 23.63-02: 20: 36.6$ & $\ldots$ & dI or Cirrus & no SDSS galaxy & & & & & & & not used \\
\hline 0132-0024 & 01:34:39.63-00:08:39.8 & $\ldots$ & dI or Cirrus & no SDSS galaxy & & & & & & & not used \\
\hline 0134-0036 & $01: 37: 28.80-00: 21: 06.4$ & $\ldots$ & dI & dwarf & & & $\ldots$ & 0.49 & $\ldots$ & $\ldots$ & bad \\
\hline 0141-0039 & $01: 44: 18.69-00: 24: 40.5$ & $\ldots$ & dI & no SDSS galaxy & & & & & & & not used \\
\hline LSBC F477-02 & $01: 48: 58.37+25: 58: 26.2$ & $\ldots$ & S/ring/interaction & spiral & & & $\ldots$ & 0.78 & $\ldots$ & $\ldots$ & good \\
\hline 0150-0114 & $01: 53: 17.65-00: 59: 18.2$ & 1032.1 & $\mathrm{Sbc}$ & high redshift & & & -22.73 & 1.18 & 11.54 & $\ldots$ & not used \\
\hline 0209-0202 & 02:12:17.64 -01:48:02.1 & $\ldots$ & $\mathrm{Sab}$ & spiral & & & $\ldots$ & 0.41 & $\ldots$ & $\ldots$ & good \\
\hline LSBC F415-01 & $02: 12: 54.90+32: 48: 54.0$ & $\ldots$ & $\mathrm{dE}$ & dwarf & & & $\ldots$ & 0.09 & $\ldots$ & $\ldots$ & good \\
\hline 0210-0042 & $02: 12: 55.51-00: 28: 01.8$ & $\ldots$ & Sbc & irregular & & & $\ldots$ & 0.13 & $\ldots$ & $\ldots$ & good \\
\hline 0211-0053 & $02: 13: 50.57-00: 39: 38.3$ & 116.0 & Sab & spiral & & & -18.21 & 0.49 & 8.82 & 3 & good \\
\hline $0213+0121$ & $02: 15: 57.80+01: 35: 43.1$ & $\ldots$ & $\mathrm{Sc}$ & spiral & & & $\ldots$ & 0.52 & $\ldots$ & $\ldots$ & good \\
\hline 0213-0056 & $02: 15: 58.48-00: 42: 49.1$ & 114.9 & $\mathrm{Sd}$ & spiral & & & -21.12 & 0.84 & 10.46 & 4 & good \\
\hline LSBC F415-02 & $02: 19: 48.04+29: 46: 49.0$ & $\ldots$ & E-p-/plumes & lenticular & & & $\ldots$ & 0.72 & $\ldots$ & $\ldots$ & not used \\
\hline LSBC F614-V01 & $02: 20: 54.56+15: 37: 30.1$ & $\ldots$ & $\mathrm{Sd}$ & spiral & & & $\ldots$ & $\ldots$ & $\ldots$ & $\ldots$ & bad \\
\hline 0222-0050 & $02: 24: 34.65-00: 36: 57.0$ & $\ldots$ & $\mathrm{Sb}$ & spiral & & & $\ldots$ & 0.49 & $\ldots$ & $\ldots$ & good \\
\hline 0222-0201 & $02: 25: 06.44-01: 48: 27.7$ & $\ldots$ & dI or Cirrus & no SDSS galaxy & & & & & & & not used \\
\hline 0223-0052 & $02: 26: 11.85-00: 39: 03.8$ & $\ldots$ & $\mathrm{Sc}$ & spiral & & & $\ldots$ & 0.72 & $\ldots$ & $\ldots$ & bad \\
\hline $0224+0233$ & $02: 27: 34.81+02: 47: 09.9$ & $\ldots$ & $\mathrm{dI}$ & no SDSS galaxy & & & & & & & not used \\
\hline
\end{tabular}


Table 1:-continued.

\begin{tabular}{|c|c|c|c|c|c|c|c|c|c|c|c|}
\hline galaxy name & $\begin{array}{c}\text { RA \& DEC } \\
(\mathrm{J} 2000.0)\end{array}$ & $\begin{array}{r}D \\
(\mathrm{Mpc})\end{array}$ & $\begin{array}{l}\text { morphology } \\
{[\mathrm{NED}]}\end{array}$ & class & $\begin{array}{c}\text { HI flux } \\
(\mathrm{Jy} \mathrm{km} / \mathrm{s})\end{array}$ & $\begin{array}{c}\log \left(M_{\mathrm{HI}}\right) \\
\left(M_{\odot}\right)\end{array}$ & $\begin{array}{c}M_{\mathrm{r}} \\
(\mathrm{mag})\end{array}$ & $\begin{array}{r}(g-r) \\
(\mathrm{mag})\end{array}$ & $\begin{array}{r}\log \left(M_{\star}\right) \\
\left(M_{\odot}\right)\end{array}$ & Iso & Flag* $^{*}$ \\
\hline $0227-0242$ & $02: 29: 57.23-02: 28: 52.8$ & $\ldots$ & $\mathrm{Sb}$ & spiral & & & $\ldots$ & 0.44 & $\ldots$ & $\ldots$ & good \\
\hline $0229-0243$ & $02: 31: 34.24-02: 29: 46.2$ & $\ldots$ & $\mathrm{Sdm}$ & spiral & & & $\ldots$ & -0.70 & $\ldots$ & $\ldots$ & good \\
\hline 0229-0158 & $02: 31: 39.32-01: 45: 42.2$ & $\ldots$ & Sc & dwarf & & & $\ldots$ & 0.31 & $\ldots$ & $\ldots$ & good \\
\hline $0229+0005$ & $02: 31: 47.21+00: 18: 42.4$ & 881.9 & Scd & high redshift & & & -22.71 & 0.68 & 10.88 & $\ldots$ & not used \\
\hline 0229-0115 & 02:31:50.31 -01:02:35.1 & 84.3 & $\mathrm{Sm}$ & spiral & & & -18.57 & 0.25 & 8.65 & 3 & good \\
\hline $0230+0221$ & $02: 32: 44.20+02: 34: 40.0$ & $\ldots$ & $\mathrm{Sb}$ & spiral & & & $\ldots$ & 0.28 & $\ldots$ & $\ldots$ & good \\
\hline 0234-0206 & 02:37:26.62 -01:53:03.6 & $\ldots$ & dI & dwarf & & & $\ldots$ & 0.39 & $\ldots$ & $\ldots$ & good \\
\hline 0235-0152 & $02: 37: 52.05-01: 39: 55.7$ & $\ldots$ & Irr & irregular & & & $\ldots$ & 0.44 & $\ldots$ & $\ldots$ & good \\
\hline $0238+0001$ & $02: 40: 56.58+00: 14: 45.6$ & 114.0 & & spiral & & & -18.82 & 0.40 & 8.94 & 1 & good \\
\hline 0240-0028 & $02: 43: 10.56-00: 15: 46.3$ & 13.8 & $\mathrm{dE}$ & dwarf & & & -15.06 & 0.40 & 7.44 & 17 & good \\
\hline 0240-0121 & 02:43:32.60-01:08:34.6 & $\ldots$ & dI & dwarf & & & $\ldots$ & 0.39 & $\ldots$ & $\ldots$ & good \\
\hline 0241-0049 & 02:43:52.98 -00:37:03.1 & 129.5 & & spiral & & & -16.61 & 0.75 & 8.53 & 3 & good \\
\hline $0243+0001$ & $02: 45: 44.70+00: 13: 55.0$ & $\ldots$ & $\mathrm{Sc}$ & spiral & & & $\ldots$ & 0.29 & $\ldots$ & $\ldots$ & bad \\
\hline 0243-0027 & $02: 45: 47.60-00: 14: 27.2$ & 99.9 & $\mathrm{Sc}$ & spiral & & & -19.00 & 0.36 & 8.97 & 4 & good \\
\hline 0243-0034 & $02: 46: 31.07-00: 21: 58.4$ & 220.1 & $\mathrm{Sbc}$ & spiral & & & -20.39 & 0.29 & 9.43 & $\ldots$ & good \\
\hline 0244-0028 & $02: 46: 37.56-00: 16: 11.5$ & $\ldots$ & dI & dwarf & & & $\ldots$ & 0.86 & $\ldots$ & $\ldots$ & good \\
\hline 0244-0127 & 02:47:31.91 -01:14:46.1 & $\ldots$ & dI & dwarf & & & $\ldots$ & 0.24 & $\ldots$ & $\ldots$ & good \\
\hline 0248-0048 & 02:50:43.92 -00:36:06.5 & $\ldots$ & interacting & star & & & $\ldots$ & 0.45 & $\ldots$ & $\ldots$ & not used \\
\hline LSBC F480-V02 & $02: 51: 50.26+25: 57: 29.7$ & $\ldots$ & Sb/distant? & spiral & & & $\ldots$ & $\ldots$ & $\ldots$ & $\ldots$ & bad \\
\hline LSBC F480-V05 & $03: 03: 19.15+27: 30: 39.5$ & $\ldots$ & S: & spiral & & & $\ldots$ & 0.72 & $\ldots$ & .. & good \\
\hline LSBC F480-V06 & $03: 03: 39.45+27: 26: 49.1$ & 154.3 & S:/ring & spiral & & & -21.38 & 0.77 & 10.46 & $\ldots$ & good \\
\hline 0310-0112 & 03:12:53.08 -01:01:29.3 & $\ldots$ & Sdm & spiral & & & $\ldots$ & 0.26 & $\ldots$ & $\ldots$ & good \\
\hline 0311-0021 & 03:13:55.69-00:10:35.3 & 40.9 & Scd & irregular & & & -15.97 & 0.18 & 7.51 & 1 & good \\
\hline $0313+0148$ & $03: 15: 58.40+01: 59: 46.3$ & $\ldots$ & $\mathrm{Sd}$ & spiral & & & $\ldots$ & $\ldots$ & $\ldots$ & $\ldots$ & bad \\
\hline $0313+0205$ & $03: 16: 23.48+02: 16: 07.2$ & $\ldots$ & $\mathrm{Sbc}$ & irregular & & & $\ldots$ & 0.11 & $\ldots$ & $\ldots$ & good \\
\hline $0314+0108$ & $03: 17: 21.93+01: 19: 47.7$ & $\ldots$ & dEn & dwarf & & & $\ldots$ & $\ldots$ & $\ldots$ & $\ldots$ & bad \\
\hline $0316+0102$ & $03: 18: 59.39+01: 13: 47.3$ & 161.1 & $\mathrm{Sc}$ & spiral & & & -18.56 & 0.59 & 9.09 & $\ldots$ & good \\
\hline 0316-0100 & 03:19:19.68 -00:50:06.6 & $\ldots$ & dI & no SDSS galaxy & & & & & & & not used \\
\hline $0317+0003$ & $03: 19: 44.62+00: 14: 22.2$ & $\ldots$ & $\mathrm{Sc}$ & spiral & & & $\ldots$ & 0.55 & $\ldots$ & $\ldots$ & good \\
\hline 0317-0121 & 03:20:21.10 -01:10:13.7 & $\ldots$ & Sc & irregular & & & $\ldots$ & 0.32 & $\ldots$ & $\ldots$ & good \\
\hline 0318-0140 & 03:20:32.92 -01:29:16.2 & $\ldots$ & Sbc & spiral & & & $\ldots$ & $\ldots$ & $\ldots$ & $\ldots$ & bad \\
\hline 0318-0101 & 03:20:46.09-00:51:00.1 & 93.0 & $\mathrm{Sm}$ & irregular & & & -18.99 & 0.38 & 9.01 & 11 & bad \\
\hline $0318+0133$ & $03: 20: 57.76+01: 44: 27.6$ & $\ldots$ & $\mathrm{Sbc}$ & spiral & & & $\ldots$ & $\ldots$ & $\ldots$ & $\ldots$ & bad \\
\hline $0319+0033$ & $03: 22: 03.94+00: 44: 12.4$ & $\ldots$ & $\mathrm{Sb}$ & spiral & & & $\ldots$ & 0.34 & $\ldots$ & $\ldots$ & good \\
\hline $0323+0230$ & $03: 26: 35.31+02: 40: 47.3$ & $\cdots$ & $\mathrm{Sd}$ & spiral & & & $\cdots$ & $\ldots$ & $\cdots$ & $\cdots$ & bad \\
\hline $0325+0135$ & $03: 28: 12.57+01: 46: 06.8$ & $\ldots$ & $\mathrm{Sc}$ & spiral & & & $\ldots$ & $\ldots$ & $\ldots$ & $\ldots$ & bad \\
\hline 0326-0113 & $03: 29: 10.83-01: 02: 46.3$ & 153.8 & $\mathrm{Sbc}$ & spiral & & & -18.66 & 0.37 & 8.85 & $\ldots$ & good \\
\hline 0329-0216 & 03:31:42.92 -02:06:15.4 & $\ldots$ & dIn & dwarf & & & $\ldots$ & $\ldots$ & $\ldots$ & $\ldots$ & bad \\
\hline $0330+0213$ & $03: 33: 20.68+02: 23: 01.8$ & $\ldots$ & Sbc & spiral & & & $\ldots$ & $\ldots$ & $\ldots$ & $\ldots$ & bad \\
\hline 0331-0032 & $03: 33: 49.62-00: 22: 55.1$ & 157.7 & $\mathrm{Sbc}$ & spiral & & & -18.71 & 0.48 & 9.01 & $\ldots$ & good \\
\hline 0332-0209 & 03:34:42.50-01:59:52.9 & $\ldots$ & Sm & spiral & & & $\ldots$ & $\ldots$ & $\ldots$ & $\ldots$ & bad \\
\hline 0332-0102 & 03:35:07.23 -00:52:37.6 & 158.2 & & spiral & & & -19.47 & 0.34 & 9.13 & $\ldots$ & good \\
\hline
\end{tabular}


Table 1:-continued

\begin{tabular}{|c|c|c|c|c|c|c|c|c|c|c|c|}
\hline galaxy name & $\begin{array}{c}\text { RA \& DEC } \\
(\mathrm{J} 2000.0)\end{array}$ & $\begin{array}{r}D \\
(\mathrm{Mpc})\end{array}$ & $\begin{array}{l}\text { morphology } \\
{[\mathrm{NED}]}\end{array}$ & class & $\begin{array}{c}\text { HI flux } \\
(\mathrm{Jy} \mathrm{km} / \mathrm{s})\end{array}$ & $\begin{array}{c}\log \left(M_{\mathrm{HI}}\right) \\
\left(M_{\odot}\right)\end{array}$ & $\begin{array}{c}M_{\mathrm{r}} \\
(\mathrm{mag})\end{array}$ & $\begin{array}{r}(g-r) \\
(\mathrm{mag})\end{array}$ & $\begin{array}{r}\log \left(M_{\star}\right) \\
\left(M_{\odot}\right)\end{array}$ & Iso & Flag* \\
\hline $0334+0010$ & $03: 36: 42.54+00: 20: 14.5$ & 156.3 & $\mathrm{Sc}$ & spiral & & & $\ldots$ & $\ldots$ & $\ldots$ & $\ldots$ & bad \\
\hline 0336-0018 & 03:39:02.28 -00:08:48.0 & $\ldots$ & $\mathrm{Sd}$ & spiral & & & $\ldots$ & 0.51 & $\ldots$ & $\ldots$ & good \\
\hline 0339-0216 & $03: 41: 58.88-02: 07: 20.3$ & $\ldots$ & Scd & spiral & & & $\ldots$ & $\ldots$ & $\ldots$ & $\ldots$ & bad \\
\hline 0340-0201 & 03:42:51.07-01:52:10.8 & 40.2 & $\mathrm{Sbc}$ & spiral & & & $\ldots$ & $\ldots$ & $\ldots$ & 1 & bad \\
\hline $0341+0220$ & $03: 43: 43.69+02: 30: 11.2$ & $\ldots$ & $\mathrm{Sm}$ & spiral & & & $\ldots$ & $\ldots$ & $\ldots$ & $\ldots$ & bad \\
\hline $0342+0107$ & $03: 45: 13.73+01: 16: 32.4$ & $\ldots$ & $\mathrm{Sc}$ & spiral & & & $\ldots$ & 0.59 & $\ldots$ & $\ldots$ & good \\
\hline $0342+0214$ & $03: 45: 32.51+02: 23: 44.3$ & $\ldots$ & $\mathrm{Sbc}$ & spiral & & & $\ldots$ & $\ldots$ & $\ldots$ & $\ldots$ & bad \\
\hline 0343-0217 & $03: 45: 51.62-02: 07: 50.7$ & $\ldots$ & $\mathrm{Sm}$ & spiral & & & $\ldots$ & $\ldots$ & $\ldots$ & $\ldots$ & bad \\
\hline $0345+0118$ & $03: 47: 42.92+01: 28: 06.1$ & $\ldots$ & $\mathrm{dE}$ & dwarf & & & $\ldots$ & $\ldots$ & $\ldots$ & $\ldots$ & bad \\
\hline 0346-0016 & 03:48:59.61 -00:07:00.7 & 378.4 & $\mathrm{dE}$ & spiral & & & -21.4 & 0.52 & 10.14 & $\ldots$ & good \\
\hline $0349+0225$ & $03: 52: 34.29+02: 34: 26.6$ & $\ldots$ & Sdm & spiral & & & $\ldots$ & $\ldots$ & $\ldots$ & .. & bad \\
\hline 0353-0125 & $03: 55: 37.71-01: 16: 22.6$ & $\ldots$ & Scd & spiral & & & $\ldots$ & 1.69 & $\ldots$ & .. & bad \\
\hline 0353-0004 & $03: 55: 45.55+00: 04: 26.9$ & $\ldots$ & $\mathrm{Sc}$ & spiral & & & $\ldots$ & 0.59 & $\ldots$ & $\ldots$ & good \\
\hline $0353+0224$ & $03: 55: 47.91+02: 32: 41.8$ & $\ldots$ & dI or Cirrus & dwarf & & & $\ldots$ & $\ldots$ & $\ldots$ & $\ldots$ & bad \\
\hline 0354-0043 & 03:56:38.92 -00:34:45.1 & $\ldots$ & $\mathrm{dE}$ & dwarf & & & $\ldots$ & 0.46 & $\ldots$ & .. & good \\
\hline $0354+0142$ & $03: 57: 16.76+01: 51: 03.5$ & $\ldots$ & $\mathrm{Sm}$ & spiral & & & $\ldots$ & $\ldots$ & $\ldots$ & .. & bad \\
\hline $0355-0031$ & $03: 57: 59.50-00: 22: 34.5$ & $\ldots$ & $\mathrm{Sc}$ & spiral & & & $\ldots$ & 0.58 & $\ldots$ & $\ldots$ & good \\
\hline 0357-0059 & 03:59:35.72 -00:51:18.1 & $\ldots$ & Sc & spiral & & & $\ldots$ & 0.65 & $\ldots$ & $\ldots$ & good \\
\hline 0357-0229 & 04:00:05.30 -02:21:12.4 & $\ldots$ & $\mathrm{Sdm}$ & spiral & & & $\ldots$ & $\ldots$ & $\ldots$ & $\ldots$ & bad \\
\hline $0359+0228$ & $04: 01: 37.11+02: 36: 20.9$ & $\ldots$ & $\mathrm{Sm}$ & spiral & & & $\ldots$ & $\ldots$ & $\ldots$ &.. & bad \\
\hline 0359-0203 & 04:02:30.73-01:55:03.6 & 65.9 & $\mathrm{Sm}$ & spiral & & & $\ldots$ & $\ldots$ & $\ldots$ & 2 & bad \\
\hline 0400-0212 & 04:03:13.28 -02:03:49.3 & $\ldots$ & $\mathrm{Sm}$ & spiral & & & $\ldots$ & $\ldots$ & $\ldots$ & $\ldots$ & bad \\
\hline $0401+0148$ & $04: 03: 42.54+01: 56: 16.1$ & $\ldots$ & $\mathrm{Sbc}$ & spiral & & & $\ldots$ & $\ldots$ & $\ldots$ & $\ldots$ & bad \\
\hline $0401+0213$ & $04: 03: 46.48+02: 21: 49.7$ & $\ldots$ & dI & dwarf & & & $\ldots$ & $\ldots$ & $\ldots$ & $\ldots$ & bad \\
\hline $0401+0146$ & $04: 03: 57.21+01: 55: 00.1$ & $\ldots$ & $\mathrm{Sc}$ & spiral & & & $\ldots$ & $\ldots$ & $\ldots$ & $\ldots$ & bad \\
\hline 0402-0205 & 04:04:33.19-01:56:55.3 & $\ldots$ & Scd & spiral & & & $\ldots$ & $\ldots$ & $\ldots$ & $\ldots$ & bad \\
\hline 0402-0157 & 04:04:52.62 -01:49:20.6 & $\ldots$ & dIn & dwarf & & & $\ldots$ & $\ldots$ & $\ldots$ & $\ldots$ & bad \\
\hline $0402+0141$ & $04: 05: 15.13+01: 49: 09.1$ & $\ldots$ & dI & dwarf & & & $\ldots$ & $\ldots$ & $\ldots$ & $\ldots$ & bad \\
\hline $0405+0214$ & $04: 08: 33.12+02: 22: 42.4$ & 128.5 & $\mathrm{Sc}$ & spiral & & & $\ldots$ & $\ldots$ & $\ldots$ & 1 & bad \\
\hline $0406+0021$ & $04: 09: 14.08+00: 29: 25.7$ & $\ldots$ & dIn & dwarf & & & $\ldots$ & 0.66 & $\ldots$ & $\ldots$ & good \\
\hline $0407+0209$ & $04: 09: 41.52+02: 17: 02.3$ & $\ldots$ & $\mathrm{Sd}$ & spiral & & & $\ldots$ & $\ldots$ & $\ldots$ & $\ldots$ & bad \\
\hline LSBC F620-01 & $04: 17: 50.22+13: 25: 06.1$ & 106.7 & $\mathrm{Sc}(\mathrm{r})$ & spiral & & & $\ldots$ & $\ldots$ & $\ldots$ & 2 & bad \\
\hline LSBC F620-V01 & $04: 19: 02.01+14: 49: 40.3$ & $\ldots$ & S/smooth & spiral & & & $\ldots$ & $\ldots$ & $\ldots$ & $\ldots$ & bad \\
\hline LSBC F620-V02 & $04: 23: 10.06+16: 18: 56.6$ & $\ldots$ & $\mathrm{Sm}$ & no SDSS galaxy & & & & & & & not used \\
\hline LSBC F620-02 & $04: 25: 01.03+12: 50: 10.8$ & 111.2 & $\mathrm{Sc}$ & spiral & & & $\ldots$ & $\ldots$ & $\ldots$ & 2 & bad \\
\hline LSBC F620-03 & $04: 31: 36.24+17: 26: 32.4$ & 59.1 & dEn: & dwarf & & & $\ldots$ & $\ldots$ & $\ldots$ & 3 & bad \\
\hline LSBC F620-V03 & $04: 31: 56.00+14: 47: 10.0$ & $\ldots$ & $\mathrm{dI}$ & dwarf & & & $\ldots$ & $\ldots$ & $\ldots$ & $\ldots$ & bad \\
\hline LSBC F558-01 & $07: 02: 41.55+20: 40: 44.9$ & $\ldots$ & $\mathrm{Sbc}$ & spiral & & & $\ldots$ & $\ldots$ & $\ldots$ & $\ldots$ & bad \\
\hline LSBC F558-02 & $07: 03: 33.44+20: 10: 31.9$ & $\ldots$ & $\mathrm{Sbc}$ & spiral & & & $\ldots$ & $\ldots$ & $\ldots$ & $\ldots$ & bad \\
\hline NGC 2418 & $07: 36: 37.51+17: 53: 02.1$ & 72.0 & $\mathrm{E}$ & interacting pair & & & -22.75 & 0.87 & 11.14 & 4 & not used \\
\hline LSBC F702-V01 & $07: 37: 57.74+10: 11: 35.6$ & 144.3 & S: & spiral & & & -21.99 & 0.89 & 10.86 & 1 & good \\
\hline LSBC F702-01 & $07: 42: 27.57+09: 22: 10.1$ & $\ldots$ & $\mathrm{E} / \mathrm{cD}$ & no SDSS galaxy & & & & & & & not used \\
\hline
\end{tabular}


Table 1:-continued.

\begin{tabular}{|c|c|c|c|c|c|c|c|c|c|c|c|}
\hline galaxy name & $\begin{array}{c}\text { RA \& DEC } \\
(\mathrm{J} 2000.0)\end{array}$ & $\begin{array}{r}D \\
(\mathrm{Mpc})\end{array}$ & $\begin{array}{l}\text { morphology } \\
\text { [NED] }\end{array}$ & class & $\begin{array}{c}\text { HI flux } \\
(\mathrm{Jy} \mathrm{km} / \mathrm{s})\end{array}$ & $\begin{array}{c}\log \left(M_{\mathrm{HI}}\right) \\
\left(M_{\odot}\right)\end{array}$ & $\begin{array}{c}M_{\mathrm{r}} \\
(\mathrm{mag})\end{array}$ & $\begin{array}{r}(g-r) \\
(\mathrm{mag})\end{array}$ & $\begin{array}{r}\log \left(M_{\star}\right) \\
\left(M_{\odot}\right)\end{array}$ & Iso & Flag $^{*}$ \\
\hline LSBC F702-02 & $07: 44: 10.77+09: 14: 03.9$ & 253.1 & $\mathrm{E}-\mathrm{p}-/ \mathrm{LSB}$ halo & $\ldots$ & & & $\ldots$ & $\ldots$ & $\ldots$ & $\ldots$ & not used \\
\hline LSBC F560-04 & $07: 46: 18.60+18: 22: 07.3$ & 225.9 & BrClG;E-p-/shells & lenticular & & & -23.79 & 0.85 & 11.53 & $\ldots$ & not used \\
\hline LSBC F560-02 & $07: 49: 19.52+21: 49: 59.8$ & $\ldots$ & $\mathrm{E}$ & lenticular & & & $\ldots$ & 0.84 & $\ldots$ & $\ldots$ & not used \\
\hline LSBC F560-03 & $07: 54: 34.02+20: 03: 42.8$ & $\ldots$ & $\mathrm{Sb}$ & spiral & & & $\ldots$ & 0.55 & $\ldots$ & $\ldots$ & good \\
\hline LSBC F561-03 & $08: 12: 51.69+19: 38: 07.9$ & $\ldots$ & $\mathrm{S} 0 / \mathrm{Sa}$ & lenticular & & & $\ldots$ & 0.70 & $\ldots$ & $\ldots$ & not used \\
\hline UGC 4288 & $08: 14: 35.84+19: 21: 07.6$ & 431.5 & S0 & high redshift & & & -22.41 & 0.42 & 10.41 & $\ldots$ & not used \\
\hline LSBC F634-V01 & $09: 03: 25.85+15: 38: 37.7$ & $\ldots$ & $\mathrm{Im}$ & interacting pair & & & $\ldots$ & 0.80 & $\ldots$ & $\ldots$ & not used \\
\hline 0910-0157 & $09: 13: 31.73-02: 10: 00.6$ & 115.4 & $\mathrm{Sc}$ & spiral & & & -18.79 & 0.38 & 8.90 & 1 & good \\
\hline NGC 2802 & $09: 16: 41.43+18: 57: 48.5$ & 124.8 & S? & spiral & & & -21.53 & 0.80 & 10.56 & 12 & good \\
\hline NGC 2803 & $09: 16: 43.87+18: 57: 16.5$ & 127.2 & S? & spiral & & & -22.03 & 0.85 & 10.83 & 11 & good \\
\hline $0914+0241$ & $09: 17: 20.82+02: 28: 44.0$ & 276.3 & Irr & irregular & & & -17.29 & 0.86 & 8.94 & $\ldots$ & good \\
\hline 0918-0104 & 09:21:03.56 -01:17:08.2 & $\ldots$ & Scd & spiral & & & $\ldots$ & 0.22 & $\ldots$ & $\ldots$ & good \\
\hline LSBC F635-01 & $09: 22: 30.75+13: 20: 45.1$ & $\ldots$ & E/LSB halo & position is off & & & $\ldots$ & 0.78 & $\ldots$ & $\ldots$ & not used \\
\hline 0920-0042 & 09:22:49.79-00:55:10.5 & $\ldots$ & $\mathrm{Sdm}$ & irregular & & & $\ldots$ & 0.10 & $\ldots$ & $\ldots$ & good \\
\hline LSBC F635-02 & 09:30:05.46 +13:58:21.4 & 219.6 & Irr & spiral & & & -22.69 & 0.86 & 11.11 & $\ldots$ & good \\
\hline LSBC F637-01 & 09:56:06.14 +16:30:57.4 & $\ldots$ & $\mathrm{SBc} / \mathrm{E}$ comp & spiral & & & $\ldots$ & 0.34 & $\ldots$ & $\ldots$ & good \\
\hline $0954+0125$ & $09: 57: 12.87+01: 11: 14.2$ & $\ldots$ & dI & dwarf & & & $\ldots$ & 0.51 & $\ldots$ & $\ldots$ & good \\
\hline 0954-0226 & 09:57:19.71 -02:40:45.7 & $\ldots$ & $\mathrm{Sbc}$ & spiral & & & $\ldots$ & 0.39 & $\ldots$ & $\ldots$ & good \\
\hline LSBC F637-02 & $09: 57: 46.04+13: 45: 16.0$ & $\ldots$ & dI & dwarf & & & $\ldots$ & 0.68 & $\ldots$ & $\ldots$ & good \\
\hline $0955+0145$ & 09:58:06.01 +01:30:49.2 & 42.8 & $\mathrm{Sbc}$ & spiral & & & -15.02 & 0.22 & 7.19 & 1 & good \\
\hline 0956-0034 & 09:59:28.64 -00:48:44.0 & $\ldots$ & Irr & no SDSS galaxy & & & & & & & not used \\
\hline 0956-0105 & 09:59:31.38 -01:19:37.8 & 197.9 & $\mathrm{Sbc}$ & spiral & & & -20.70 & 0.28 & 9.54 & $\ldots$ & good \\
\hline $0957+0049$ & $09: 59: 39.43+00: 35: 09.7$ & 282.3 & interacting & interacting & & & -22.39 & 0.69 & 10.75 & $\ldots$ & not used \\
\hline $1006-0120$ & 10:08:43.79-01:35:34.1 & $\ldots$ & $\mathrm{Sd}$ & spiral & & & $\ldots$ & 0.52 & $\ldots$ & $\ldots$ & good \\
\hline $1008+0208$ & $10: 10: 57.64+01: 53: 52.3$ & $\ldots$ & $\mathrm{Sd}$ & irregular & & & $\ldots$ & 0.72 & $\ldots$ & $\ldots$ & good \\
\hline $1010-0159$ & $10: 12: 35.43-02: 14: 21.5$ & 83.8 & $\mathrm{Sd}$ & spiral & & & -18.18 & 0.35 & 8.63 & 12 & good \\
\hline LSBC F638-V01 & $10: 14: 48.67+14: 25: 00.1$ & 124.4 & $\mathrm{Sm} / \mathrm{Im}$ & spiral & & & -18.26 & 0.46 & 8.80 & 10 & good \\
\hline $1013-0232$ & $10: 16: 04.02-02: 47: 53.8$ & $\ldots$ & $\mathrm{Sm}$ & spiral & & & $\ldots$ & 0.10 & $\ldots$ & $\ldots$ & good \\
\hline LSBC F638-V02 & $10: 18: 35.40+14: 51: 07.3$ & 306.7 & S/Malin-like & lenticular & & & -23.00 & 0.96 & 11.37 & $\ldots$ & not used \\
\hline $1016-0257$ & $10: 19: 12.84-03: 12: 51.5$ & 129.8 & Sc & spiral & & & -19.22 & 0.61 & 9.39 & 5 & good \\
\hline $1017-0110$ & $10: 20: 10.57-01: 25: 15.1$ & 196.1 & $\mathrm{Sc}$ & $\ldots$ & & & -17.72 & 0.22 & 8.26 & $\ldots$ & not used \\
\hline $1019+0126$ & $10: 22: 27.29+01: 11: 27.5$ & $\ldots$ & $\mathrm{dE}$ & dwarf & & & $\ldots$ & -0.70 & $\ldots$ & .. & good \\
\hline NGC 3226 & $10: 23: 27.01+19: 53: 54.7$ & 18.8 & E2: pec & lenticular & & & -20.14 & 0.81 & 10.02 & 35 & not used \\
\hline $1021+0143$ & $10: 24: 09.61+01: 28: 02.1$ & 1268.4 & $\mathrm{Sc}$ & high redshift & & & -22.82 & 1.31 & 11.75 & $\ldots$ & not used \\
\hline $1023-0224$ & $10: 25: 33.06-02: 39: 35.8$ & 1128.9 & $\mathrm{Sd}$ & high redshift & & & -22.42 & 0.66 & 10.73 & $\ldots$ & not used \\
\hline $1023-0159$ & $10: 25: 38.23-02: 14: 38.9$ & $\ldots$ & $\mathrm{Sbc}$ & spiral & & & $\ldots$ & 0.16 & $\ldots$ & $\ldots$ & good \\
\hline $1024+0025$ & $10: 26: 59.61+00: 10: 28.1$ & $\ldots$ & Scd & $\ldots$ & & & $\ldots$ & 0.36 & $\ldots$ & $\ldots$ & not used \\
\hline $1025-0040$ & $10: 27: 41.38-00: 56: 09.2$ & 170.5 & dEn & dwarf & & & -14.30 & 1.81 & 9.00 & $\ldots$ & good \\
\hline $1028-0137$ & $10: 30: 40.40-01: 53: 07.4$ & 127.1 & $\mathrm{Sc}$ & spiral & & & -19.86 & 0.36 & 9.31 & 5 & good \\
\hline $1029-0040$ & $10: 31: 35.13-00: 56: 24.5$ & 142.2 & $\mathrm{Sc}$ & spiral & & & -20.01 & 0.51 & 9.57 & 4 & good \\
\hline $1031-0024$ & $10: 33: 39.73-00: 39: 39.9$ & 134.9 & $\mathrm{Sc}$ & spiral & & & -19.06 & 0.31 & 8.93 & 7 & good \\
\hline $1036+0148$ & $10: 38: 48.14+01: 32: 24.2$ & 466.8 & $S$ & high redshift & & & -20.81 & 0.28 & 9.59 & $\ldots$ & not used \\
\hline
\end{tabular}


Table 1:-continued

\begin{tabular}{|c|c|c|c|c|c|c|c|c|c|c|c|}
\hline galaxy name & $\begin{array}{c}\text { RA \& DEC } \\
(\mathrm{J} 2000.0)\end{array}$ & $\begin{array}{r}D \\
(\mathrm{Mpc})\end{array}$ & $\begin{array}{l}\text { morphology } \\
\text { [NED] }\end{array}$ & class & $\begin{array}{c}\text { HI flux } \\
\text { (Jy km/s) }\end{array}$ & $\begin{array}{c}\log \left(M_{\mathrm{HI}}\right) \\
\left(M_{\odot}\right)\end{array}$ & $\begin{array}{c}M_{\mathrm{r}} \\
(\mathrm{mag})\end{array}$ & $\begin{array}{r}(g-r) \\
(\mathrm{mag})\end{array}$ & $\begin{array}{r}\log \left(M_{\star}\right) \\
\left(M_{\odot}\right)\end{array}$ & Iso & Flag* \\
\hline $1040-0236$ & $10: 43: 05.53-02: 52: 14.5$ & $\ldots$ & $\mathrm{Sm}$ & $\ldots$ & & & $\ldots$ & 0.34 & $\ldots$ & $\ldots$ & not used \\
\hline $1040-0038$ & $10: 43: 30.92-00: 53: 56.3$ & 162.7 & $\mathrm{Sdm}$ & $\ldots$ & & & -14.22 & -0.20 & 6.28 & $\ldots$ & not used \\
\hline $1042-0242$ & $10: 45: 27.29-02: 57: 53.1$ & 110.5 & $\mathrm{Sm}$ & dwarf & & & -17.33 & 0.22 & 8.11 & 1 & good \\
\hline $1050+0021$ & $10: 53: 06.02+00: 05: 25.3$ & $\ldots$ & $\mathrm{Sdm}$ & irregular & & & $\ldots$ & 0.26 & $\ldots$ & $\ldots$ & good \\
\hline $1051+0201$ & $10: 53: 44.33+01: 45: 22.7$ & 160.6 & $\mathrm{Sbc}$ & dwarf & & & -18.12 & 0.34 & 8.59 & $\ldots$ & good \\
\hline $1056-0111$ & $10: 59: 24.59-01: 27: 33.1$ & 163.3 & $\mathrm{Sm}$ & spiral & & & -17.52 & 0.57 & 8.65 & $\ldots$ & good \\
\hline LSBC F640-V03 & $11: 00: 52.00+13: 52: 52.0$ & $\ldots$ & $\mathrm{dE}:$ & dwarf & & & $\ldots$ & 0.71 & $\ldots$ & $\ldots$ & good \\
\hline $1104+0026$ & $11: 07: 00.47+00: 10: 22.3$ & 162.1 & $\mathrm{Sm}$ & spiral & & & -18.63 & 0.32 & 8.77 & $\ldots$ & good \\
\hline $1104+0038$ & $11: 07: 08.46+00: 21: 52.4$ & $\ldots$ & $\mathrm{dEn}$ & dwarf & & & $\ldots$ & -0.40 & $\ldots$ & $\ldots$ & good \\
\hline UGC 6175 & $11: 07: 20.20+18: 25: 52.0$ & 117.3 & DBL SYS & position is off & & & -21.03 & 0.84 & 10.42 & 6 & not used \\
\hline $1105-0240$ & 11:08:03.39-02:57:15.7 & 140.0 & $\mathrm{Sc}$ & spiral & & & -19.20 & 0.39 & 9.08 & 8 & good \\
\hline $1105-0204$ & $11: 08: 16.79-02: 20: 57.9$ & 200.0 & Sc & spiral & & & -18.81 & 0.29 & 8.80 & $\ldots$ & good \\
\hline $1106-0200$ & 11:09:03.41 -02:17:10.7 & 169.6 & $\mathrm{Sbc}$ & spiral & & & -19.12 & 0.36 & 9.01 & $\ldots$ & good \\
\hline $1107+0053$ & $11: 10: 29.38+00: 36: 57.4$ & 860.8 & $\mathrm{dI}$ & high redshift & & & -21.57 & 0.88 & 10.69 & $\ldots$ & not used \\
\hline $1108-0003$ & $11: 10: 56.99-00: 19: 47.5$ & $\ldots$ & $\mathrm{Sm}$ & irregular & & & $\ldots$ & 0.25 & $\ldots$ & $\ldots$ & good \\
\hline $1109-0255$ & $11: 12: 23.07-03: 11: 55.7$ & 341.8 & Irr & irregular & & & -21.71 & 0.43 & 10.14 & $\ldots$ & good \\
\hline LSBC F640-V04 & $11: 12: 31.68+16: 17: 22.7$ & 17.9 & $\mathrm{dE}$ & dwarf & & & -15.35 & 0.63 & 7.86 & 66 & bad \\
\hline LSBC F570-04 & $11: 12: 57.30+18: 45: 41.7$ & 11.2 & Sc & spiral & & & -15.01 & 0.61 & 7.70 & 95 & good \\
\hline NGC 3599 & $11: 15: 26.96+18: 06: 37.4$ & 12.0 & SA0: & lenticular & & & -18.39 & 0.71 & 9.19 & 92 & not used \\
\hline LSBC F570-06 & $11: 17: 38.20+17: 49: 05.1$ & 18.5 & $\mathrm{SB} 0 / \mathrm{p}$ & spiral & & & -16.83 & 0.66 & 8.50 & 61 & good \\
\hline LSBC F570-01 & $11: 17: 57.89+22: 30: 10.8$ & 111.0 & SB0: & lenticular & & & -21.34 & 0.79 & 10.48 & 2 & not used \\
\hline $1115-0042$ & $11: 18: 25.53-00: 58: 32.4$ & 202.1 & $\mathrm{Sdm}$ & spiral & & & -14.25 & -0.30 & 6.11 & $\ldots$ & good \\
\hline $1116+0303$ & $11: 19: 19.80+02: 47: 30.5$ & $\ldots$ & $\mathrm{dE}$ & dwarf & & & $\ldots$ & 0.51 & $\ldots$ & $\ldots$ & good \\
\hline $1118+0225$ & $11: 21: 09.22+02: 09: 11.1$ & $\ldots$ & $\mathrm{Sdm}$ & dwarf & & & $\ldots$ & 0.25 & $\ldots$ & $\ldots$ & good \\
\hline $1120-0216$ & $11: 23: 24.16-02: 32: 45.0$ & $\ldots$ & $\mathrm{Sbc}$ & spiral & & & $\ldots$ & 0.20 & $\ldots$ & $\ldots$ & good \\
\hline $1121-0135$ & $11: 24: 33.45-01: 51: 33.6$ & 192.5 & $\mathrm{Sbc}$ & spiral & & & -19.47 & 0.45 & 9.27 & $\ldots$ & good \\
\hline 1124-0104 & $11: 26: 33.95-01: 20: 34.6$ & 966.5 & $\mathrm{Sbc}$ & high redshift & & & -22.81 & 0.95 & 11.27 & $\ldots$ & not used \\
\hline $1124-0047$ & $11: 27: 18.85-01: 03: 35.7$ & 177.1 & $\mathrm{Sd}$ & spiral & & & -18.90 & 0.47 & 9.07 & $\ldots$ & good \\
\hline $1129+0056$ & $11: 31: 49.41+00: 40: 25.7$ & 298.5 & $\mathrm{Sc}$ & dwarf & & & -19.47 & 0.33 & 9.11 & $\ldots$ & good \\
\hline LSBC F571-07 & $11: 38: 41.53+19: 43: 52.8$ & $\ldots$ & $\mathrm{S} ?$ & no SDSS galaxy & & & & & & & not used \\
\hline NGC 3816 & $11: 41: 48.04+20: 06: 13.1$ & 82.4 & S0/a & lenticular & & & -22.25 & 0.69 & 10.71 & 43 & not used \\
\hline LSBC F571-02 & $11: 45: 17.58+21: 25: 14.3$ & 292.6 & & lenticular & & & -22.92 & 0.86 & 11.19 & $\ldots$ & not used \\
\hline $1149-0241$ & $11: 51: 37.26-02: 57: 55.3$ & 116.3 & $\mathrm{Sbc}$ & spiral & & & -18.25 & 0.53 & 8.89 & 5 & good \\
\hline $1150-0058$ & $11: 52: 51.97-01: 15: 40.7$ & 123.8 & Scd & irregular & & & -17.49 & 0.33 & 8.32 & 2 & good \\
\hline $1151+0226$ & $11: 53: 36.89+02: 09: 57.9$ & 170.1 & $\mathrm{Sd}$ & spiral & & & -18.57 & 0.25 & 8.65 & $\ldots$ & good \\
\hline $1151-0012$ & $11: 54: 12.07-00: 28: 56.7$ & 26.2 & $\mathrm{Sc}$ & dwarf & & & -14.86 & 0.34 & 7.28 & 16 & good \\
\hline $1154-0215$ & $11: 57: 07.11-02: 31: 58.8$ & 87.5 & $\mathrm{Sbc}$ & dwarf & & & -17.28 & 0.36 & 8.28 & 23 & good \\
\hline $1157-0040$ & $11: 59: 36.33-00: 57: 29.4$ & $\ldots$ & $\mathrm{Sc}$ & spiral & & & $\ldots$ & 0.42 & $\ldots$ & $\ldots$ & good \\
\hline $1157-0101$ & 12:00:05.59-01:18:35.0 & $\ldots$ & $\mathrm{dE}$ & dwarf & & & $\ldots$ & 0.31 & $\ldots$ & $\ldots$ & good \\
\hline $1158+0023$ & $12: 00: 38.13+00: 06: 37.4$ & $\ldots$ & dI & dwarf & & & $\ldots$ & 0.35 & $\ldots$ & $\ldots$ & good \\
\hline $1158+0220$ & $12: 01: 18.26+02: 03: 54.8$ & 283.9 & $\mathrm{Sc}$ & spiral & & & -19.49 & 0.41 & 9.23 & $\ldots$ & good \\
\hline $1159-0055$ & $12: 01: 40.16-01: 12: 15.3$ & $\ldots$ & $\mathrm{dE}$ & dwarf & & & $\ldots$ & 0.52 & $\ldots$ & $\ldots$ & good \\
\hline
\end{tabular}


Table 1:-continued.

\begin{tabular}{|c|c|c|c|c|c|c|c|c|c|c|c|}
\hline galaxy name & $\begin{array}{c}\text { RA \& DEC } \\
(\text { J2000.0) }\end{array}$ & $\begin{array}{r}D \\
(\mathrm{Mpc})\end{array}$ & $\begin{array}{l}\text { morphology } \\
{[\mathrm{NED}]}\end{array}$ & class & $\begin{array}{c}\text { HI flux } \\
(\mathrm{Jy} \mathrm{km} / \mathrm{s})\end{array}$ & $\begin{array}{c}\log \left(M_{\mathrm{HI}}\right) \\
\left(M_{\odot}\right) \\
\end{array}$ & $\begin{array}{c}M_{\mathrm{r}} \\
(\mathrm{mag})\end{array}$ & $\begin{array}{r}(g-r) \\
(\mathrm{mag}) \\
\end{array}$ & $\begin{array}{r}\log \left(M_{\star}\right) \\
\left(M_{\odot}\right)\end{array}$ & Iso & Flag* \\
\hline $1159+0027$ & $12: 01: 43.47+00: 10: 59.2$ & 447.1 & $\mathrm{Sc}$ & lenticular & & & -19.83 & 0.45 & 9.42 & $\ldots$ & not used \\
\hline $1201-0240$ & 12:03:41.91 -02:57:04.4 & 267.7 & Scd & spiral & & & -19.05 & 0.29 & 8.90 & $\ldots$ & good \\
\hline $1205-0215$ & 12:08:06.17 -02:31:56.1 & 110.8 & Sc & spiral & & & -19.16 & 0.40 & 9.08 & 3 & good \\
\hline $1206-0214$ & 12:09:01.79-02:31:22.6 & 242.4 & $\mathrm{Sbc}$ & spiral & & & -19.09 & 0.32 & 8.95 & $\ldots$ & good \\
\hline UGC 7137 & $12: 09: 26.90+22: 05: 36.0$ & 104.6 & DBL SYS & position is off & & & -19.23 & 0.45 & 9.18 & 11 & not used \\
\hline $1208-0300$ & $12: 11: 13.35-03: 16: 52.5$ & 754.9 & Sbc & high redshift & & & -22.36 & 1.00 & 11.15 & $\ldots$ & not used \\
\hline $1209+0136$ & $12: 12: 03.75+01: 19: 30.1$ & $\ldots$ & Sc & dwarf & & & $\ldots$ & 0.44 & $\ldots$ & $\ldots$ & good \\
\hline $1210+0115$ & $12: 12: 43.79+00: 58: 54.9$ & $\ldots$ & dIn & dwarf & & & $\ldots$ & 1.17 & $\ldots$ & $\ldots$ & good \\
\hline $1210+0130$ & $12: 12: 57.13+01: 13: 48.4$ & $\ldots$ & $\mathrm{dE}$ & dwarf & & & $\ldots$ & 0.61 & $\ldots$ & $\ldots$ & good \\
\hline $1211+0156$ & $12: 14: 06.67+01: 39: 39.8$ & $\ldots$ & dI & dwarf & & & $\ldots$ & 0.37 & $\ldots$ & $\ldots$ & good \\
\hline LSBC F644-03 & $12: 14: 11.57+15: 57: 54.5$ & $\ldots$ & $\mathrm{dE} 2$ : & dwarf & & & $\ldots$ & 0.45 & $\ldots$ & $\ldots$ & good \\
\hline $1212-0039$ & $12: 15: 26.98-00: 56: 22.7$ & 321.4 & $\mathrm{Sc}$ & lenticular & & & -19.48 & 0.54 & 9.40 & $\ldots$ & not used \\
\hline $1213-0218$ & $12: 15: 44.84-02: 35: 28.3$ & $\ldots$ & $\mathrm{Sm}$ & spiral & & & $\cdots$ & 1.22 & ... & $\ldots$ & good \\
\hline $1214-0110$ & $12: 16: 38.70-01: 27: 06.6$ & 12.7 & Irr & irregular & & & -14.28 & 0.30 & 7.00 & 23 & good \\
\hline LSBC F573-05 & $12: 17: 13.12+19: 05: 13.8$ & 190.5 & $\mathrm{~S} 0 / \mathrm{p}$ & lenticular & & & -22.20 & 0.89 & 10.94 & $\ldots$ & not used \\
\hline UGC 7346 & $12: 18: 41.78+17: 43: 08.5$ & 11.7 & $\mathrm{dE}$ & dwarf & & & -16.35 & 0.53 & 8.13 & 128 & good \\
\hline $1216-0207$ & $12: 18: 58.83-02: 24: 18.6$ & $\ldots$ & dI & no SDSS galaxy & & & & & & & not used \\
\hline $1216-0140$ & $12: 18: 59.88-01: 56: 52.6$ & $\ldots$ & $\mathrm{Sm}$ & dwarf & & & $\ldots$ & 0.44 & $\ldots$ & $\cdots$ & good \\
\hline LSBC F644-05 & $12: 19: 30.09+13: 59: 26.5$ & $\ldots$ & dE0 & dwarf & & & $\cdots$ & 0.09 & $\ldots$ & $\ldots$ & good \\
\hline LSBC F573-10 & $12: 22: 23.79+17: 01: 10.9$ & $\ldots$ & $\mathrm{dE} 4$ & dwarf & & & $\ldots$ & 0.56 & $\ldots$ & $\ldots$ & good \\
\hline 1221-0106 & $12: 24: 01.30-01: 22: 45.9$ & 105.0 & Sbc & dwarf & & & -16.46 & 0.18 & 7.71 & 4 & good \\
\hline NGC 4382 & $12: 25: 24.11+18: 11: 29.4$ & 10.4 & $\mathrm{SA}(\mathrm{s}) 0^{+}$pec & spiral & & & -19.71 & 0.56 & 9.52 & 158 & bad \\
\hline LSBC F644-04 & $12: 25: 35.98+15: 50: 52.1$ & 15.5 & dE5 & dwarf & & & -15.62 & 0.61 & 7.94 & 158 & good \\
\hline $1223-0052$ & $12: 26: 10.05-01: 09: 23.1$ & 179.8 & $\mathrm{Sa}$ & lenticular & & & -20.24 & 0.53 & 9.68 & $\ldots$ & not used \\
\hline $1224-0037$ & $12: 27: 04.56-00: 54: 23.2$ & 31.8 & $\mathrm{Sm}$ & lenticular & & & -17.33 & 0.32 & 8.25 & 21 & not used \\
\hline $1224-0145$ & $12: 27: 19.43-02: 01: 47.4$ & 675.8 & $\mathrm{Sm}$ & $\ldots$ & & & -16.94 & -1.30 & 5.90 & $\cdots$ & not used \\
\hline LSBC F573-06 & $12: 27: 38.78+18: 26: 04.4$ & 15.1 & $\mathrm{dEn}$ & dwarf & & & -16.25 & 0.58 & 8.15 & 85 & good \\
\hline $1226-0212$ & $12: 29: 12.92-02: 29: 20.3$ & 273.2 & $\mathrm{Sc}$ & lenticular & & & ... . & $\ldots$ & $\ldots$ & $\ldots$ & not used \\
\hline 1227-0101 & $12: 29: 46.24-01: 17: 42.4$ & 32.4 & Irr & irregular & & & -16.15 & 0.25 & 7.69 & 21 & good \\
\hline LSBC F574-08 & $12: 32: 36.16+18: 01: 23.0$ & 12.9 & S0/a & spiral & & & -16.23 & 0.64 & 8.22 & 110 & bad \\
\hline $1230-0005$ & $12: 33: 09.56-00: 22: 30.8$ & $\ldots$ & $\mathrm{dE}$ & dwarf & & & $\ldots$ & 0.66 & $\ldots$ & $\ldots$ & good \\
\hline UGC 7707 & $12: 33: 18.47+17: 27: 33.7$ & 16.8 & $\mathrm{dE} 4$ & dwarf & & & -15.94 & 0.60 & 8.05 & 90 & good \\
\hline LSBC F574-07 & $12: 39: 30.23+18: 22: 05.7$ & 13.5 & dS0 & spiral & & & -15.05 & 0.58 & 7.68 & 79 & good \\
\hline LSBC F574-09 & $12: 42: 20.57+17: 30: 35.1$ & 17.4 & $\mathrm{~S} 0 / \mathrm{p}$ & spiral & & & -16.60 & 0.32 & 7.96 & 44 & good \\
\hline UGC 7929 & $12: 45: 20.78+21: 25: 37.5$ & $\ldots$ & dwarf & dwarf & & & $\ldots$ & 0.49 & $\ldots$ & $\ldots$ & good \\
\hline NGC 4685 & $12: 47: 11.44+19: 27: 51.7$ & 97.0 & S0-: & lenticular & & & -22.26 & 0.78 & 10.82 & 4 & not used \\
\hline LSBC F574-06 & $12: 48: 20.23+18: 38: 19.4$ & $\cdots$ & dI & dwarf & & & $\cdots$ & 0.20 & ... & $\cdots$ & good \\
\hline $1247+0231$ & $12: 50: 07.33+02: 14: 52.6$ & 15.3 & $\mathrm{dE}$ & dwarf & & & -14.49 & 0.54 & 7.41 & 161 & good \\
\hline $1250-0058$ & $12: 52: 49.14-01: 14: 25.0$ & $\ldots$ & $\mathrm{dE}$ & high redshift & & & $\ldots$ & 1.06 & $\ldots$ & $\ldots$ & not used \\
\hline $1250+0200$ & $12: 52: 49.40+01: 44: 04.3$ & 11.9 & $\mathrm{dE}$ & dwarf & & & -13.50 & 0.58 & 7.05 & 161 & not used \\
\hline $1250-0009$ & $12: 53: 23.50-00: 25: 26.0$ & 201.7 & interacting & interacting & & & -20.83 & 0.54 & 9.93 & $\cdots$ & not used \\
\hline $1250+0212$ & $12: 53: 24.20+01: 55: 53.1$ & 12.7 & $\mathrm{dEn}$ & dwarf & & & -14.28 & 0.62 & 7.43 & 160 & good \\
\hline
\end{tabular}


Table 1:-continued

\begin{tabular}{|c|c|c|c|c|c|c|c|c|c|c|c|}
\hline galaxy name & $\begin{array}{c}\text { RA \& DEC } \\
(\mathrm{J} 2000.0)\end{array}$ & $\begin{array}{r}D \\
(\mathrm{Mpc})\end{array}$ & $\begin{array}{l}\text { morphology } \\
{[\mathrm{NED}]}\end{array}$ & class & $\begin{array}{c}\text { HI flux } \\
(\mathrm{Jy} \mathrm{km} / \mathrm{s})\end{array}$ & $\begin{array}{c}\log \left(M_{\mathrm{HI}}\right) \\
\left(M_{\odot}\right)\end{array}$ & $\begin{array}{c}M_{\mathrm{r}} \\
(\mathrm{mag})\end{array}$ & $\begin{array}{r}(g-r) \\
(\mathrm{mag})\end{array}$ & $\begin{array}{r}\log \left(M_{\star}\right) \\
\left(M_{\odot}\right)\end{array}$ & Iso & Flag* $^{*}$ \\
\hline $1251+0218$ & $12: 53: 53.05+02: 02: 00.1$ & 212.9 & dI & dwarf & & & -19.17 & 0.46 & 9.17 & $\ldots$ & good \\
\hline $1251+0010$ & $12: 54: 05.17-00: 06: 04.4$ & 13.9 & $\mathrm{dE}$ & dwarf & & & -14.93 & 0.61 & 7.66 & 133 & good \\
\hline LSBC F646-02 & $12: 56: 25.00+15: 05: 09.1$ & $\ldots$ & dwarf & dwarf & & & $\ldots$ & 1.70 & $\ldots$ & $\ldots$ & good \\
\hline $1254-0015$ & $12: 56: 35.47-00: 31: 40.2$ & $\ldots$ & dI & dwarf & & & $\ldots$ & 0.07 & $\ldots$ & .. & good \\
\hline $1258-0145$ & 13:00:59.63-02:01:08.4 & $\ldots$ & dI & dwarf & & & $\ldots$ & 0.36 & $\ldots$ & .. & good \\
\hline LSBC F575-01 & $13: 02: 41.87+21: 59: 50.6$ & $\ldots$ & IB?m V & irregular & & & $\ldots$ & 0.55 & $\ldots$ & $\ldots$ & good \\
\hline $1300+0228$ & $13: 02: 54.84+02: 12: 06.8$ & $\ldots$ & $\mathrm{dE}$ & dwarf & & & $\ldots$ & 1.71 & $\ldots$ & .. & good \\
\hline LSBC F508-01 & $13: 02: 57.62+26: 04: 39.9$ & $\ldots$ & dI & dwarf & & & $\ldots$ & 0.60 & $\ldots$ & $\ldots$ & good \\
\hline $1301-0143$ & 13:04:16.50-02:00:01.6 & $\ldots$ & Scd & spiral & & & $\ldots$ & 0.46 & $\ldots$ & $\ldots$ & good \\
\hline LSBC F575-04 & $13: 04: 29.91+17: 45: 32.1$ & $\ldots$ & $\mathrm{dE}$ & dwarf & & & $\ldots$ & 0.55 & $\ldots$ & $\ldots$ & good \\
\hline $1303-0125$ & $13: 05: 42.16-01: 41: 41.4$ & $\ldots$ & $\mathrm{Sc}$ & irregular & & & $\ldots$ & 0.56 & $\ldots$ & $\ldots$ & good \\
\hline $1304+0054$ & $13: 06: 38.41+00: 38: 40.2$ & $\ldots$ & dI & no SDSS galaxy & & & & & & & not used \\
\hline LSBC F508-02 & $13: 06: 58.98+22: 44: 14.9$ & 148.6 & Sb-p- & spiral & & & -21.76 & 0.74 & 10.57 & 4 & good \\
\hline $1309+0229$ & $13: 11: 34.37+02: 13: 21.9$ & 323.8 & $\mathrm{Sd}$ & dwarf & & & -19.15 & 0.71 & 9.49 & $\ldots$ & good \\
\hline $1309-0035$ & $13: 11: 53.88-00: 51: 30.3$ & $\ldots$ & $\mathrm{Sbc}$ & spiral & & & $\ldots$ & 0.43 & $\ldots$ & $\ldots$ & good \\
\hline $1310+0013$ & $13: 12: 44.92-00: 02: 24.0$ & 126.0 & dEn & dwarf & & & -19.21 & 0.40 & 9.11 & 1 & good \\
\hline IC 858 & $13: 14: 51.94+17: 13: 36.4$ & 98.1 & S0? & lenticular & & & -22.04 & 0.82 & 10.79 & 14 & not used \\
\hline $1317+0128$ & $13: 19: 57.24+01: 12: 47.2$ & $\ldots$ & dI & dwarf & & & $\ldots$ & 0.73 & $\ldots$ & $\ldots$ & good \\
\hline $1319+0200$ & $13: 21: 43.41+01: 45: 16.9$ & $\ldots$ & interacting & interacting & & & $\ldots$ & 0.02 & $\ldots$ & $\ldots$ & not used \\
\hline $1321+0118$ & $13: 23: 45.23+01: 02: 31.4$ & 455.2 & $\mathrm{Sc}$ & high redshift & & & -22.64 & 0.58 & 10.71 & $\ldots$ & not used \\
\hline $1325-0205$ & $13: 27: 54.98-02: 21: 02.4$ & 50.1 & $\mathrm{Sc}$ & spiral & & & -15.60 & 0.07 & 7.23 & 12 & good \\
\hline $1327-0141$ & $13: 30: 16.48-01: 56: 55.2$ & $\ldots$ & $\mathrm{Sdm}$ & dwarf & & & $\ldots$ & 0.29 & $\ldots$ & $\ldots$ & good \\
\hline 1329-0106 & $13: 32: 26.96-01: 22: 12.4$ & 54.0 & $\mathrm{dEn}$ & dwarf & & & -16.92 & 0.31 & 8.07 & 10 & good \\
\hline LSBC F577-01 & $13: 43: 35.07+18: 03: 23.7$ & 112.9 & Ep & lenticular & & & -21.73 & 0.82 & 10.66 & 13 & not used \\
\hline UGC 8691 & $13: 44: 25.00+20: 24: 50.0$ & 116.9 & S? & spiral & & & -20.80 & 0.80 & 10.27 & 8 & good \\
\hline $1351-0103$ & $13: 53: 46.47-01: 18: 28.5$ & 105.4 & $\mathrm{dE}$ & dwarf & & & -18.46 & 0.37 & 8.77 & 8 & good \\
\hline $1352-0131$ & $13: 54: 39.10-01: 45: 47.1$ & 220.6 & $\mathrm{dE}$ & dwarf & & & -19.39 & 0.37 & 9.14 & $\ldots$ & good \\
\hline $1353+0156$ & $13: 55: 43.17+01: 42: 12.6$ & 209.3 & dI & dwarf & & & -19.40 & 0.44 & 9.24 & $\ldots$ & good \\
\hline $1353-0153$ & $13: 56: 33.69-02: 07: 45.0$ & 614.1 & $\mathrm{Sbc}$ & high redshift & & & -22.06 & 0.82 & 10.79 & $\ldots$ & not used \\
\hline $1354-0100$ & $13: 56: 49.42-01: 15: 22.5$ & 805.7 & $\mathrm{Sm}$ & high redshift & & & -22.74 & 0.73 & 10.95 & $\ldots$ & not used \\
\hline $1354-0051$ & $13: 56: 58.18-01: 06: 06.2$ & 130.9 & $\mathrm{Sc}$ & spiral & & & -19.03 & 0.41 & 9.05 & 4 & good \\
\hline $1358-0228$ & $14: 01: 26.66-02: 42: 45.9$ & 127.4 & $\mathrm{Sm}$ & spiral & & & -20.50 & 0.41 & 9.63 & 1 & good \\
\hline 1359-0106 & $14: 01: 53.80-01: 20: 34.4$ & 107.6 & dI & dwarf & & & -16.17 & -1.20 & 5.77 & 9 & good \\
\hline $1404+0226$ & $14: 07: 21.02+02: 12: 37.4$ & $\ldots$ & $\mathrm{Sbc}$ & spiral & & & $\ldots$ & 0.29 & $\ldots$ & $\ldots$ & good \\
\hline $1408-0023$ & $14: 10: 59.75-00: 37: 52.5$ & 140.0 & $\mathrm{Sbc}$ & spiral & & & -18.15 & 0.29 & 8.53 & 2 & good \\
\hline $1408+0056$ & $14: 11: 30.06+00: 41: 59.9$ & 227.8 & & spiral & & & -19.38 & 0.30 & 9.04 & $\ldots$ & good \\
\hline $1409-0049$ & $14: 11: 40.70-01: 03: 07.8$ & 103.8 & & spiral & & & -18.08 & 0.21 & 8.39 & 13 & good \\
\hline UGC 9087 & $14: 12: 16.83+18: 17: 58.1$ & 73.3 & S0? & spiral & & & -20.96 & 0.91 & 10.48 & 10 & good \\
\hline $1409-0020$ & $14: 12: 18.10-00: 34: 09.5$ & $\ldots$ & dI & dwarf & & & $\ldots$ & 0.26 & $\ldots$ & $\ldots$ & good \\
\hline LSBC F578-01 & $14: 12: 39.58+20: 23: 13.2$ & 122.3 & $\mathrm{E} / \mathrm{S} 0$ & lenticular & & & -22.03 & 0.83 & 10.81 & 7 & not used \\
\hline NGC 5513 & $14: 13: 08.63+20: 24: 58.6$ & 71.3 & So & lenticular & & & -22.11 & 0.73 & 10.69 & 14 & not used \\
\hline $1428-0226$ & $14: 31: 27.20-02: 40: 09.0$ & 104.9 & $\mathrm{Sd}$ & spiral & & & -18.20 & 0.31 & 8.58 & 1 & good \\
\hline
\end{tabular}


Table 1:-continued.

\begin{tabular}{|c|c|c|c|c|c|c|c|c|c|c|c|}
\hline galaxy name & $\begin{array}{c}\text { RA \& DEC } \\
(\text { J2000.0) }\end{array}$ & $\begin{array}{r}D \\
(\mathrm{Mpc})\end{array}$ & $\begin{array}{l}\text { morphology } \\
\text { [NED] }\end{array}$ & class & $\begin{array}{c}\text { HI flux } \\
(\mathrm{Jy} \mathrm{km} / \mathrm{s})\end{array}$ & $\begin{array}{c}\log \left(M_{\mathrm{HI}}\right) \\
\left(M_{\odot}\right) \\
\end{array}$ & $\begin{array}{c}M_{\mathrm{r}} \\
(\mathrm{mag})\end{array}$ & $\begin{array}{r}(g-r) \\
(\mathrm{mag}) \\
\end{array}$ & $\begin{array}{r}\log \left(M_{\star}\right) \\
\left(M_{\odot}\right)\end{array}$ & Iso & Flag* \\
\hline $1430+0214$ & $14: 33: 11.64+02: 01: 29.8$ & 483.7 & $\mathrm{Sc}$ & high redshift & & & -21.79 & 1.07 & 11.02 & $\ldots$ & not used \\
\hline $1430-0049$ & $14: 33: 21.43-01: 03: 04.3$ & 127.3 & Scd & spiral & & & -18.18 & 0.44 & 8.74 & 1 & good \\
\hline LSBC F579-04 & $14: 33: 46.66+18: 51: 54.0$ & 326.4 & dI: & $\ldots$ & & & -22.43 & 0.96 & 11.13 & $\ldots$ & not used \\
\hline $1432+0214$ & $14: 34: 43.48+02: 01: 02.1$ & $\ldots$ & Sc & dwarf & & & $\ldots$ & 0.22 & $\ldots$ & $\ldots$ & good \\
\hline $1433+0255$ & $14: 35: 36.57+02: 42: 22.7$ & $\ldots$ & dI & dwarf & & & $\ldots$ & 0.26 & $\ldots$ & $\ldots$ & good \\
\hline $1434+0020$ & $14: 36: 38.63+00: 07: 02.6$ & 127.7 & dEn & dwarf & & & -19.29 & 0.49 & 9.26 & 6 & good \\
\hline LSBC F580-05 & $14: 36: 53.38+18: 19: 16.5$ & $\ldots$ & $\mathrm{S} 0 / \mathrm{Sa}$ & no SDSS galaxy & & & & & & & not used \\
\hline $1434+0155$ & $14: 37: 16.68+01: 42: 27.9$ & $\ldots$ & Sc & spiral & & & $\ldots$ & 0.34 & $\ldots$ & $\ldots$ & good \\
\hline $1434-0221$ & $14: 37: 28.72-02: 34: 26.2$ & 109.1 & $\mathrm{Sb}$ & spiral & & & -18.32 & 0.36 & 8.70 & 2 & good \\
\hline $1434-0055$ & 14:37:29.91-01:08:31.1 & 60.3 & $\mathrm{dE}$ & dwarf & & & -16.54 & 0.24 & 7.82 & 1 & good \\
\hline $1435-0129$ & $14: 37: 51.25-01: 42: 31.4$ & $\ldots$ & dI & no SDSS galaxy & & & & & & & not used \\
\hline $1435-0118$ & $14: 38: 04.21-01: 31: 19.7$ & $\ldots$ & $\mathrm{Sdm}$ & no SDSS galaxy & & & & & & & not used \\
\hline LSBC F580-06 & $14: 39: 58.10+21: 35: 49.1$ & 132.8 & $\mathrm{Sc} / \mathrm{p}$ & spiral & & & -20.61 & 0.84 & 10.24 & 1 & good \\
\hline LSBC F580-03 & $14: 41: 20.00+19: 06: 00.9$ & $\ldots$ & $\mathrm{Sb}(\mathrm{r})$ & no SDSS galaxy & & & & & & & not used \\
\hline LSBC F723-V03 & $14: 44: 27.10+12: 24: 31.0$ & $\ldots$ & Im & no SDSS galaxy & & & & & & & not used \\
\hline $1443+0209$ & $14: 45: 40.10+01: 57: 16.0$ & $\ldots$ & $\mathrm{dE}$ & dwarf & & & $\ldots$ & $\ldots$ & $\ldots$ & $\ldots$ & bad \\
\hline $1443-0052$ & $14: 46: 20.63-01: 05: 20.1$ & 124.3 & $\operatorname{Irr}(\mathrm{sa})$ & interacting & & & -18.19 & 0.04 & 8.11 & 3 & not used \\
\hline $1443-0138$ & $14: 46: 30.74-01: 51: 28.0$ & 126.3 & dIn & dwarf & & & -18.32 & 0.09 & 8.34 & 3 & good \\
\hline $1443+0058$ & $14: 46: 31.77+00: 45: 36.0$ & 889.9 & $\mathrm{Sc}$ & high redshift & & & -22.94 & 0.99 & 11.37 & $\ldots$ & not used \\
\hline $1444-0210$ & $14: 47: 02.37-02: 23: 07.3$ & 126.9 & $\mathrm{Sm}$ & spiral & & & -18.88 & 0.29 & 8.82 & 2 & good \\
\hline UGC 9532 & $14: 47: 55.25+19: 03: 26.9$ & 180.3 & Compact Group & position is off & & & -21.49 & 0.88 & 10.65 & $\ldots$ & not used \\
\hline $1446-0041$ & $14: 49: 09.35-00: 54: 10.2$ & 118.3 & Sc & spiral & & & -20.00 & 0.38 & 9.40 & 10 & good \\
\hline $1446-0121$ & $14: 49: 23.16-01: 33: 34.8$ & $\ldots$ & dIn & dwarf & & & $\ldots$ & 0.06 & ... & $\ldots$ & good \\
\hline $1449+0100$ & $14: 52: 16.45+00: 48: 14.7$ & 908.0 & & high redshift & & & -22.64 & 0.91 & 11.15 & $\ldots$ & not used \\
\hline $1450+0230$ & $14: 53: 25.26+02: 18: 11.0$ & 116.5 & Sbc & spiral & & & -18.21 & 0.29 & 8.56 & 5 & good \\
\hline $1451-0055$ & $14: 54: 23.87-01: 07: 47.4$ & 99.3 & $\mathrm{IB}(\mathrm{s}) \mathrm{m}$ & spiral & & & -18.16 & -0.30 & 7.74 & 2 & good \\
\hline LSBC F581-02 & $14: 56: 50.29+19: 55: 47.1$ & 256.5 & SOp & lenticular & & & -22.00 & 0.86 & 10.82 & $\ldots$ & not used \\
\hline LSBC F507-V01 & $15: 20: 57.42+24: 48: 51.5$ & $\ldots$ & $\mathrm{Sm}$ & no SDSS galaxy & & & & & & & not used \\
\hline LSBC F582-01 & $15: 30: 37.16+22: 52: 24.3$ & $\ldots$ & Sbc & no SDSS galaxy & & & & & & & not used \\
\hline LSBC F507-V02 & $15: 33: 20.60+24: 05: 45.8$ & $\ldots$ & $\mathrm{dI} / \mathrm{Im}$ & no SDSS galaxy & & & & & & & not used \\
\hline UGC 9927 & $15: 36: 27.77+22: 30: 01.8$ & 61.8 & SB0 & lenticular & & & -20.72 & 0.73 & 10.14 & 1 & not used \\
\hline LSBC F507-V03 & $15: 39: 54.58+26: 25: 27.1$ & $\ldots$ & dI & no SDSS galaxy & & & & & & & not used \\
\hline UGC 10049 & $15: 49: 17.23+21: 49: 41.9$ & 150.1 & S0? & irregular & & & -15.23 & 0.05 & 6.92 & 6 & good \\
\hline UGC 10050 & $15: 49: 44.91+18: 31: 36.9$ & 59.0 & S0 & lenticular & & & -20.94 & 0.66 & 10.14 & 7 & not used \\
\hline LSBC F515-01 & $15: 49: 46.97+26: 35: 50.9$ & $\cdots$ & $\mathrm{S}(\mathrm{r})$ & no SDSS galaxy & & & & & & & not used \\
\hline LSBC F583-03 & $15: 51: 33.93+20: 12: 03.3$ & $\ldots$ & $\mathrm{S} 0 / \mathrm{p}$ & high redshift & & & & & & & not used \\
\hline LSBC F727-V01 & $15: 51: 40.52+08: 52: 26.1$ & 302.1 & $\mathrm{Sc}$ & spiral & & & -21.36 & 0.80 & 10.49 & $\ldots$ & good \\
\hline LSBC F515-02 & $15: 58: 22.67+23: 48: 36.0$ & 243.9 & S: & spiral & & & -16.33 & 1.47 & 9.36 & $\ldots$ & bad \\
\hline NGC 6027 & $15: 59: 12.54+20: 45: 48.1$ & 63.5 & S0 pec & merger & & & -20.73 & 0.77 & 10.19 & 16 & not used \\
\hline LSBC F515-V01 & $16: 01: 52.77+26: 30: 18.2$ & $\ldots$ & ring & high redshft & & & $\ldots$ & 0.96 & $\ldots$ & $\ldots$ & not used \\
\hline LSBC F585-V01 & $16: 25: 57.37+20: 39: 33.6$ & 28.4 & dI & dwarf & & & -15.02 & 0.08 & 7.01 & 5 & good \\
\hline LSBC F728-02 & $16: 29: 01.60+11: 22: 36.6$ & $\ldots$ & Sm/ring & spiral & & & $\ldots$ & 0.78 & $\ldots$ & $\ldots$ & good \\
\hline
\end{tabular}


Table 1:-continued

\begin{tabular}{|c|c|c|c|c|c|c|c|c|c|c|c|}
\hline galaxy name & $\begin{array}{c}\text { RA \& DEC } \\
(\mathrm{J} 2000.0)\end{array}$ & $\begin{array}{r}D \\
(\mathrm{Mpc})\end{array}$ & $\begin{array}{l}\text { morphology } \\
\text { [NED] }\end{array}$ & class & $\begin{array}{c}\text { HI flux } \\
(\mathrm{Jy} \mathrm{km} / \mathrm{s})\end{array}$ & $\begin{array}{c}\log \left(M_{\mathrm{HI}}\right) \\
\left(M_{\odot}\right)\end{array}$ & $\begin{array}{c}M_{\mathrm{r}} \\
(\mathrm{mag})\end{array}$ & $\begin{array}{r}(g-r) \\
(\mathrm{mag})\end{array}$ & $\begin{array}{r}\log \left(M_{\star}\right) \\
\left(M_{\odot}\right)\end{array}$ & Iso & Flag* $^{*}$ \\
\hline LSBC F728-V03 & $16: 31: 27.19+11: 12: 29.3$ & & ring & spiral & & & $\ldots$ & 0.51 & $\ldots$ & $\ldots$ & good \\
\hline LSBC F585-01 & $16: 33: 01.62+22: 47: 50.6$ & 155.2 & E/S0 & lenticular & & & -22.69 & 0.94 & 11.21 & $\ldots$ & not used \\
\hline LSBC F657-01 & $16: 38: 15.46+14: 16: 28.1$ & 373.8 & Irr & $\ldots$ & & & -21.83 & 0.81 & 10.70 & $\ldots$ & not used \\
\hline LSBC F657-02 & $16: 47: 55.90+15: 26: 50.0$ & $\ldots$ & $\mathrm{Sc}$ & spiral & & & $\ldots$ & 0.82 & $\ldots$ & .. & bad \\
\hline LSBC F730-01 & $16: 56: 36.43+08: 46: 21.3$ & $\ldots$ & $\mathrm{dI} / \mathrm{dE}$ & dwarf & & & $\ldots$ & $\ldots$ & $\ldots$ & $\ldots$ & bad \\
\hline LSBC F730-V01 & $17: 03: 55.90+10: 10: 48.0$ & 153.1 & $\mathrm{Sm}$ & spiral & & & -20.12 & 0.48 & 9.57 & $\ldots$ & good \\
\hline LSBC F519-01 & $17: 18: 46.09+26: 25: 56.4$ & $\ldots$ & E/S0 & position is off & & & $\ldots$ & 1.00 & $\ldots$ & $\ldots$ & not used \\
\hline LSBC F519-02 & $17: 22: 32.52+25: 57: 35.2$ & $\ldots$ & $\mathrm{Sc}$ & spiral & & & $\ldots$ & 0.81 & $\ldots$ & $\ldots$ & good \\
\hline LSBC F520-01 & $17: 28: 54.62+25: 49: 02.6$ & $\ldots$ & $\mathrm{SBb}$ & spiral & & & $\ldots$ & 0.74 & $\ldots$ & $\ldots$ & good \\
\hline LSBC F520-02 & $17: 38: 18.13+25: 59: 02.7$ & $\ldots$ & $\mathrm{Im} / \mathrm{dI}$ & dwarf & & & $\ldots$ & 0.63 & $\ldots$ & $\ldots$ & good \\
\hline LSBC F520-V01 & $17: 46: 50.90+24: 48: 29.0$ & $\ldots$ & $\mathrm{Sc} / \mathrm{Irr}$ & spiral & & & $\ldots$ & 0.31 & $\ldots$ & $\ldots$ & good \\
\hline LSBC F520-03 & $17: 48: 41.64+26: 12: 07.2$ & 40.5 & dI & dwarf & & & -16.76 & 0.25 & 7.93 & 3 & good \\
\hline LSBC F597-01 & $20: 43: 55.08+22: 03: 51.6$ & $\ldots$ & $\mathrm{Sc}$ & spiral & & & $\ldots$ & $\ldots$ & $\ldots$ & $\ldots$ & bad \\
\hline LSBC F597-V01 & $20: 44: 05.90+22: 05: 38.2$ & $\ldots$ & S/ring & spiral & & & $\ldots$ & $\ldots$ & $\ldots$ & $\ldots$ & bad \\
\hline LSBC F530-02 & $21: 08: 13.67+27: 14: 08.2$ & 208.2 & $\mathrm{~S}(\mathrm{r})$ & spiral & & & $\ldots$ & $\ldots$ & $\ldots$ & $\ldots$ & bad \\
\hline LSBC F672-V01 & $21: 49: 32.40+15: 52: 32.0$ & $\ldots$ & $\mathrm{Sc} / \mathrm{Sm}$ & spiral & & & $\ldots$ & 0.13 & $\ldots$ & $\ldots$ & good \\
\hline LSBC F672-V02 & $21: 49: 38.55+15: 51: 13.6$ & $\ldots$ & Im: & no SDSS galaxy & & & & & & & not used \\
\hline LSBC F745-V02 & $21: 57: 48.40+11: 00: 21.0$ & $\ldots$ & $\mathrm{Sc}(\mathrm{r})$ & spiral & & & $\ldots$ & 0.77 & $\ldots$ & $\ldots$ & good \\
\hline LSBC F532-V01 & $22: 02: 48.71+26: 06: 28.2$ & $\ldots$ & ring & spiral & & & $\ldots$ & 0.82 & $\ldots$ & $\ldots$ & good \\
\hline LSBC F673-02 & $22: 14: 31.95+13: 46: 21.9$ & 104.2 & S/Malin-like & spiral & & & -21.05 & 0.77 & 10.33 & 29 & bad \\
\hline LSBC F746-V01 & $22: 17: 15.21+09: 54: 16.8$ & $\ldots$ & $\mathrm{S}(\mathrm{r})$ & dwarf & & & $\ldots$ & 0.80 & $\ldots$ & $\ldots$ & good \\
\hline LSBC F602-V03 & $22: 32: 14.50+18: 38: 02.0$ & $\ldots$ & $\mathrm{Im} / \mathrm{Sm}$ & irregular & & & $\ldots$ & 0.08 & $\ldots$ & $\ldots$ & good \\
\hline LSBC F746-V02 & $22: 33: 33.55+11: 30: 53.7$ & $\ldots$ & Irr & no SDSS galaxy & & & & & & & not used \\
\hline LSBC F533-02 & $22: 33: 56.59+25: 09: 39.1$ & $\ldots$ & ring/Sb-p- & spiral & & & $\ldots$ & 0.41 & $\ldots$ & $\ldots$ & good \\
\hline LSBC F533-V01 & $22: 36: 11.70+23: 42: 44.0$ & $\ldots$ & $\mathrm{Sd}$ & irregular & & & $\ldots$ & 0.58 & $\ldots$ & $\ldots$ & good \\
\hline $2250+0059$ & $22: 52: 55.53+01: 15: 57.5$ & $\ldots$ & $\mathrm{Sdm}$ & irregular & & & $\ldots$ & 0.32 & $\ldots$ & $\ldots$ & good \\
\hline $2253-0128$ & $22: 56: 25.48-01: 12: 27.6$ & $\ldots$ & dI & dwarf & & & $\ldots$ & 0.61 & $\ldots$ & $\ldots$ & good \\
\hline 2254-0158 & 22:56:44.21 -01:42:20.8 & $\ldots$ & $\mathrm{Sdm}$ & irregular & & & $\ldots$ & 0.25 & $\ldots$ & $\ldots$ & good \\
\hline $2254-0243$ & $22: 57: 07.87-02: 27: 08.2$ & 36.8 & dIn & dwarf & & & -16.40 & 0.06 & 7.37 & 4 & good \\
\hline $2257+0025$ & $22: 59: 55.72+00: 41: 19.3$ & $\ldots$ & $\mathrm{Sd}$ & $\ldots$ & & & $\ldots$ & 0.38 & $\ldots$ & $\ldots$ & not used \\
\hline $2257-0253$ & $22: 59: 59.19-02: 37: 33.8$ & $\ldots$ & $\mathrm{Sc}$ & irregular & & & $\ldots$ & 0.36 & $\ldots$ & $\ldots$ & good \\
\hline LSBC F677-01 & $23: 11: 58.30+15: 49: 49.0$ & $\ldots$ & $\mathrm{Sm}$ & spiral & & & $\ldots$ & 0.61 & $\ldots$ & $\ldots$ & good \\
\hline 2309-0122 & $23: 12: 21.04-01: 05: 42.5$ & 111.8 & $\mathrm{SBc}$ & spiral & & & -18.50 & 0.61 & 9.10 & 9 & good \\
\hline $2310-0237$ & 23:12:51.47 -02:20:56.3 & 434.5 & dI & high redshift & & & -21.77 & -0.30 & 9.17 & $\ldots$ & not used \\
\hline $2314+0230$ & $23: 16: 38.97+02: 46: 29.3$ & $\ldots$ & $\mathrm{Sc}$ & spiral & & & $\ldots$ & 0.56 & $\ldots$ & $\ldots$ & good \\
\hline $2314-0230$ & $23: 16: 49.55-02: 13: 38.0$ & $\ldots$ & $\mathrm{Sm}$ & spiral & & & $\ldots$ & 0.21 & $\ldots$ & $\ldots$ & good \\
\hline $2314-0046$ & $23: 17: 18.75-00: 29: 44.4$ & 186.0 & $\mathrm{Sc}$ & spiral & & & -19.05 & 0.43 & 9.08 & $\ldots$ & good \\
\hline LSBC F821-01 & $23: 21: 49.30+03: 49: 43.9$ & 132.4 & Sc-p-/one-arm & interacting pair & & & -21.34 & 0.63 & 10.26 & 2 & not used \\
\hline $2320-0118$ & $23: 22: 58.37-01: 01: 41.5$ & 146.8 & $\mathrm{Sc}$ & spiral & & & -18.33 & 0.33 & 8.66 & 3 & good \\
\hline LSBC F821-02 & $23: 23: 31.63+03: 03: 10.9$ & 239.3 & S0 & lenticular & & & -22.81 & 1.00 & 11.33 & $\ldots$ & not used \\
\hline LSBC F677-V07 & $23: 28: 27.90+17: 12: 30.0$ & $\ldots$ & dI & dwarf & & & $\ldots$ & 0.37 & $\ldots$ & $\ldots$ & good \\
\hline $2328-0011$ & $23: 30: 47.11+00: 05: 11.4$ & 76.8 & $\mathrm{Sbc}$ & spiral & & & -18.23 & 0.52 & 8.87 & 7 & good \\
\hline
\end{tabular}


Table 1:- continued.

\begin{tabular}{|c|c|c|c|c|c|c|c|c|c|c|c|}
\hline galaxy name & $\begin{array}{c}\text { RA \& DEC } \\
(\mathrm{J} 2000.0)\end{array}$ & $\begin{array}{r}D \\
(\mathrm{Mpc})\end{array}$ & $\begin{array}{l}\text { morphology } \\
{[\mathrm{NED}]}\end{array}$ & class & $\begin{array}{c}\text { HI flux } \\
(\mathrm{Jy} \mathrm{km} / \mathrm{s})\end{array}$ & $\begin{array}{c}\log \left(M_{\mathrm{HI}}\right) \\
\left(M_{\odot}\right)\end{array}$ & $\begin{array}{c}M_{\mathrm{r}} \\
(\mathrm{mag})\end{array}$ & $\begin{array}{r}(g-r) \\
(\mathrm{mag})\end{array}$ & $\begin{array}{r}\log \left(M_{\star}\right) \\
\left(M_{\odot}\right)\end{array}$ & Iso & Flag* \\
\hline $2328+0004$ & $23: 31: 08.70+00: 20: 48.6$ & 179.6 & Scd & spiral & & & -18.68 & 0.30 & 8.75 & $\ldots$ & good \\
\hline 2329-0204 & $23: 31: 40.84-01: 48: 01.3$ & $\ldots$ & $\mathrm{Sc}$ & spiral & & & $\ldots$ & 0.68 & $\ldots$ & $\ldots$ & good \\
\hline $2332-0056$ & $23: 34: 45.02-00: 40: 22.8$ & 256.5 & dEn & dwarf & & & -20.62 & 0.56 & 9.88 & $\ldots$ & good \\
\hline $2333+0017$ & $23: 36: 02.41+00: 34: 03.5$ & $\ldots$ & Scd & irregular & & & $\ldots$ & 0.66 & $\ldots$ & $\ldots$ & good \\
\hline $2333+0132$ & $23: 36: 29.39+01: 49: 13.6$ & $\ldots$ & $\mathrm{dE}$ & dwarf & & & $\ldots$ & 0.73 & $\ldots$ & $\ldots$ & good \\
\hline $2334-0235$ & $23: 37: 06.78-02: 18: 46.2$ & 146.1 & Scd & spiral & & & -20.23 & 0.54 & 9.70 & 1 & good \\
\hline LSBC F750-01 & $23: 37: 50.50+11: 19: 03.2$ & $\ldots$ & Sc & spiral & & & $\ldots$ & 0.55 & $\ldots$ & $\ldots$ & good \\
\hline $2335-0044$ & $23: 38: 11.04-00: 27: 46.9$ & 151.2 & Sd & spiral & & & -20.64 & 0.67 & 10.03 & $\ldots$ & good \\
\hline 2339-0122 & $23: 41: 45.48-01: 05: 29.6$ & 154.0 & $\mathrm{Sc}$ & spiral & & & -18.73 & 0.41 & 8.93 & $\ldots$ & good \\
\hline $2339+0237$ & $23: 42: 02.20+02: 54: 21.7$ & $\ldots$ & $\mathrm{Sb}$ & spiral & & & $\ldots$ & 0.22 & $\ldots$ & $\ldots$ & good \\
\hline $2339-0244$ & $23: 42: 06.26-02: 27: 40.1$ & 102.8 & Scd & spiral & & & -19.41 & 0.32 & 9.08 & 4 & good \\
\hline LSBC F750-03 & $23: 42: 13.38+11: 04: 34.6$ & 257.0 & $\mathrm{Sb}$ & spiral & & & -21.79 & 0.48 & 10.24 & $\ldots$ & good \\
\hline $2342+0213$ & $23: 45: 31.53+02: 30: 04.1$ & $\ldots$ & Scd & spiral & & & $\ldots$ & 0.79 & $\ldots$ & $\ldots$ & good \\
\hline $2343+0025$ & $23: 46: 23.56+00: 42: 26.0$ & $\ldots$ & $\mathrm{Sbc}$ & spiral & & & $\ldots$ & 0.26 & $\ldots$ & $\ldots$ & good \\
\hline $2345-0247$ & $23: 47: 51.01-02: 30: 53.8$ & $\ldots$ & $\mathrm{Sbc}$ & dwarf & & & $\ldots$ & 0.27 & $\ldots$ & $\ldots$ & good \\
\hline $2347+0136$ & $23: 50: 09.54+01: 53: 26.6$ & $\ldots$ & Sc & spiral & & & $\ldots$ & 0.80 & $\ldots$ & $\ldots$ & good \\
\hline $2348+0044$ & $23: 51: 02.53+01: 01: 06.9$ & $\ldots$ & $\mathrm{Sbc}$ & spiral & & & $\ldots$ & 0.36 & $\ldots$ & $\ldots$ & good \\
\hline $2351+0212$ & $23: 53: 35.68+02: 29: 23.6$ & $\ldots$ & dI & dwarf & & & $\ldots$ & 0.04 & $\ldots$ & $\ldots$ & good \\
\hline LSBC F750-V01 & $23: 54: 19.58+10: 56: 35.7$ & 13.5 & Irr & irregular & & & -13.92 & 0.69 & 7.37 & 2 & not used \\
\hline
\end{tabular}

